\title{
EFFECTS OF DELAMINATION ON COMPOSITE STRUCTURES UNDER STATIC AND FATIGUE LOADING
}

\author{
A Thesis \\ presented to \\ the Faculty of California Polytechnic State University \\ San Luis Obispo \\ In Partial Fulfillment \\ of the Requirements for the Degree \\ Masters of Science in Aerospace Engineering
}

by

Eugene E. Eswonia

December 2009 
(C) 2009

Eugene Eswonia

ALL RIGHTS RESERVED 


\section{Committee Membership}

Title:

EFFECTS OF DELAMINATION ON COMPOSITE STRUCTURE UNDER MONOTONIC AND FATIGUE LOADING

Author: $\quad$ Eugene Eswonia

Date Submitted: $\quad$ December 2009

Committee Chair: $\quad$ Dr. Faysal Kolkailah

Committee Member: Dr. Eltahry Elghandour

Committee Member: Dr. Dianne DeTurris

Committee Member: Dr. Eric Kasper 


\section{Abstract \\ Effects of Delamination on Composite Structure Under Monotonic and Fatigue Loading Eugene Eswonia}

This thesis will present the experimental and numerical analysis of composite sandwich structures under monotonic and fatigue loading. The sandwich skins were made of fiberglass and the core used was a closed cell PVC foam. Initial delaminations were introduced into the sandwich structures during manufacturing to see the effect of delamination size on the ultimate strength and monotonic fracture. Fiberglass rods, called shear keys, added to the foam core to determine whether or not they increased the strength of the test specimens. Furthermore, shear key locations were also varied and their effects noted. The fixed rate static behavior for all of the above cases listed were determined. The fatigue life and behavior were determined for sandwich structures with no initial delamination, 0.5 inch initial delamination, and 0.5 inch initial delamination with a shear key 0 inch from the delamination depth. The fatigue specimens were tested at various percentages of the ultimate monotonic failure loads to determine the fatigue life. A static numerical analysis was performed using Abaqus/CAE 6.7.1 to observe at the monotonic behavior of the test specimens with no initial delamination and with 0.5 inch initial delamination.

The sandwich structures with an initial delamination and/or a shear key in the foam core experienced over a $70 \%$ reduction in the ultimate monotonic failure load. The two delamination lengths had no significant effect on the ultimate monotonic failure load, but the presence of an initial delamination corresponded to a material response dominated by plastic behavior. The experimental testing also showed that the location of the shear key in the sandwich structure had little effect on the monotonic strength, but moving the shear keys further away from the back edge of the delamination caused a reduction in strength. The monotonic testing determined that composite sandwich structures containing shear keys had approximately a 7\% reduction in the monotonic failure load of test specimens with an initial delamination. Numerical analysis results matched the ultimate failure loads within 5\% for the test specimens with a 0.5 inch an initial delamination and within $15 \%$ for the test specimens with no 
initial delamination. The fatigue testing showed that sandwich structures containing shear keys had life reduction of approximately $33 \%$. Preliminary experiments involved with rotating the shear keys $90^{\circ}$ showed increased ultimate monotonic failure loads of the composite sandwich structures by as much as $30 \%$. Future funding and research would be necessary to verify the increased structural performance of the newly oriented shear keys. 


\section{Acknowledgements}

First and foremost I would like to thank Dr. Nilanjan Mitra for your knowledge and insight during the development of the shear key research. It was your notion to develop shear key rods to increase sandwich structure strength which made my research possible. Next I would like to thank Dr. Eltahry Elghandour for your advice and wisdom during the entire duration of my research. You always imparted your experience upon me when issues arose and without your help this research would not have been completed. I would like to thank Dr. Eric Kasper for your help working through my numerical analysis as I was trying to model my experimental test results. I would like to thank Dr. Faysal Kolkailah for introducing me to aircraft structures because you sparked my interest in the beginning. I would also like to thank Dr. Dianne DeTurris for teaching me how to properly construct a lab report and for your insight into experimental testing and procedures. I would also like to thank Thomas and Mike for your assistance in my experimental research and instrumentation.

To all of my friends I've meet on this journey through my higher education I cannot forget you because without you it would have not been possible to balance the work/play aspect of college. To my Sequoia dorm friends, James, Nick, Trev, T-Money, Jorien, Steve, and Greg, we kicked the tires and lit the fires at the start. We had one hell of a ride that will not be forgotten. From Beerfest and Boilmakers to 4-square and Paradise Island, we did it all and I think of you all like brothers. You are always welcome in SD and I look forward to our shenanigans in the future. To my Aero friends and colleagues, if we are to take only one thing away from our tenure at Cal Poly SLO it should be that you don't have to live in the labs to get work accomplished. If anything, get out of the labs every once in a while and swing the hammer because sunshine is good for you. To my Spraying Mantis team, Kev, Ryan, BMo, Blaine, and Ror; I don't think McDonald could have ever imagined the perfect storm he created by grouping us together. We killed it for an entire year and we did it our way, "Often imitated, but never duplicated." 
I would like to thank my tribe the Yavapai-Apache Nation because through your scholarships my higher education became possible. I am extremely grateful and amazed at how much support you have shown to me and other higher education students.

To my family, there is no way that I can express the gratitude that I have for everyone of you because words could not describe it. You always pushed me and told me to follow my dreams, for that I am thankful. Hearing your words of encouragement when I was struggling in school meant the world to me and no matter how stressed out or frustrated I may have been, you always put everything back into perspective and refocused my vision on the end goal of graduation.

Last but certainly not least I would like to thank Tang and our two puppies Bruto and Nala. Bruto and Nala, as bad as you both are, you could completely changed my day whenever I came home and saw you. Your wagging tails and happy barks could make me forget anything troubling me and put me in a better mood. Tang, I am thankful for your never ending support and standing by my side as I struggled through long days and even longer nights in the lab. Your patience and understanding are endearing and I am very fortunate to have you in my life, I love you. 


\section{Table of Contents}

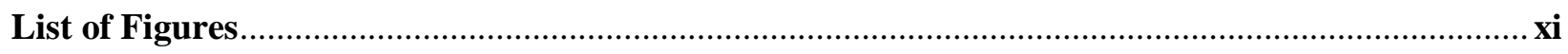

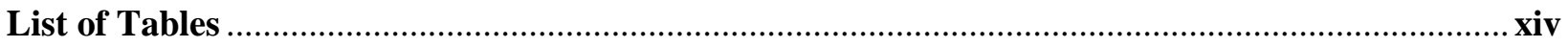

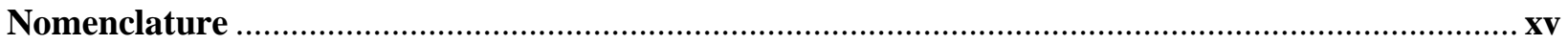

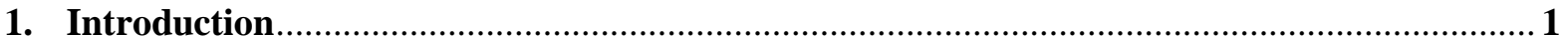

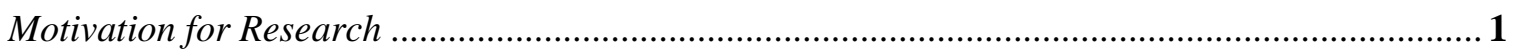

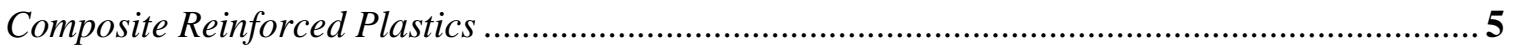

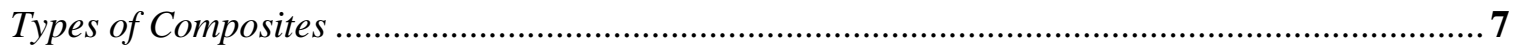

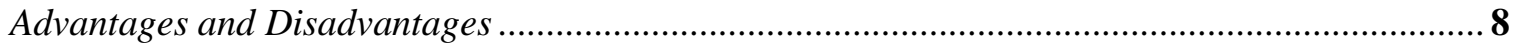

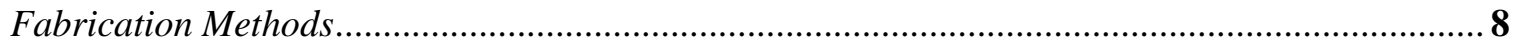

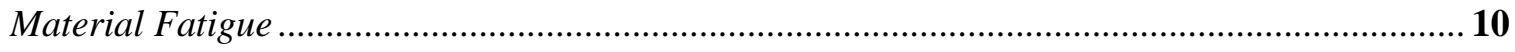

2. Design and Manufacturing of Test Specimens ............................................................... 13

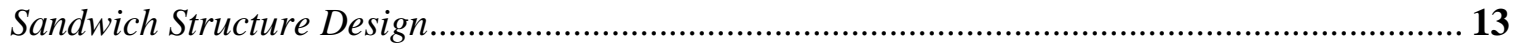

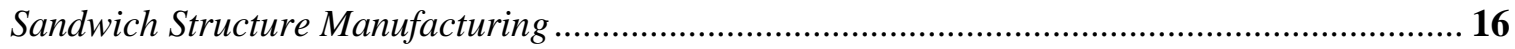

Material Preparation - No Initial Delamination …...................................................... 16

Material Preparation - Test Specimens with Initial Delamination ................................... 19

Material Preparation - Test Specimens with Initial Delamination and Shear Keys ......... 20

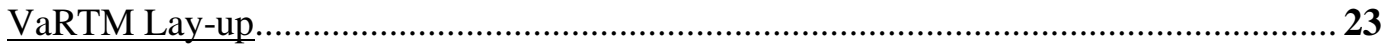

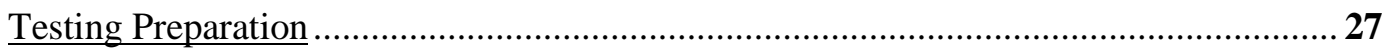

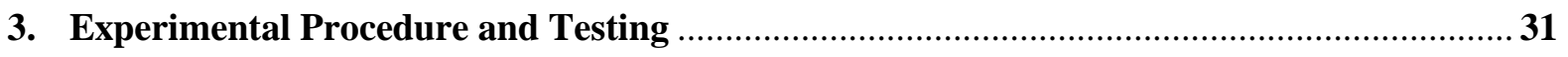

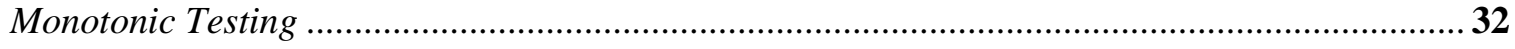

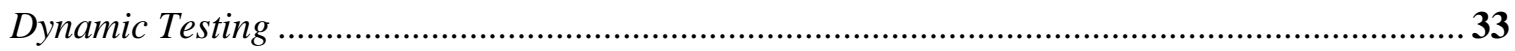

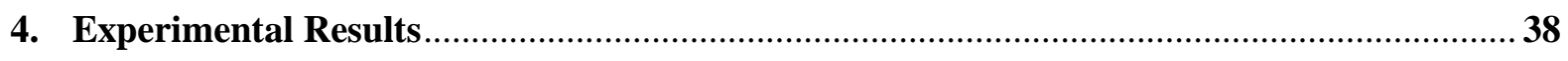

Monotonic Testing

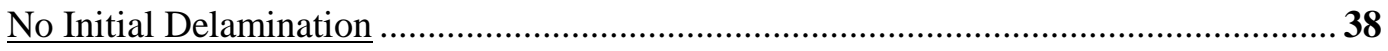

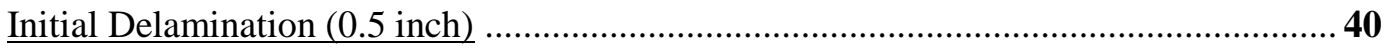

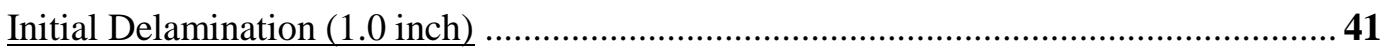


Data Summary

Monotonic Testing

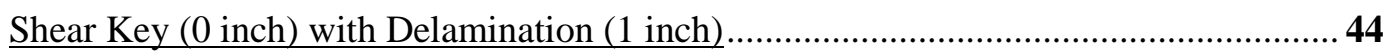

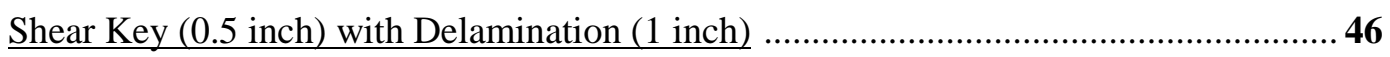

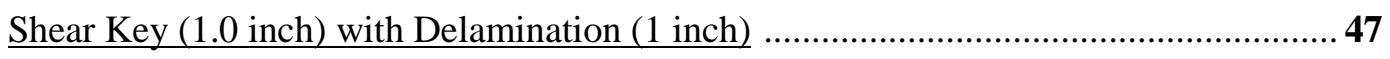

Dynamic Testing

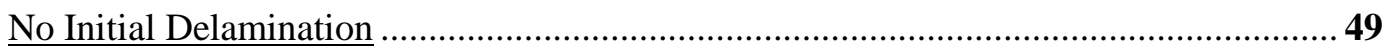

Test Specimens with 1.0 inch Initial Delamination .................................................53

1.0 inch Initial Delamination with 0 inch Shear Key..................................................55

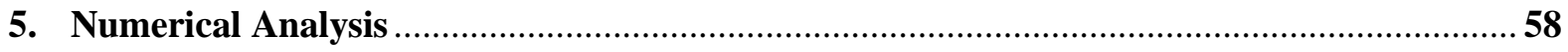

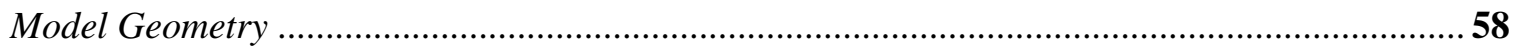

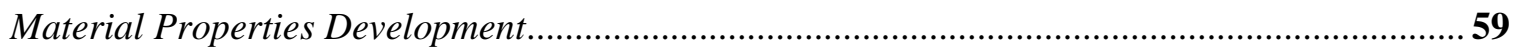

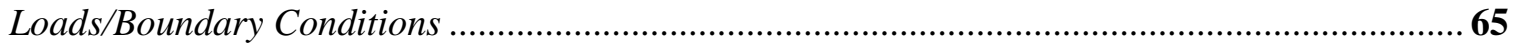

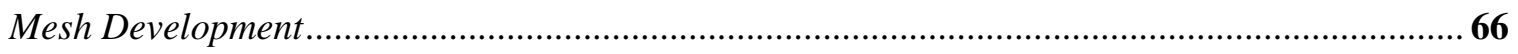

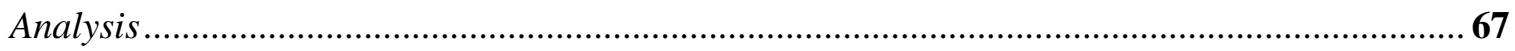

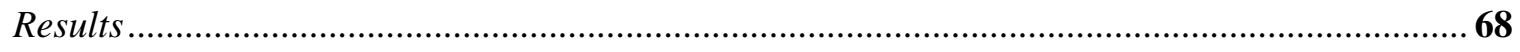

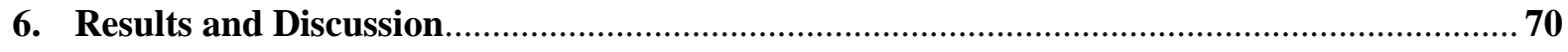

Monotonic Failure Analysis

No Initial Delamination - Cracks in the Foam ……................................................. 70

No Initial Delamination - Cracks in the Matrix ….................................................... 71

0.5 inch Initial Delamination - Cracks in the Foam .................................................. 72

1 inch Initial Delamination - Cracks in the Foam .................................................. 73

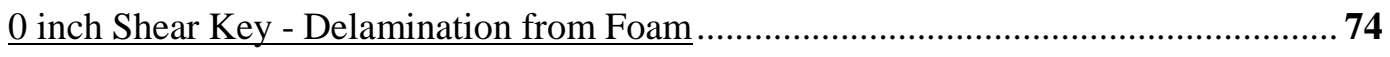

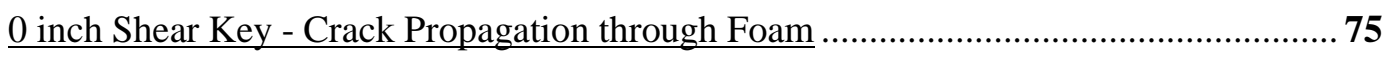

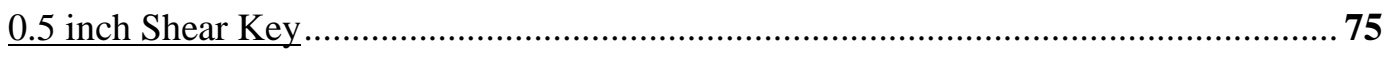

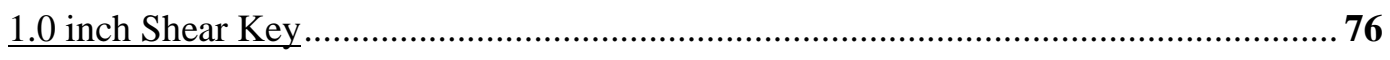

Dynamic Failure Analysis 


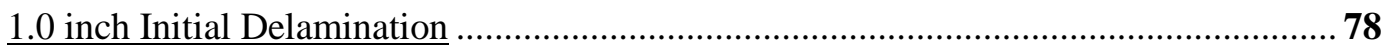

1.0 inch Initial Delamination with 0 inch Shear Key.................................................. 81

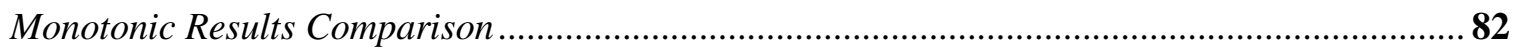

Experimental and Numerical Monotonic Results Comparison...................................................85

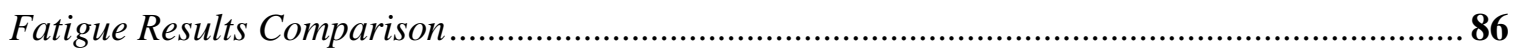

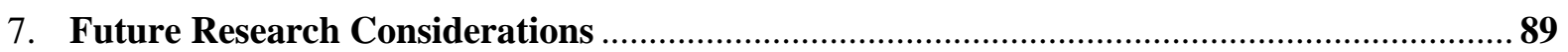

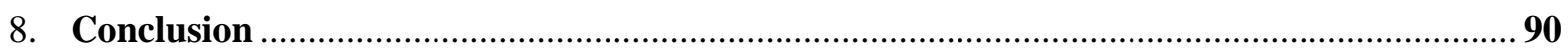

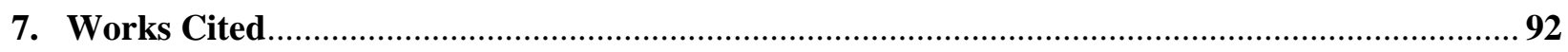




\section{List of Figures}

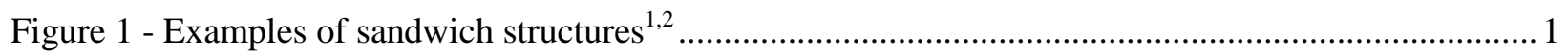

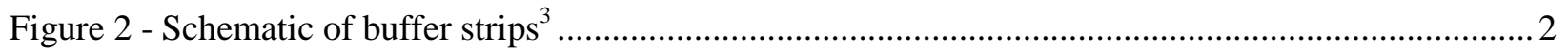

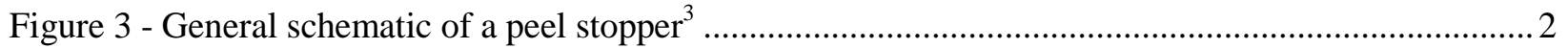

Figure 4 - Peel stopper ending delamination ${ }^{3}$.............................................................................. 3

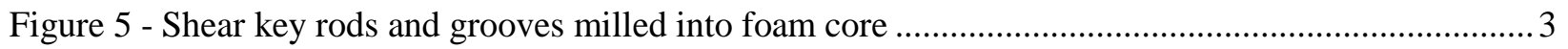

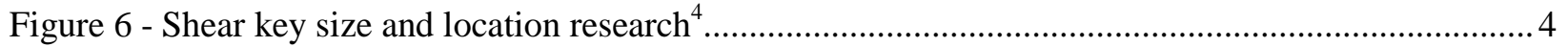

Figure 7 - Composite sandwich structures under shear testing (ASTM C373) ${ }^{4}$.......................................... 5

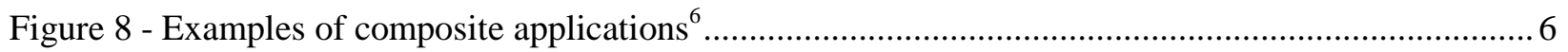

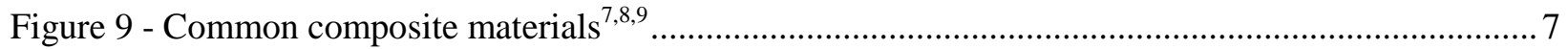

Figure 10 - Hand wet lay-up composite manufacturing technique ${ }^{10}$.................................................... 9

Figure 11 - Composite lay-up using pre-preg carbon fiber ${ }^{11}$........................................................... 9

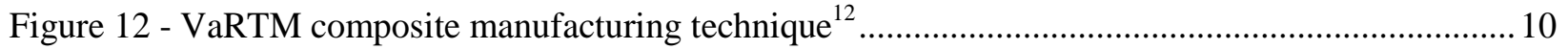

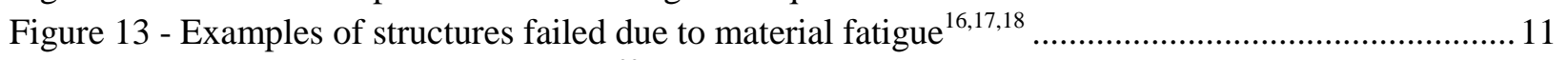

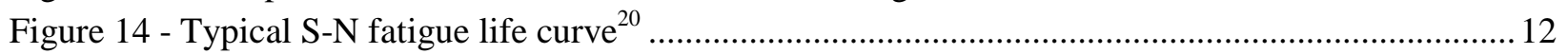

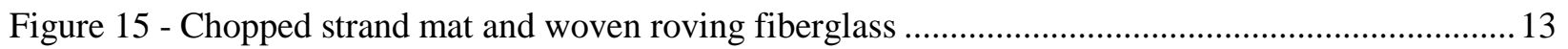

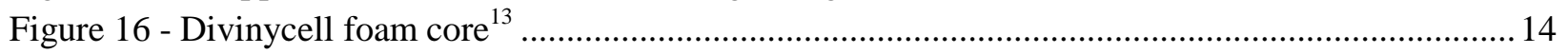

Figure 17 - Test specimen schematic for no initial delamination ......................................................... 15

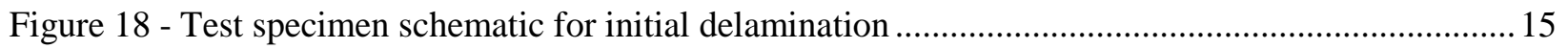

Figure 19 - Test specimen schematic for initial delamination with shear keys ....................................... 15

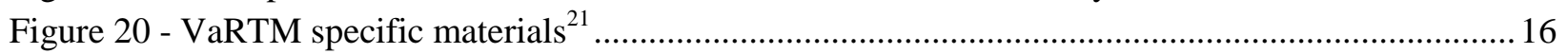

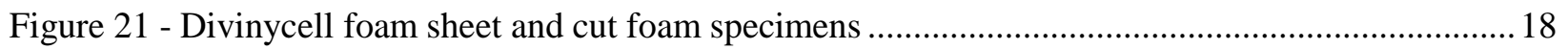

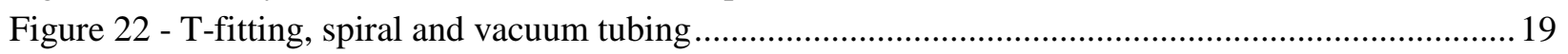

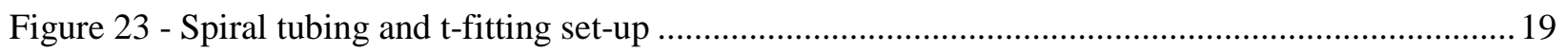

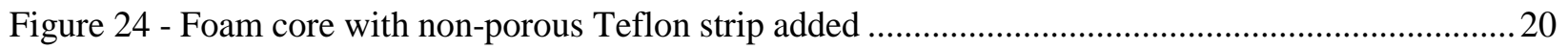

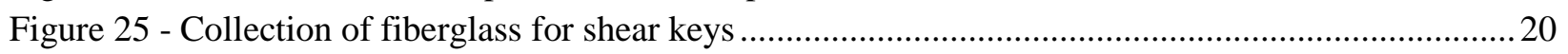

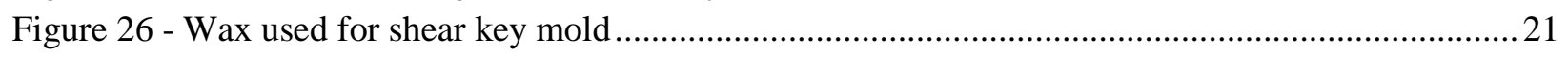

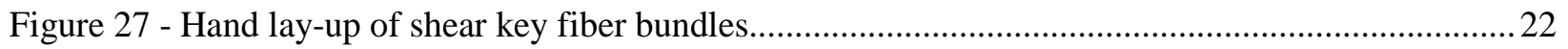

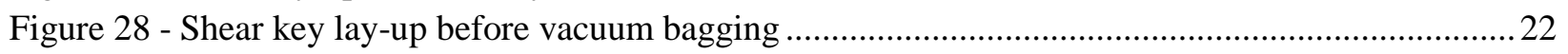

Figure 29 - Stacked VaRTM lay-up before vacuum bagging ............................................................2 24

Figure 30 - Vacuum bagged composite sandwich structure after lay-up .................................................25

Figure 31 - West System resin and hardener used for lay-up ...........................................................25

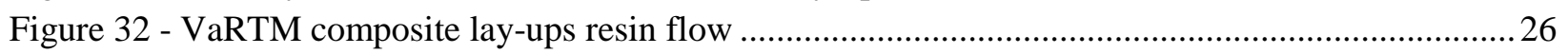

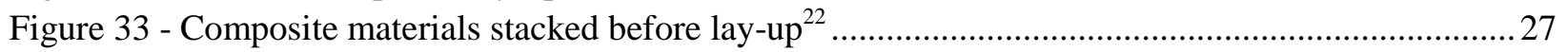

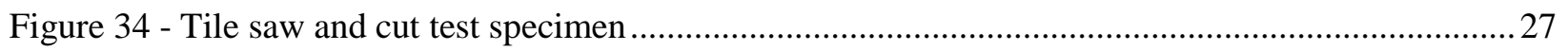

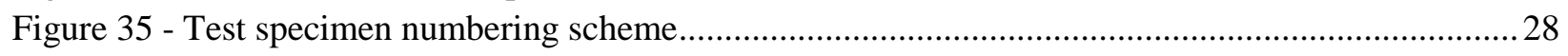

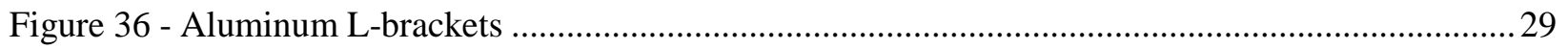

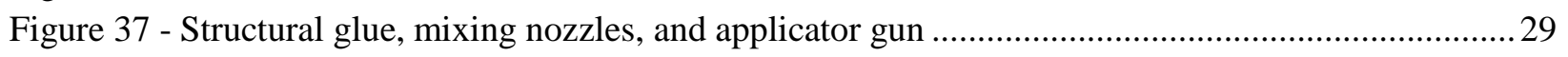

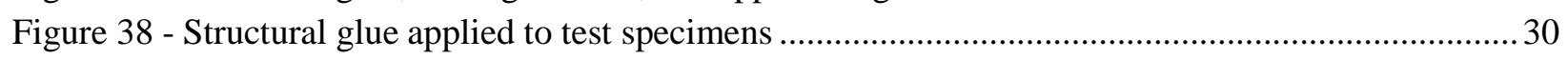

Figure 39 - $100 \mathrm{kN}$ load cell Instron grip configuration ................................................................... 31

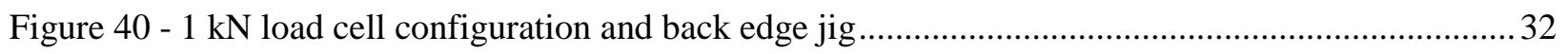

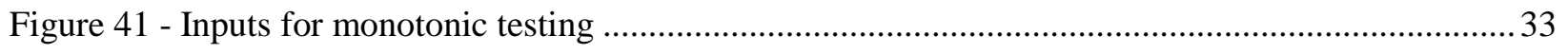




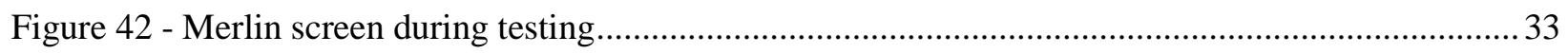

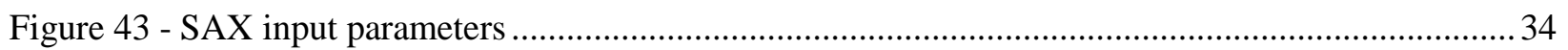

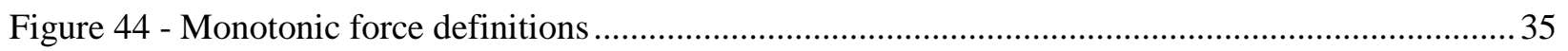

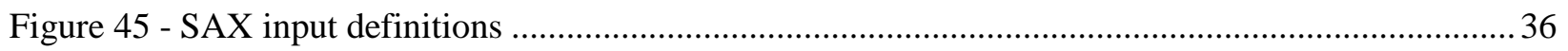

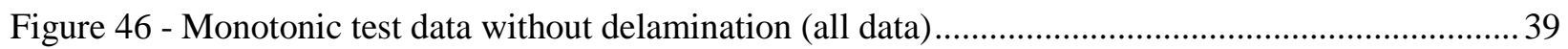

Figure 47 - Monotonic test data without delamination (averaged data) .................................................. 40

Figure 48 - Monotonic test data 0.5 inch specimen with delamination (all data) ..................................... 40

Figure 49 - Monotonic test data for 0.5 inch initial delamination (averaged data) .................................... 41

Figure 50 - Monotonic test data for 1.0 inch initial delamination (all data) ........................................... 42

Figure 51 - Monotonic test data for 1.0 inch initial delamination (averaged data) ................................... 43

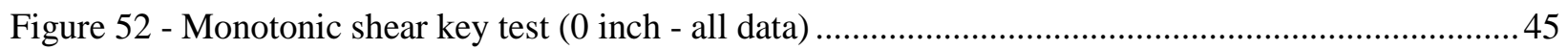

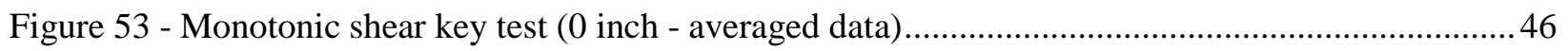

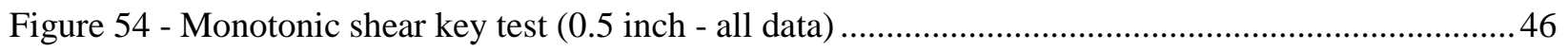

Figure 55 - Monotonic shear key test $(0.5$ inch - averaged data) ......................................................... 47

Figure 56 - Monotonic shear key test (1.0 inch - all data) ....................................................................... 48

Figure 57 - Monotonic shear key test (1.0 inch - averaged data) .......................................................... 49

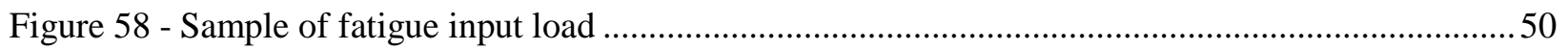

Figure 59 - Sample of load spectrum during specimen failure ….......................................................51

Figure 60 - Fatigue testing no delamination (all data) .......................................................................52

Figure 61 - Fatigue testing no initial delamination (averaged data) ......................................................53

Figure 62 - Fatigue testing 1.0 in. initial delamination (all data) .........................................................5

Figure 63 - Fatigue testing 1.0 in. initial delamination (averaged data) ................................................55

Figure 64 - Fatigue test data 1.0 initial delamination with 0 in. shear key (all data) ...............................56

Figure 65 - Fatigue test data 1.0 in. initial delamination with 0 in. shear key (averaged data) ..................57

Figure 66 - Finite element geometry for test specimen.....................................................................5

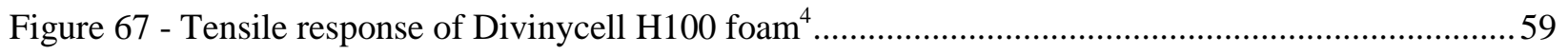

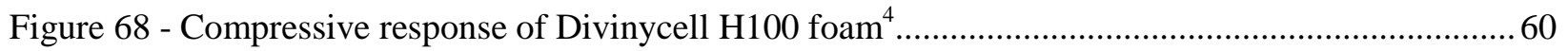

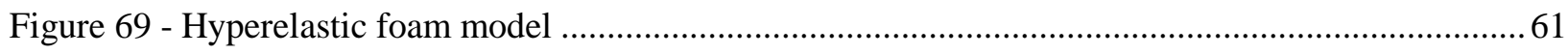

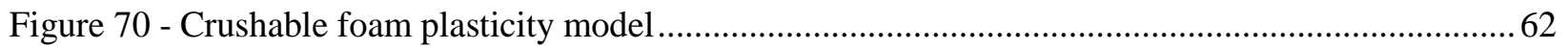

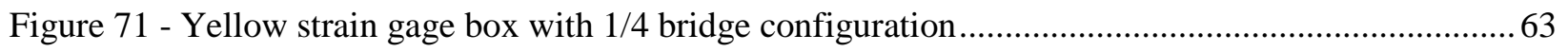

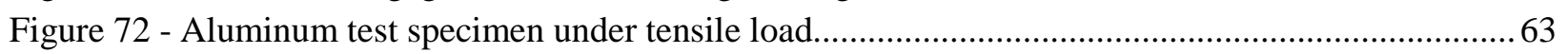

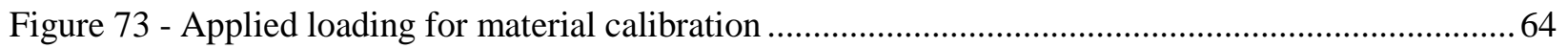

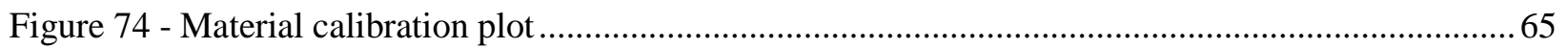

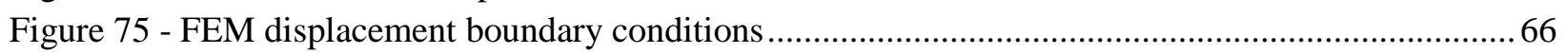

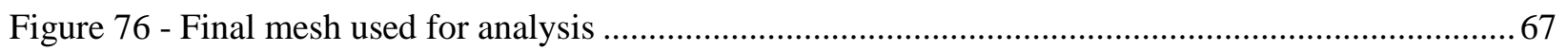

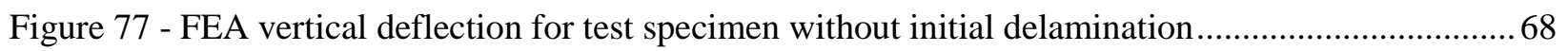

Figure 78 - FEA vertical deflection for test specimen with 0.5 inch initial delamination ..........................69

Figure 79 - Monotonic failure of specimens with no initial delamination ................................................. 71

Figure 80 - Monotonic failure of test specimens without initial delamination .........................................72

Figure 81 - Monotonic failure of test specimens with 0.5 inch initial delamination .................................. 73

Figure 82 - Monotonic failure of test specimens with 1.0 inch initial delamination ................................. 74

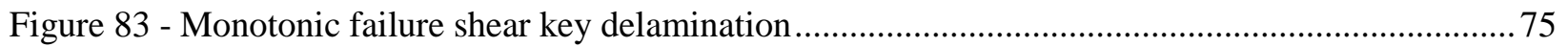

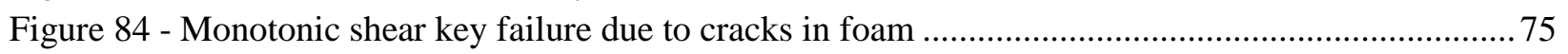

Figure 85 - Monotonic shear key failure (0.5 inch shear key) ........................................................... 76 
Figure 86 - Monotonic shear key failure through matrix (1.0 inch shear key) ....................................... 77

Figure 87 - Monotonic shear key failure cracks in foam (1.0 inch shear key)........................................ 77

Figure 88 - Monotonic shear key failure type II (1.0 inch shear key).................................................. 78

Figure 89 - 1.0 inch delamination fatigue crack propagation through foam ........................................... 79

Figure 90 - 1.0 inch delamination fatigue crack propagation type II through foam .................................. 80

Figure 91 - 1.0 inch delamination fatigue crack propagation through matrix.......................................... 81

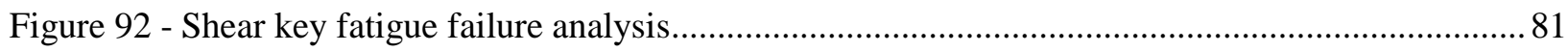

Figure 93 - Monotonic experimental results comparison (delamination) .............................................. 82

Figure 94 - Experimental monotonic results (shear keys and delamination) ......................................... 84

Figure 95 - Experimental/Numerical Analysis comparison (No initial delamination) ............................. 85

Figure 96 - Experimental/Numerical Analysis Comparison (0.5 inch initial delamination) ......................86

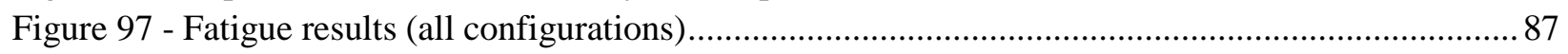

Figure 98 - Fatigue results initial delamination and 0 inch shear key ................................................... 88

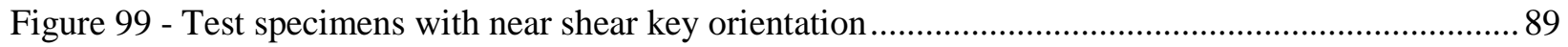




\section{List of Tables}

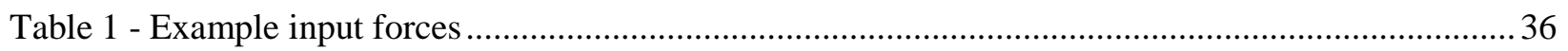

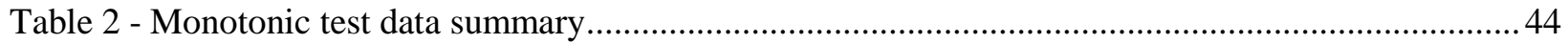

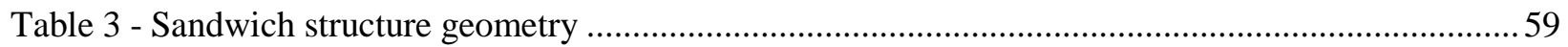

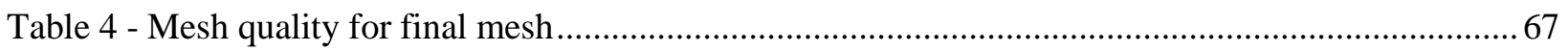

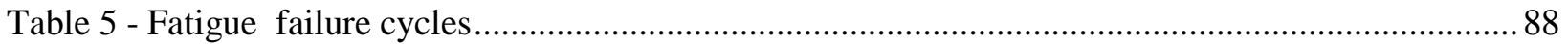




\section{Nomenclature}

\begin{tabular}{|c|c|}
\hline $\mathrm{CNC}$ & Computer numeric control \\
\hline $\mathrm{E}$ & Young's Modulus $\left(\frac{l b_{f}}{i n^{2}}\right)$ \\
\hline $\mathrm{F}$ & Force $\left(\mathrm{lb}_{\mathrm{f}}\right)$ \\
\hline FEA & Finite element analysis \\
\hline $\mathrm{g}$ & Grams \\
\hline $\mathrm{h}$ & height (in.) \\
\hline in. & Inches \\
\hline $\mathrm{kg}$ & Kilograms \\
\hline $\mathrm{kN}$ & Kilonewtons \\
\hline 1 & length (in.) \\
\hline$b_{f}$ & Pounds force \\
\hline $\mathrm{m}$ & Meters \\
\hline $\mathrm{N}$ & Number of cycles \\
\hline Pre-preg & Pre-impregnated \\
\hline psi & $\frac{l b_{f}}{i n^{2}}$ \\
\hline PVC & Polyvinyl chloride \\
\hline $\mathrm{U}$ & Displacement \\
\hline $\mathrm{S}$ & Stress $\left(\frac{l b_{f}}{i n^{2}}\right)$ \\
\hline $\sec$ & Seconds \\
\hline $\mathrm{t}$ & Time \\
\hline w & width (in.) \\
\hline$\Omega$ & Resistance (ohms) \\
\hline o & Degrees \\
\hline
\end{tabular}




$\begin{array}{ll}\text { Subscripts } & \\ \text { amp } & \text { Amplitude } \\ \text { max } & \text { Maximum } \\ \text { min } & \text { Minimum } \\ \text { mean } & \text { Mean } \\ \text { ult } & \text { Ultimate } \\ \text { y } & \text { Yield } \\ 1 & \mathrm{X} \\ 2 & \mathrm{Y} \\ 3 & \mathrm{Z}\end{array}$




\section{Motivation for Research}

\section{Introduction}

Composite sandwich structures are becoming more heavily integrated into everyday applications ranging from marine to aerospace. A composite sandwich structure consists of two composite skins on each side of a core material. Core materials are generally lightweight materials such as balsa wood, honeycomb structure, or foam. A sandwich structure with an aluminum honeycomb core and an open celled foam core are shown in Figure 1. Composite sandwich structures offer high strength-to-weight ratios when compared to traditional metals. Using composites allow designers more flexibility in being able to tailor the material properties of their part based on the orientation of the composite. However, composite sandwich structures also have disadvantages such as water intrusion and impact, which can cause the composite skin to delaminate from the core. A delaminated sandwich structure significantly loses its structural strength and can approach the point of catastrophic failure.

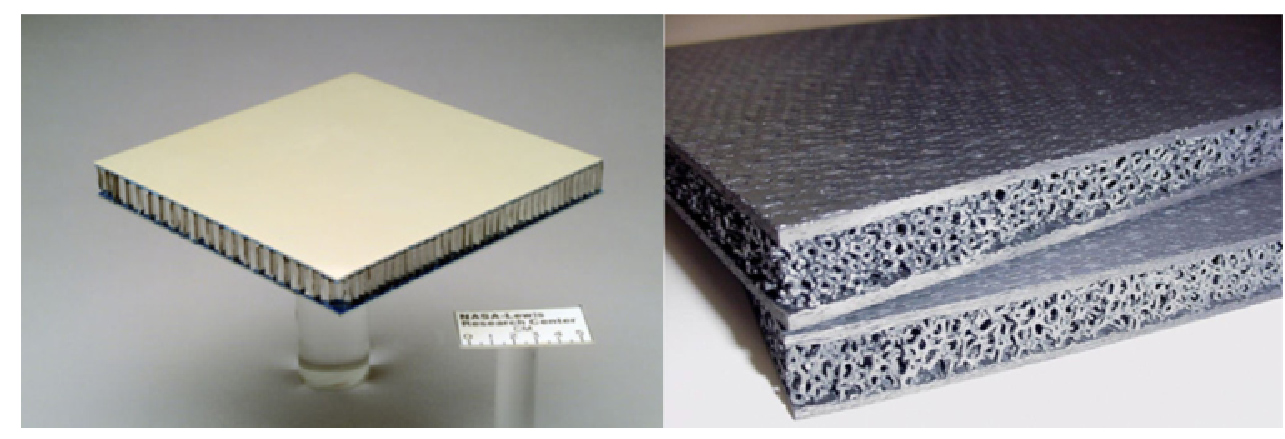

Figure 1 - Examples of sandwich structures ${ }^{1,2}$

Thus far, only three techniques have been discovered to help stop a composite skin from separating once it has begun to delaminate from the core. The three research methods studied involve buffer strips, peel stoppers, and shear keys. Buffer strips ${ }^{3}$ are used to increase the strength of a composite plate that already has cracks or defects. Buffer strips are additional layers of composite strips that are added to the defective regions or to regions where it is anticipated that cracks will occur. Figure 2 shows a general schematic of a buffer strip added to the defective regions a composite panel containing cracks. 
Under fatigue loading, after additional Kevlar or structural fiberglass strips were added to carbon fiber composite panels, the buffer strips arrested the crack growth and increased the panel's residual strength ${ }^{3}$.

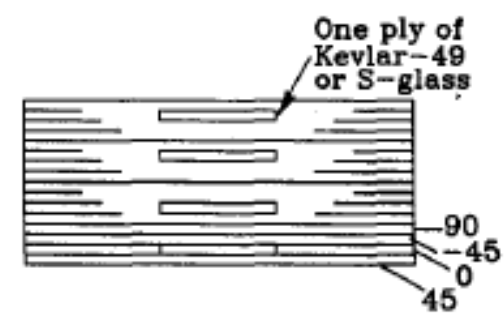

Figure 2 - Schematic of buffer strips ${ }^{3}$

Another method used for stopping composite face sheet delamination involves a marine peel stopper, developed by Christopher Wonderly and Joachim Grenestedt at Leigh University. A schematic of a peel stopper is shown Figure 3. A peel stopper essentially divides the composite sandwich structure into different regions, preventing a delaminated skin from traveling into consecutive regions. The peel stopper causes the delaminated face sheet to separate away from the structure and leave the remaining composite intact. The upper part of Figure 4 shows a delaminated skin and the lower part of Figure 4 shows the outer skin breaking away from the structure. Peel stoppers have shown promising performance in stopping delamination, are relatively simple and easy to manufacture, and cost effective. Preliminary tests that were performed have shown that peel stoppers possess good quasi-static in-plane strength ${ }^{3}$.

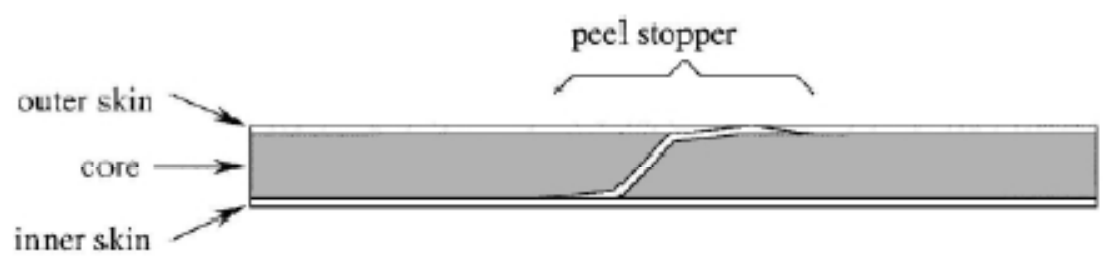

Figure 3 - General schematic of a peel stopper ${ }^{3}$ 

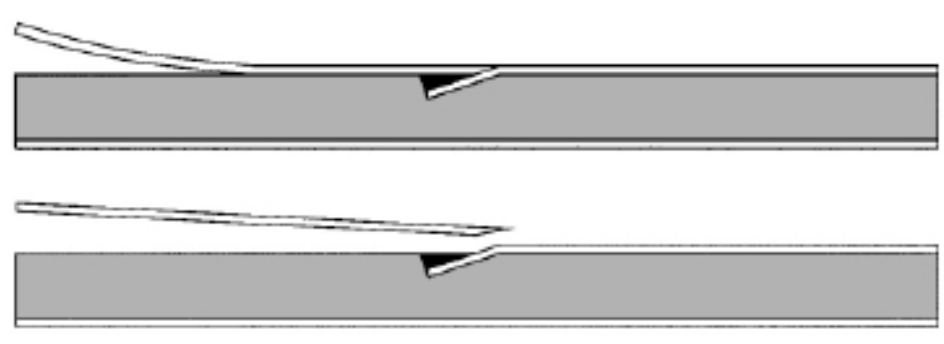

Figure 4 - Peel stopper ending delamination ${ }^{3}$

In 2008, Dr. Nilanjan Mitra, Dr. Eltahry Elghandour, and Dr. Eric Kasper began researching another cost effective solution to increasing the shear strength of a composite sandwich ${ }^{4}$ structure at California Polytechnic State University in San Luis Obispo. The research was conducted under the sponsorship of the C3RP-ONR grant. The sandwich structures selected consisted of fiberglass face sheets surrounding a closed cell PVC foam core. Fiberglass rods, called shear keys, were incorporated into the foam to increase the shear strength. The shear keys were semicircular fiberglass rods manufactured out of intertwined strands of fiberglass. The left side of Figure 5 shows shear key rods and the right side shows milled out grooves in the foam where the shear keys will be placed.

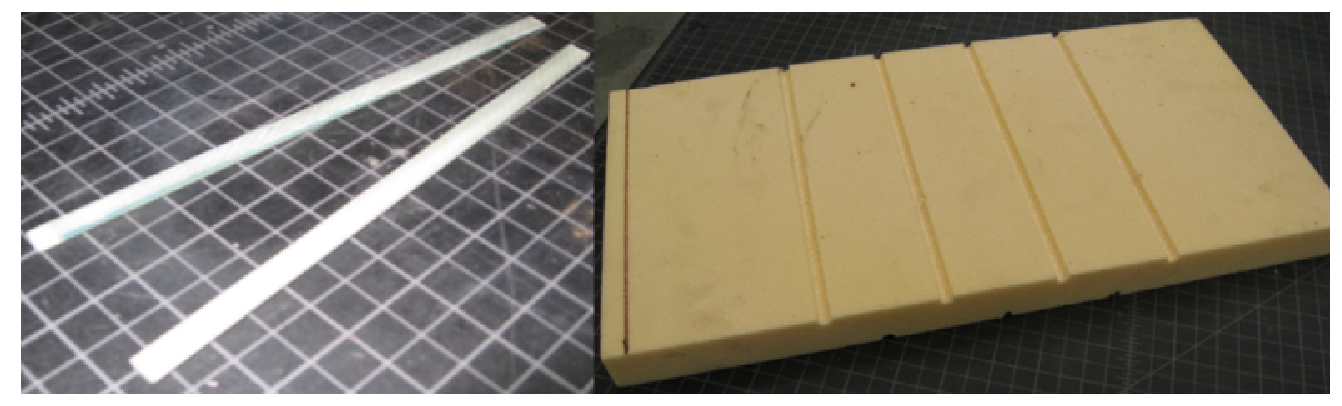

Figure 5 - Shear key rods and grooves milled into foam core

Dr. Mitra's research focused on the size, shape, and the location of the shear keys. Triangular shaped shear keys are shown in the right side of Figure 6. Under shear loading conditions, the nonstaggered triangular shear keys showed little increase in shear strength, attributed to the stress concentrations introduced at the tips of the triangles. The large circular shear keys as shown on the left 
side of Figure 6, but in a non-staggered configuration were then tested. Although it was determined that the large circular shear keys were stronger than the triangular shear keys, failure often occurred in the foam between the shear keys because there was less core material present. To address the problem circular shear keys were placed in a staggered manner helping to provide increased shear strength. Shrinking the radius of the shear keys provided the best results because less of the foam was removed.

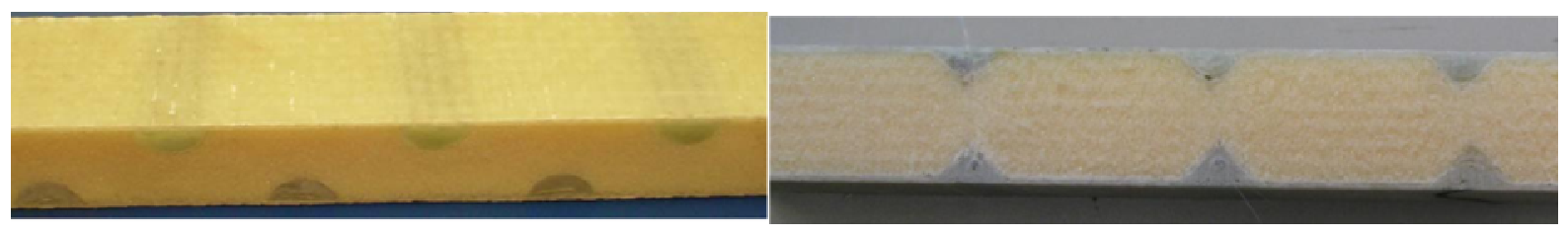

Figure 6 - Shear key size and location research ${ }^{4}$

Figure 7 shows a sandwich structures being tested under shear loading conditions. After the sandwich structures were tested under shear loading, and maximum shear strengths were determined, Dr. Mitra devoted some research looking into how the shear keys could aid in preventing composite delamination due to peeling. The goal of the research was to investigate how delamination length and shear key location affected the monotonic failure characteristics of the composite sandwich structure ${ }^{6}$. The initial results gathered from the delamination testing were inconclusive because many test specimens failed prematurely and therefore only a small sample of tested specimens could be used. This thesis research will continue on with the shear key work that Dr. Nilanjan Mitra started but will focus primarily on the response of the shear keys in preventing delamination peeling. 


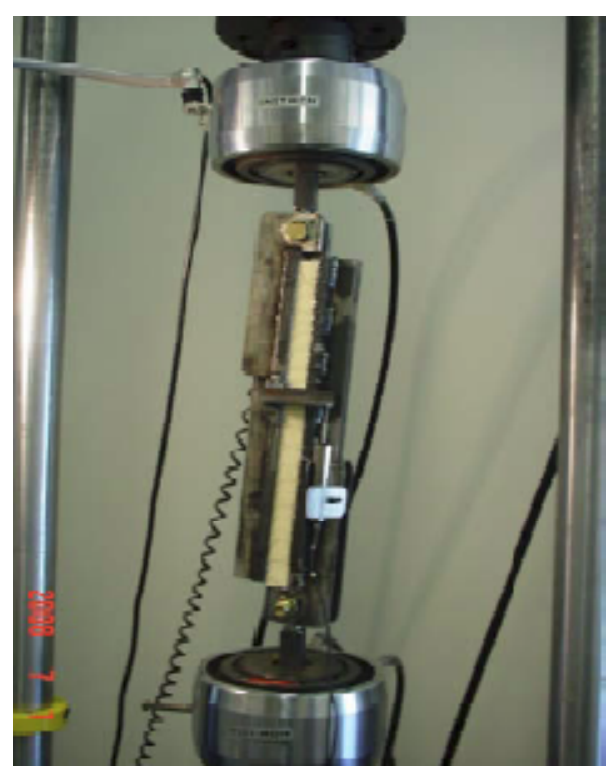

Figure 7 - Composite sandwich structures under shear testing (ASTM C373) ${ }^{4}$

\section{Composite Reinforced Plastics}

Composite materials have become widely used in a variety ways ranging from aerospace and automotive applications to sporting goods. Some examples of everyday composites are shown Figure 8 below. Composite materials are particularly attractive for aerospace and military applications because its reduced weight is directly related to reduced costs. Composite materials have traditionally been used extensively in aerospace applications such as rockets and fighter aircraft. In sporting goods, composites are used to make golf club shafts because its light weight and stiffness allow for a higher percentage of the weight to be concentrated in the head, which provides better performance. 


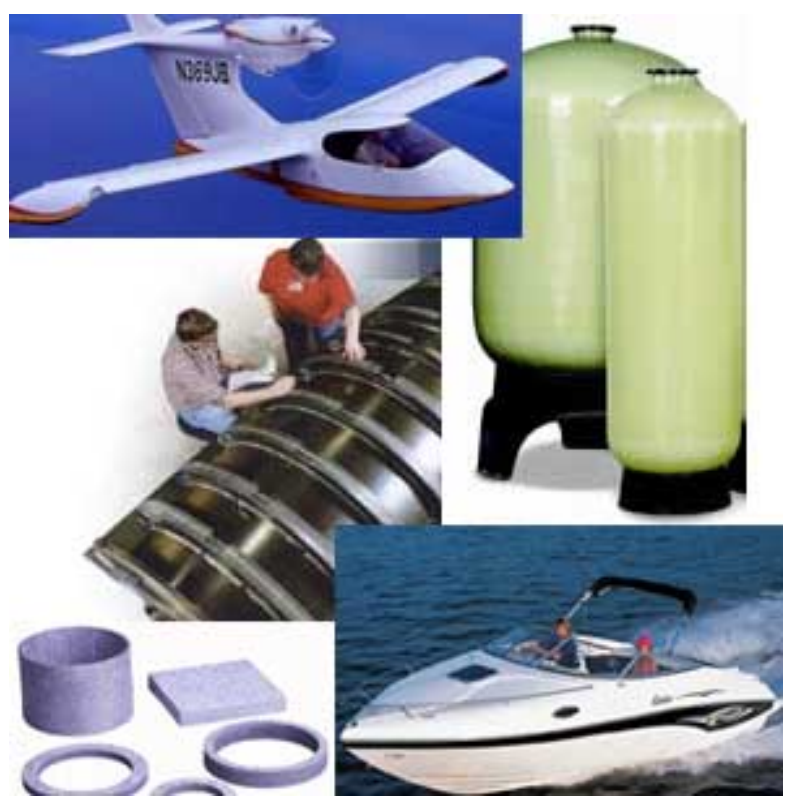

Figure 8 - Examples of composite applications ${ }^{6}$

Composites offer high strength and stiffness to weight ratios relative to conventional metallic materials. Another attractive feature it possesses is that the material's strength and stiffness can be designed based on its intended application. Composite materials are composed of two constituent materials: the matrix and the reinforcement. The reinforcement material consists of fibers to provide strength and the matrix functions in bonding the fibers together. Composites are considered to be an anisotropic material because its materials properties vary depending on the orientation of the fibers and the curing process. Composite fabric sheets can be oriented at different angles to make the material less anisotropic to fulfill certain tasks. In contrast, metals such as aluminum and steel have mechanical properties that are the same in all directions and are considered to be homogenous isotropic materials. 


\section{Types of Composites}

Composite materials have been around for many years with the earliest composites being bricks made by combining straw and mud. Modern day composites have two distinct parts, a matrix and fibers. Separately the two materials are weak but can become very strong when combined. The matrix materials cure by an irreversible chemical process and the most commonly used matrix materials are: thermosetting epoxy, bismaleimide, and polyimide ${ }^{10}$. Matrix materials can either be embedded within the reinforcement fiber weave during manufacturing, or they can be combined with dry reinforcement fabric. Common reinforcement materials are: boron, glass, Aramid, and carbon fiber. Figure 9 shows some common composite materials with a carbon fiber weave on the left, fiberglass in the middle, and a Aramid weave on the right.
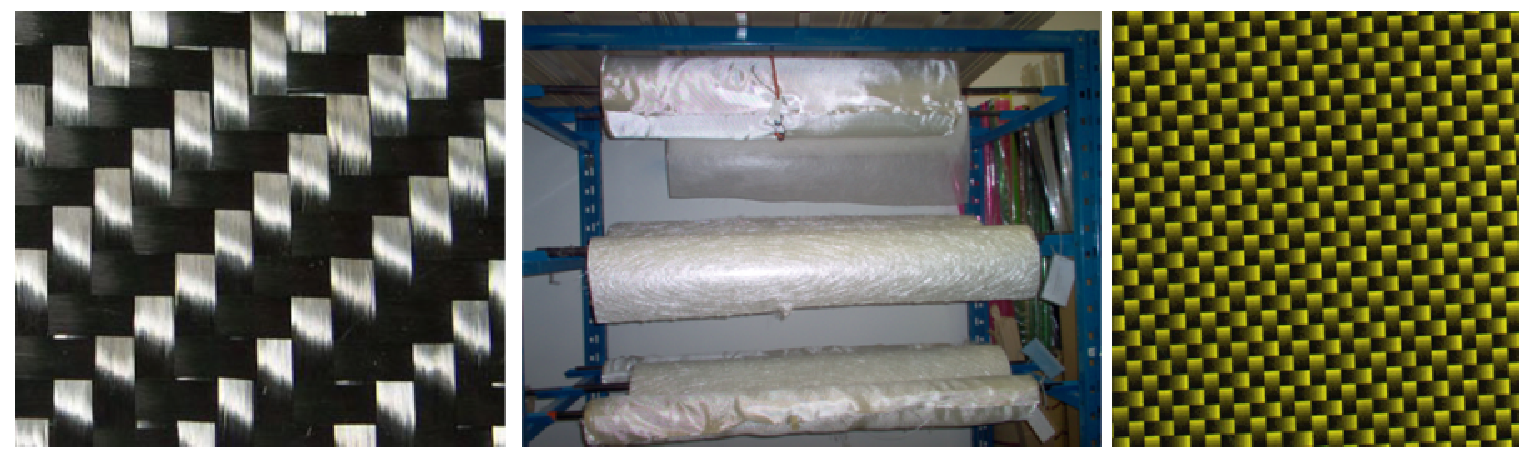

Figure 9 - Common composite materials ${ }^{7,8,9}$

Composite fibers can either come in continuous form or chopped fiber. The fibers are very small in diameter so thousands of fibers are wound together to create a tow. Tows can then be woven together to create either a unidirectional or multidirectional composite fabric. Boron composite fibers were developed during late 1960s. but because of its high cost, boron was not integrated as a widely used composite material. Today fiberglass is the most widely used composite material because of its low cost, its resistance to corrosion, and efficient manufacturing processes. Fiberglass has high elongation, low stiffness-to-weight, and moderate strength-to-weight. Aramid fibers, also known as Kevlar, provide 
higher strength and stiffness-to-weight ratios compared to fiberglass. Aramid also has good response to impact, high tensile strength, but low compressive strength. Carbon fibers have very high stiffness-toweight and high strength-to-weight ratios with low density, which have made it second in use to fiberglass. Since carbon fiber has a very high stiffness-to-weight ratio its cost is also much higher than fiberglass and most Kevlar materials.

\section{Advantages \& Disadvantages}

One of the biggest advantages of using composite materials is they are very lightweight when compared with traditional metal materials. Lightweight structures are particularly desirable to aerospace applications because less weight correlates directly to decreased overall cost. Additionally, composites come in a wide array of strengths that can be altered based on the number and direction of the reinforcement fibers. Composites also have a much better fatigue life and are more resistant to corrosion compared to metal materials.

Although composites have many advantages there are also some issues that make composites problematic. Composites are very brittle materials which make them very susceptible to impact. Impact can cause the fibers to separate and fracture. Many composites, particularly the high strength fibers can be very expensive. Water intrusion into composite plates can also cause the fibers to delaminate so care must be taken to add a layer of sealant if the composites are to be exposed to water. Furthermore, some composites cannot handle high temperature conditions because the matrix material that holds the reinforcement fibers could melt.

\subsection{Fabrication Methods}

There are three different ways to manufacture a part using composites. The first and most basic is a hand wet lay-up. During a hand wet lay-up the resin and hardener are mixed together and the epoxy is manually worked through the fibers to wet out the fabric. A hand wet lay-up is the least expensive 
manufacturing method but resin consistency throughout the part can vary, resulting in an increased part weight and decreased part strength. A hand wet lay-up is shown in Figure 10.

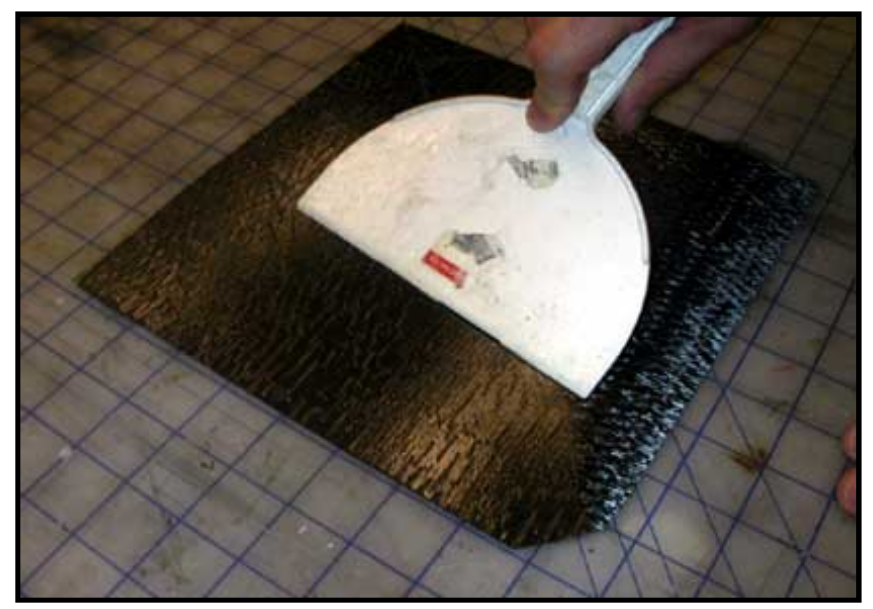

Figure 10 - Hand wet lay-up composite manufacturing technique ${ }^{10}$

Another manufacturing technique involves using pre-impregnated ("pre-preg") composite fabric which is fabric that already has the matrix in it. Pre-preg has the ideal matrix to fiber ratio which yields lightweight parts with the greatest possible strength. A pre-preg lay-up is much cleaner and easier than the other lay-up methods because the layers of pre-preg composite are cut to the correct dimensions and then stacked appropriately. Figure 11 shows a pre-preg composite lay-up being performed.

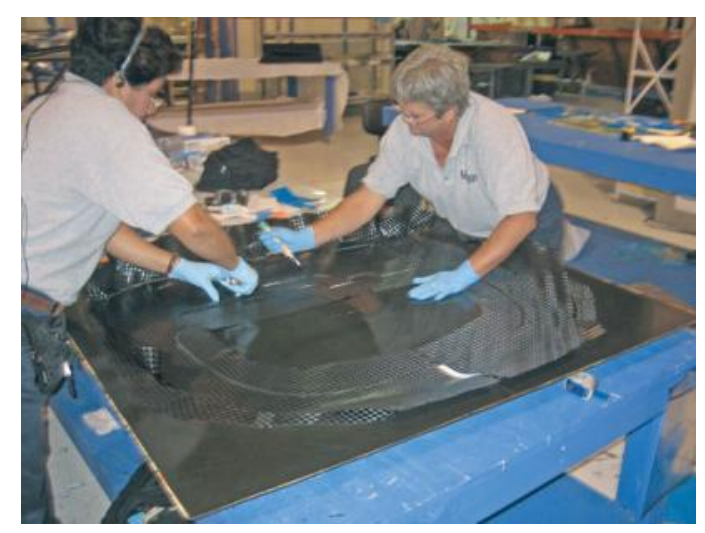

Figure 11 - Composite lay-up using pre-preg carbon fiber ${ }^{11}$

The last way to manufacture parts using composites is by the vacuum assisted resin transfer method (VaRTM). A VaRTM lay-up is similar to a hand wet lay-up because composite cloth is initially 
dry and sealed inside of a vacuum bag. The resin is injected into the part using the suction from a vacuum. VaRTM parts provide fiber to matrix ratios similar to pre-preg but VaRTM is a more cost effective method. VaRTM parts are also lighter weight than hand wet lay-up parts because the excess resin will either get sucked into the resin trap or it will get peeled off during debagging. Figure 12 shows a composite part being manufactured using VaRTM.

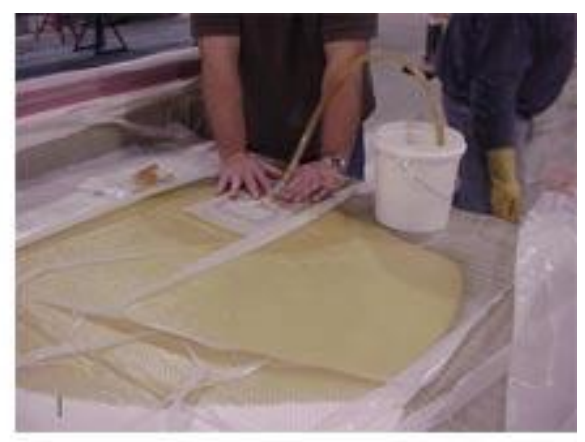

Figure 12 - VaRTM composite manufacturing technique ${ }^{12}$

\section{Material Fatigue}

Material fatigue is progressive and damage occurs when a structure is subjected to cyclic loading $^{15}$. Material fatigue is the primary cause of most structural failures. Material fatigue usually starts at high stress regions and leads to the development of cracks. The cracks will continue to grow and results in catastrophic failure unless maintenance inspections detect them first. Figure 13 shows examples of parts that have failed due to material fatigue. Some typical causes of fatigue include: geometry, material type, environment, temperature, surface finish, microstructure, the presence of oxidizing or inert chemicals, and residual stresses. Fatigue is also a stochastic process because fatigue strength can often shows a large scatter even under ideal testing environments. The best solution for avoiding fatigue is to avoid designing structures with regions of high localized stress. 

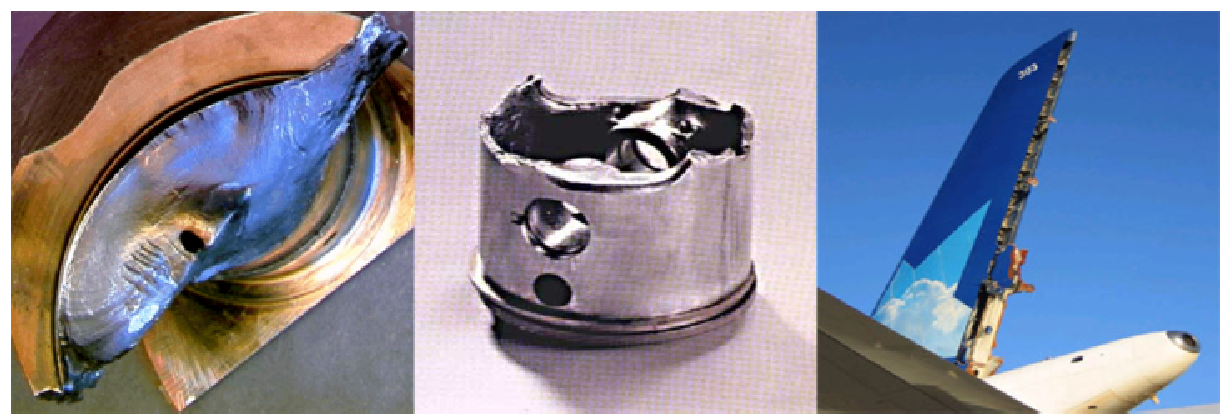

Figure 13 - Examples of structures failed due to material fatigue ${ }^{16,17,18}$

There are two types of material fatigue, low and high cycle fatigue. High cycle fatigue is the most common type and failure is the result of highly elastic behavior because the structure fails before it reaches its yield point. High cycle fatigue causes failure in structures that have been in many years of service. Recently the entire US Air Force F-15 fleet was grounded after a Missouri Air National Guard F15C came apart midflight and crashed ${ }^{19}$. A review of the accident determined that the cause of the failure due to improper longeron manufacturing, which led to fatigue cracks. Low cycle fatigue is the other type of failure and is largely due to widespread plasticity.

The majority of previous fatigue research has focused on the fatigue in isotropic materials such as metals. The fatigue life of a structure can be described using a cyclic stress (S) vs. number of cycles before failure $(\mathrm{N})$ diagram. An example of a S-N curve is shown in Figure 14 below. A S-N curve is generally plotted on a log-log scale with stress on the y-axis and number of cycles on the $\mathrm{x}$-axis. S-N curves are generated by cycling a specimen under a loading spectrum and determining how many cycles it takes before it fails. A significant item on an S-N curve is the fatigue limit because parts loaded below the fatigue strength it will not break $^{20}$ regardless of the number of cycles ran. The fatigue strength is the stress value corresponding to the fatigue limit. 


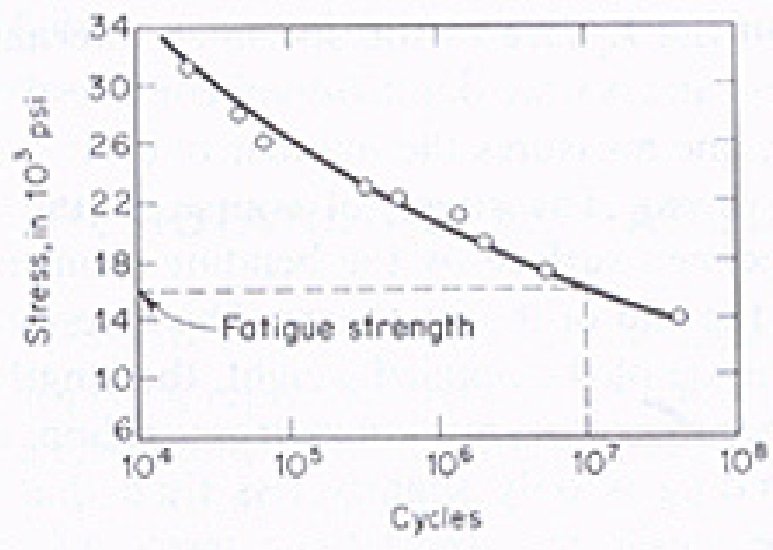

Figure 14 - Typical S-N fatigue life curve ${ }^{20}$

Although composite materials have been around for many years, only recently are they becoming heavily integrated into non-military applications. Little research has been conducted in the fatigue behavior of composite materials because they are not isotropic materials. Their varying properties based upon the direction the fibers are layered in the manufacturing process have made them an especially challenging material to fully understand. 


\section{Design and Manufacturing of Specimen}

\section{Sandwich Structure Design}

The materials selected for this research were the same materials Dr. Mitra used for his research. The composite materials used for the face sheets were woven roving fiberglass and chopped strand fiberglass mats. The chopped strand mat consists of 3 inch fibers that are randomly oriented. The intent of the chopped strand mat is to give the composite sandwich structure more isotropic properties. Woven roving is a fiberglass weave with fibers oriented at angles of $0^{\circ}$ and $90^{\circ}$. Sandwich structures' strength comes from the woven roving mat. Figure 15 shows chopped strand mat on the left and woven roving mat on the right.

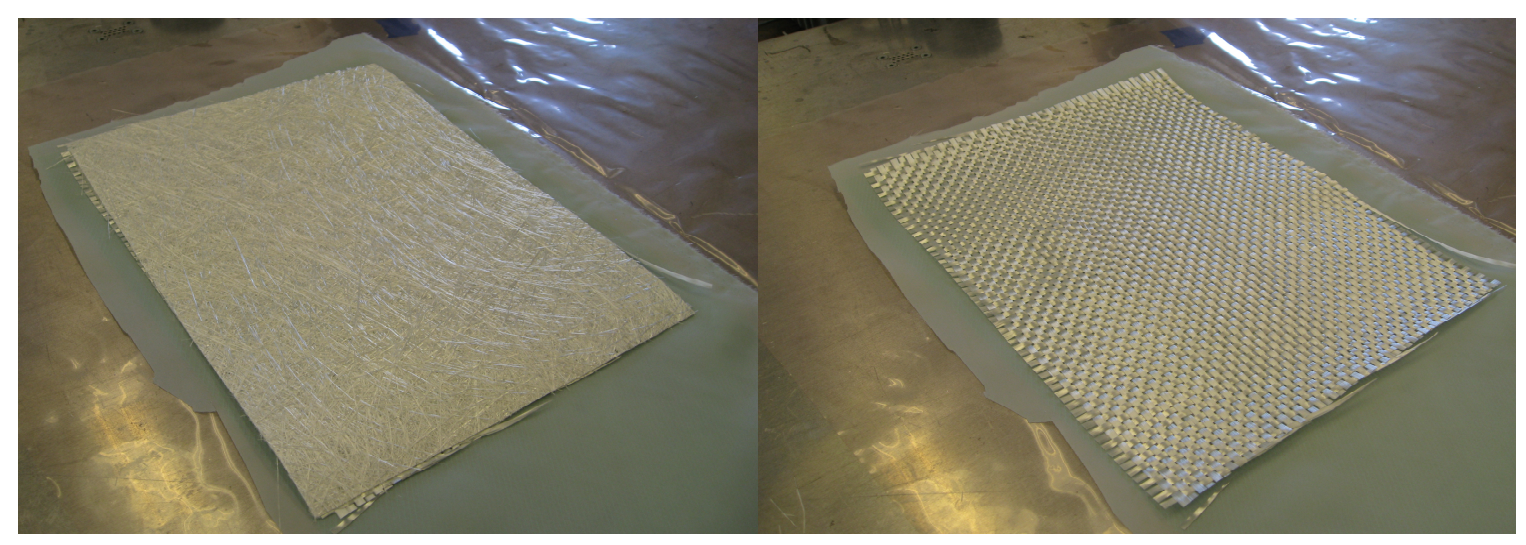

Figure 15 - Chopped strand mat and woven roving fiberglass

The core material used was Divinycell's H 100 PVC foam with a thickness of $20 \mathrm{~mm}$ and a density of $100 \mathrm{~kg} / \mathrm{m}^{3}$. This closed cell foam has a high strength-to-weight ratio as well as excellent ductile qualities. The purpose of the PVC foam core is to increase the sandwich structure's bending and torsional stiffness while only slightly increasing the weight of the test specimens. A stack of different Divinycell foams are shown in Figure 16. 


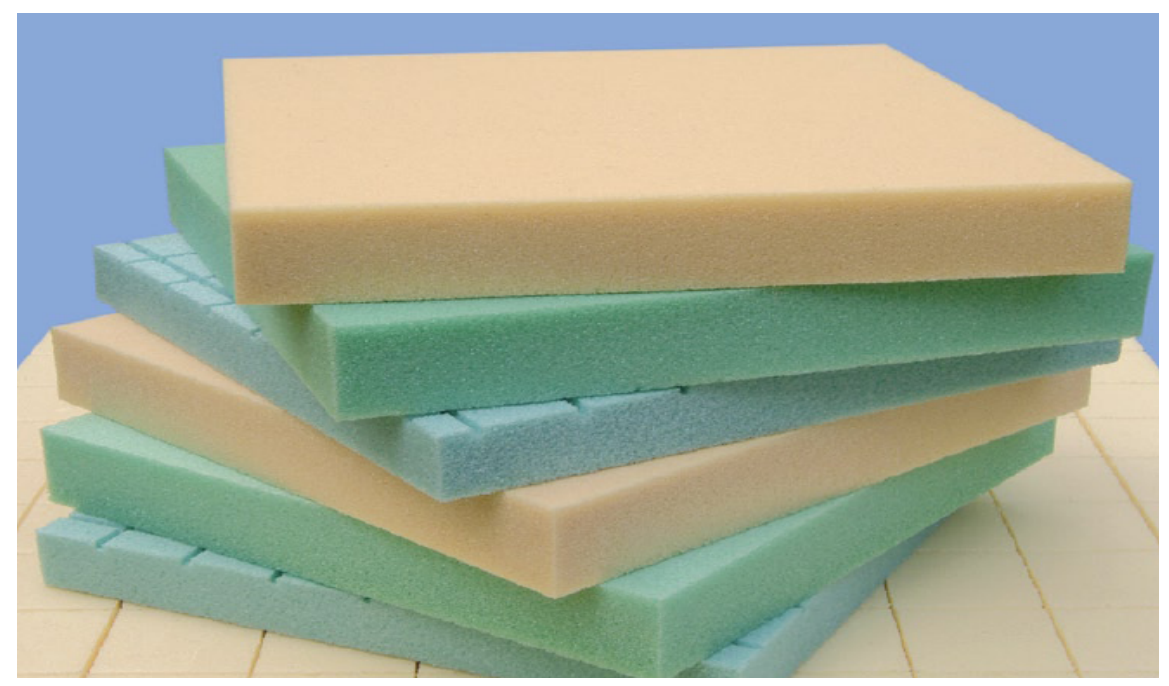

Figure 16 - Divinycell foam core $^{13}$

The composite lay-up used to manufacture the sandwich structures consisted of four layers of fiberglass on either side of the foam core. The stacking sequence of the skin, starting from the outer most layer was: woven roving, chopped strand mat, woven, chopped, core, chopped, woven, chopped, woven.

Six different composite sandwich structure configurations were manufactured and tested are listed below:

1. No Initial Delamination

2. 0.5 inch Initial Delamination

3. 1.0 inch Initial Delamination

4. 1.0 inch Initial Delamination with 0 inch shear key

5. 1.0 inch Initial Delamination with 0.5 inch shear key

6. 1.0 inch Initial Delamination with 1.0 inch shear key 
Figure 17 thru Figure 19 below show schematics of the six different configurations with important components and dimensions labeled. All of the test specimens have the following dimensions: 6 inch x 1.5 inch x 0.787 inch.

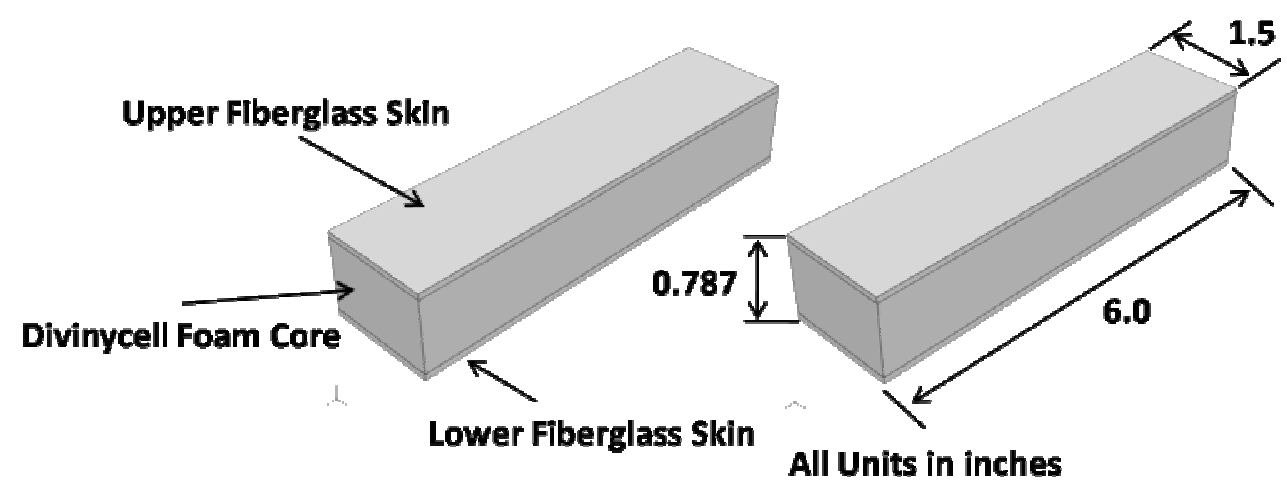

Figure 17 - Test specimen schematic for no initial delamination
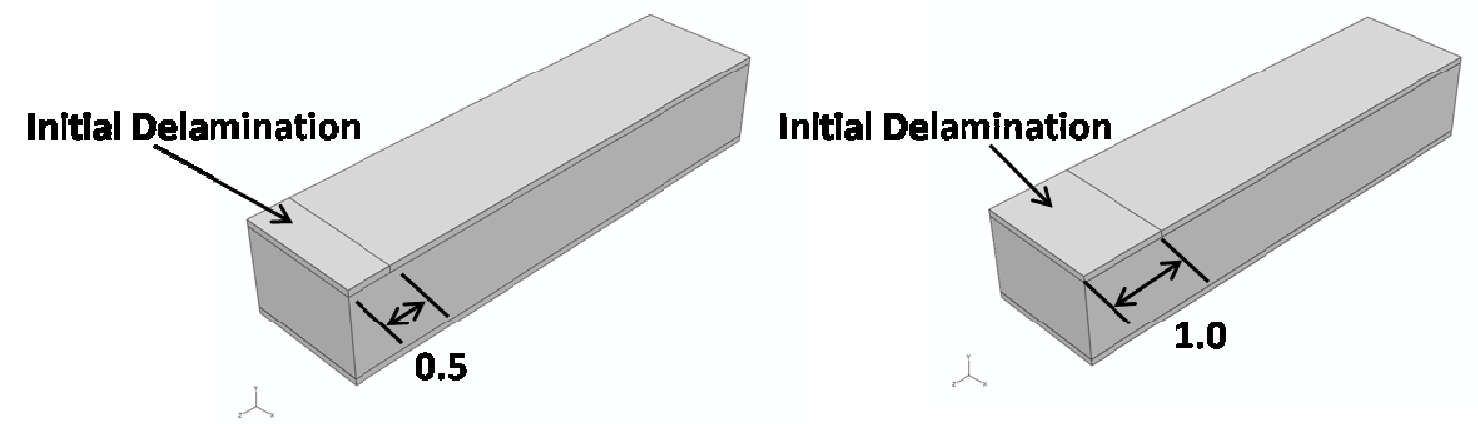

Figure 18 - Test specimen schematic for initial delamination

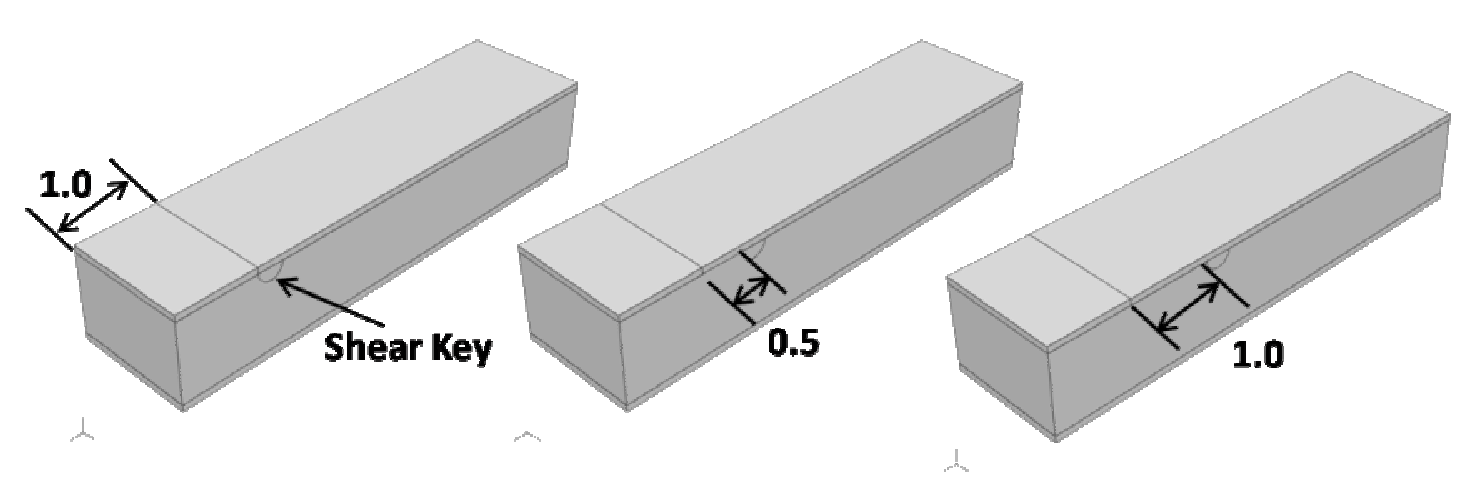

Figure 19 - Test specimen schematic for initial delamination with shear keys 
The composite sandwich structures were manufactured using the vacuum assisted resin transfer method (VaRTM). VaRTM was selected for the manufacturing process because it was the same method Dr. Mitra used in his earlier research.

\section{Sandwich Structure Manufacturing}

The test specimen manufacturing process consisted of three different phases: material preparation, VaRTM lay-up, and testing preparation. During material preparation, all of the materials required for the lay-up were gathered and cut to the appropriate dimensions and stacked. The VaRTM lay-up phase consisted of vacuum sealing the sandwich structure and infusing the resin through it. In preparation for the testing phase, the cured sandwich structure was removed from the vacuum bag, cut into $6 \times 1.5 \times 0.787$ inch test specimens, and aluminum tabs were attached.

\section{Material Prepartion - No Initial Delamination}

Figure 20 below show some of the materials required to manufacture a part using a VaRTM layup. All of the materials used to manufacture the composite sandwich structures are listed below Figure 20.

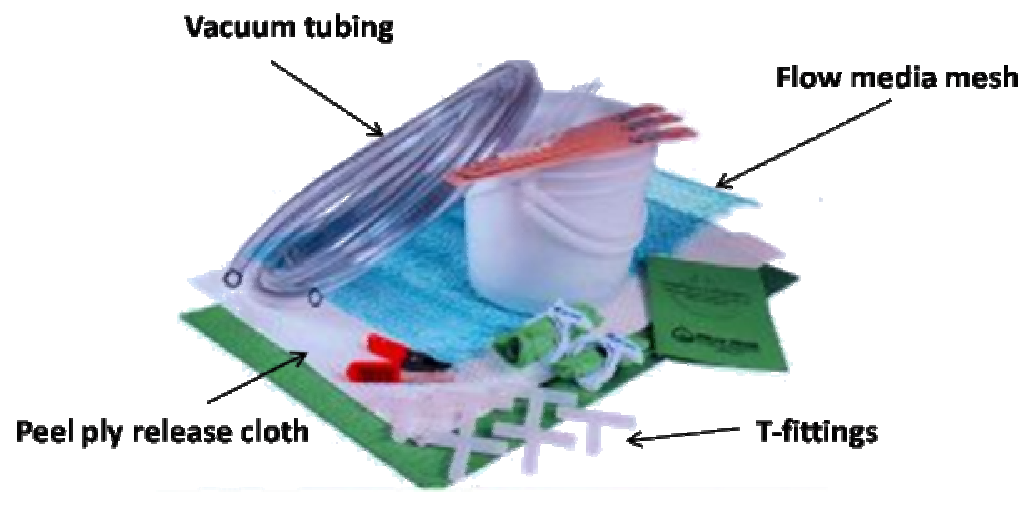

Figure 20 - VaRTM specific materials ${ }^{21}$

\section{List of Materials:}

- Woven roving fiberglass

- Chopped strand fiberglass mat 
- Divinycell H 100 foam

- Peel ply release cloth

- Flow media

- Vacuum bag

- Chromate tacky tape

- Spiral tubing

- T-fittings

- Plastic tubing

- Epoxy/Hardener

- Mixing cups

- Mixing sticks 
During the material preparation phase, large Divinycell PVC foam sheets were obtained and cut into $13 \times 10$ inch squares using a jig saw (Figure 21). 13 x 10 inch dimensions were selected because it provided 12 test specimens would results from each lay-up batch.

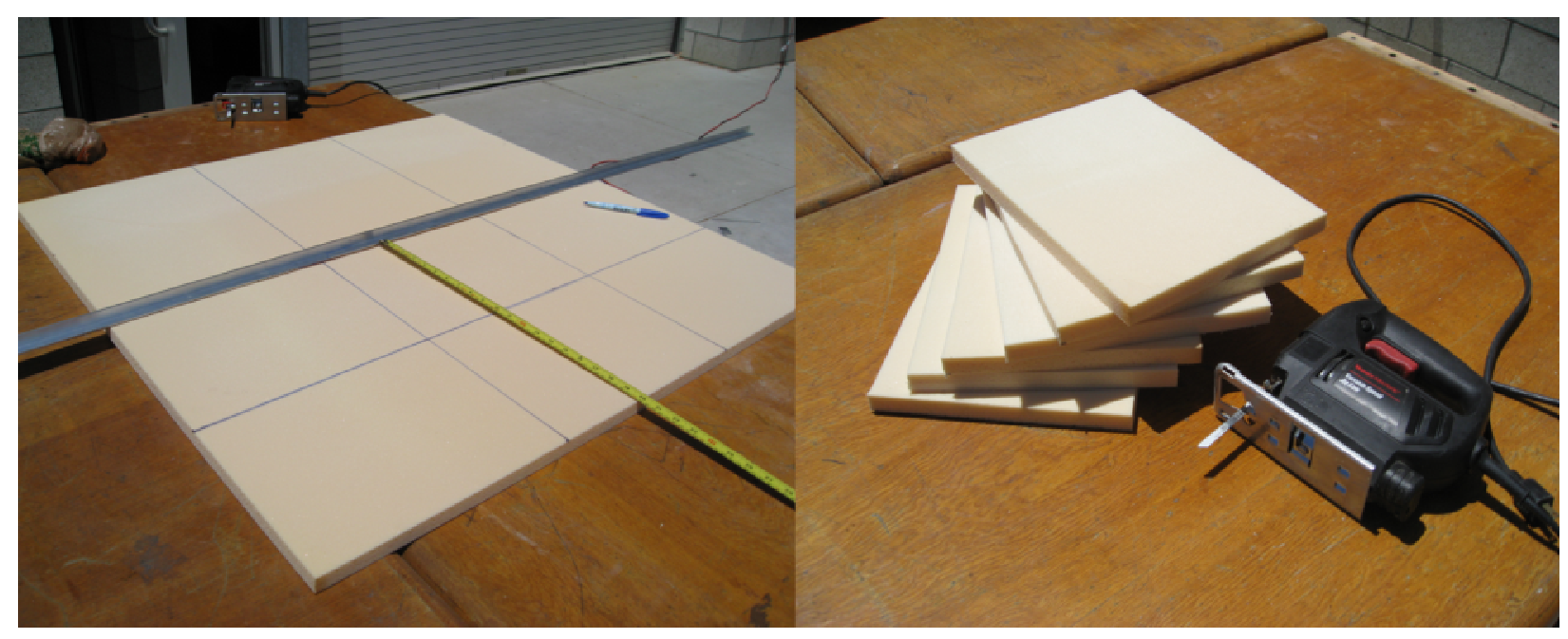

Figure 21 - Divinycell foam sheet and cut foam specimens

Four layers of chopped strand mat and woven roving layers were then cut into 13 x 10 inch square sheets. The composite layers were weighed and used to determine the amount of resin and hardener needed to be mixed. The flow media was cut approximately 1 inch longer than the composite layers but with the same width. The peel ply release cloth was cut approximately 2 inch larger on all side than the flow media. The vacuum bag was cut approximately 2 inch longer on all sides than the peel ply release cloth. Two 15 inch segments of plastic tubing were cut and were used to aid the resin flow through the composite sandwich structure. One t-fitting and a segment of spiral tubing were cut to the width of the sandwich structure (10 inch). The spiral tubing was used to dispense the resin's flow through the structure from the t-fittings. Figure 22 shows the spiral tubing, vacuum tubing, and the t-fittings used for the lay-up and Figure 23 shows how the three items are used in the lay-up. 


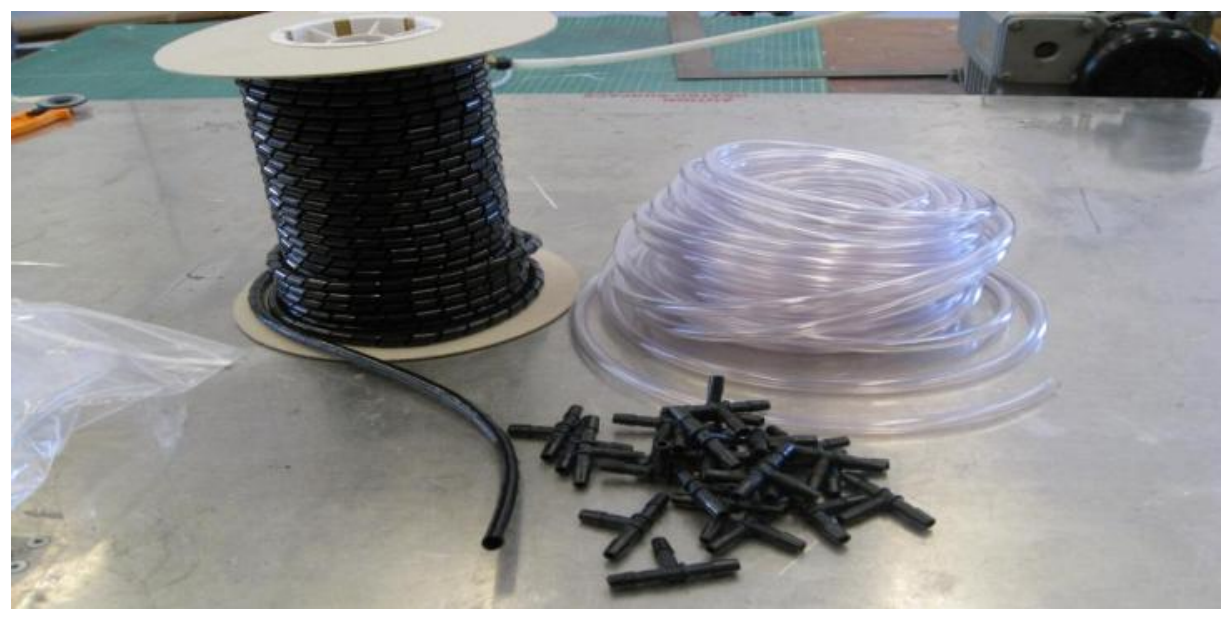

Figure 22 - T-fitting, spiral and vacuum tubing

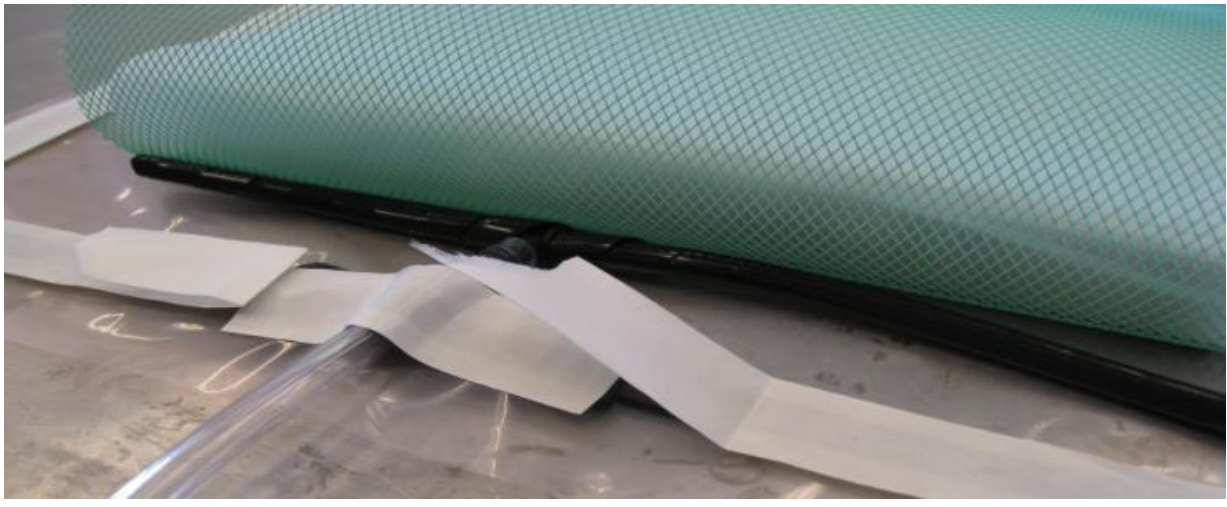

Figure 23 - Spiral tubing and t-fitting set-up

\section{Material Preparation - Test Specimen with Initial Delamination}

The composite sandwich structures with an initial delamination were manufactured in a similar manner compared to the test specimens without delamination but with one difference. A strip of nonporous Teflon material was added to the top of the foam which will prevented the composite layer from bonding to the foam core (shown in Figure 24). The strip of non-porous Teflon paper was cut to approximately $0.25-0.33$ inches. Although extra length was added to the Teflon, the margins were lost when the composite sandwich structure were cut to appropriate dimensions. 


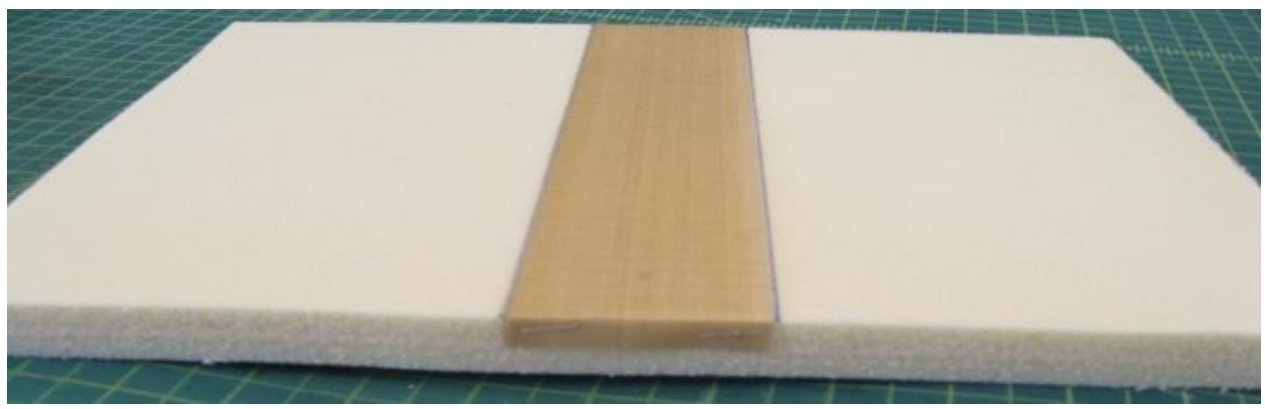

Figure 24 - Foam core with non-porous Teflon strip added

\section{Material Preparation - Test Specimen with Initial Delamination and Shear Keys}

Shear keys were manufactured using an aluminum mold. The aluminum mold contained semicircular grooves with a $4 \mathrm{~mm}$ radius. Individual strands of fiberglass were separated from the woven roving mat (Figure 25) and used to make shear keys. Each shear key is composed of approximately 2530 strands of fiberglass.

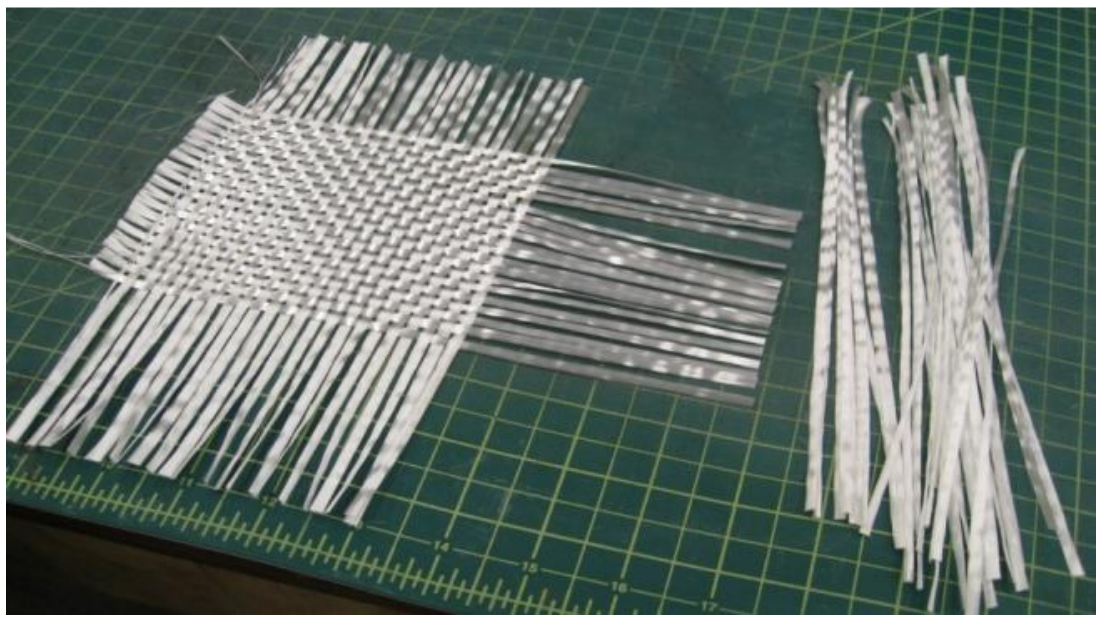

Figure 25 - Collection of fiberglass for shear keys

The shear keys were manufactured using the aluminum mold shown in Figure 26. Before any shear keys could be made, the mold was waxed with Partial High-Temp Release Wax. A thin layer of the wax was applied using a paper towel and left to set for approximately 5 minutes. Excess wax was 
buffed off with a clean paper towel. The process was repeated 2 more times to ensure that the cured shear keys could be easily removed from the mold after the lay-up.

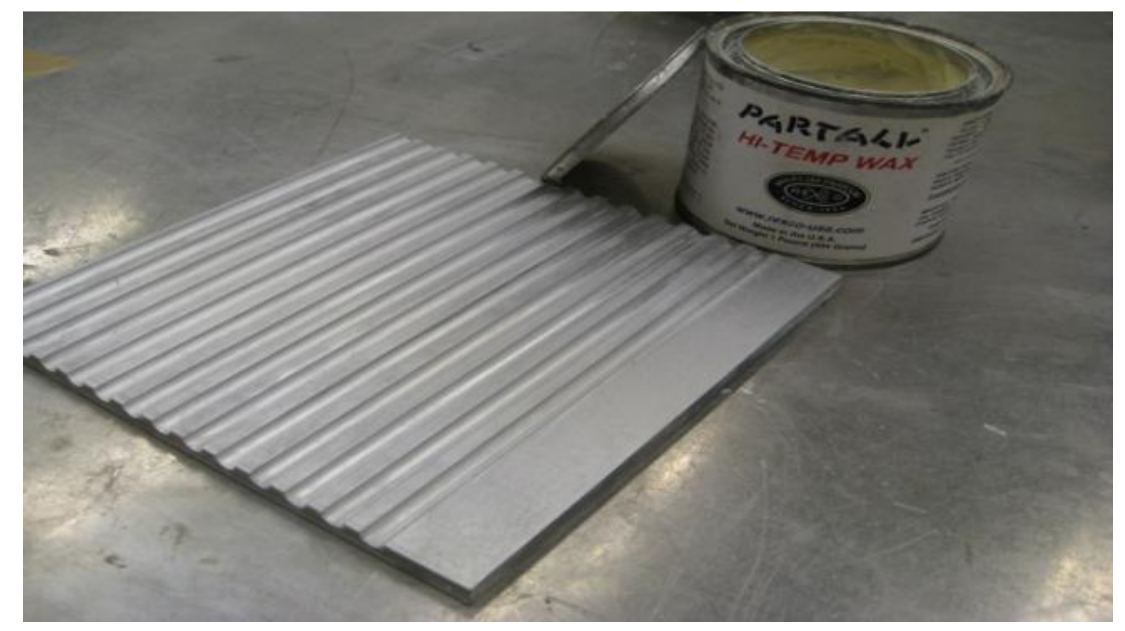

Figure 26 - Wax used for shear key mold

Shear key bundles were weighed to determine the amount of resin and hardener needed to cure the fibers. West System Epoxy System and Hardener was used for the shear key lay-up. Shear keys were initially made using a VaRTM lay-up but the epoxy wasn't traveling through the entire depth of the shear keys, leaving some fibers dry and unsatisfactory for testing. To avoid producing shear keys with dry fibers a hand wet lay-up was used. Approximately 5 times more resin and hardener were mixed to ensure that all of the fibers were wet. The epoxy was applied to each shear key bundle and the resin was worked through the fibers by hand. Figure 27 shows the wet shear key bundles being placed into the aluminum mold. 


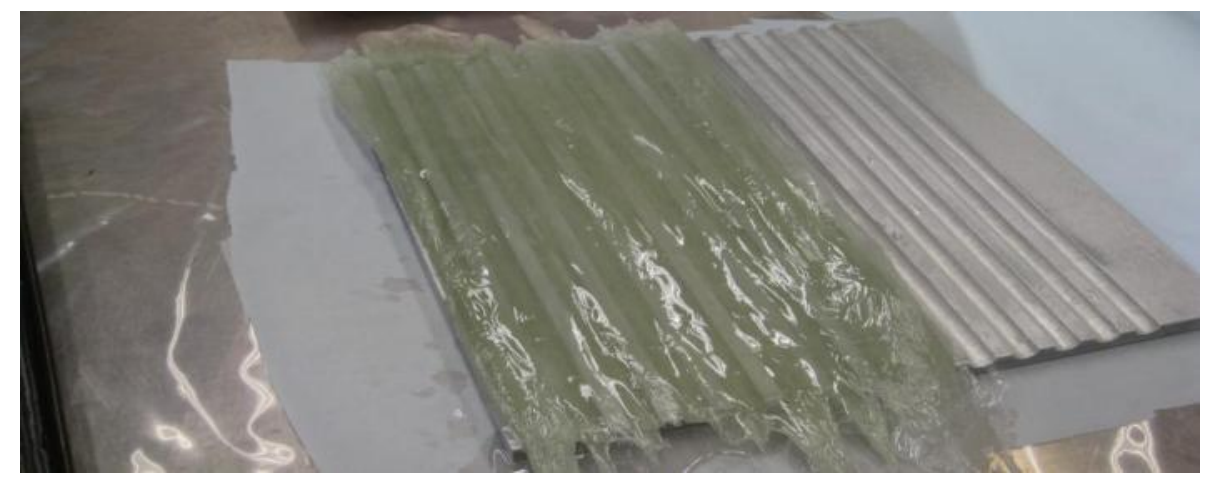

Figure 27 - Hand lay-up of shear key fiber bundles

A sheet of peel ply was wrapped around the mold. A sheet of thick breather material was then added to the top of the peel ply shown in Figure 28. The shear key mold was vacuum sealed with a tube running from the breather cloth on top of the mold to the vacuum. The vacuum was turned on and the shear keys are left to cure for approximately 12 hours.

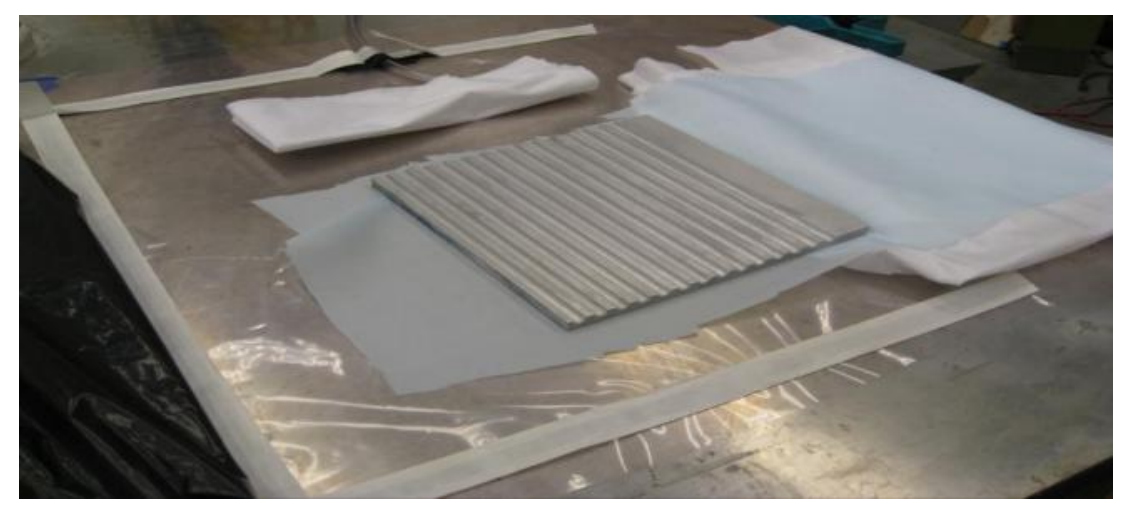

Figure 28 - Shear key lay-up before vacuum bagging

The vacuum bag was cut open and the cured shear keys were removed from the mold. The tile saw was used to cut the fiberglass plate into individual shear keys. The belt sander was used to sand off any excess fiberglass and resin connected to the shear keys. Shear keys were then placed into the milled out grooves in an extra sheet of foam core. The top surface of the shear keys were sanded down flat using the plane sander. 
The sandwich structures with shear keys were manufactured in a similar manner to the test specimens with an initial delamination. A piece of foam with the same dimensions used for the previous lay-ups had $4 \mathrm{~mm}$ radius grooves milled out using a manual mill. Then a strip of non-porous Teflon film was added in between the shear keys on the foam just like the test specimens with an initial delamination. As before all of the vacuum bagging materials were gathered and set-up to the point right before the vacuum bag was sealed. A small amount of epoxy was mixed (approximately $30 \mathrm{~g}$ ) which was used to bond the shear keys to the foam. After the epoxy was adequately mixed then the epoxy was applied to the milled out foam regions using a wooden popsicle stick. Finally the shear keys were inserted into the grooves and the upper skin of fiberglass was stacked on top and the bag was sealed up for the resin to flow through.

\section{$\underline{\text { VaRTM Lay-up }}$}

After all of the materials have been cut and prepared the materials were stacked in the lay-up level. The vacuum bag was laid out on a flat surface and the flow media was placed on top of it followed by the release cloth. Components of the composite lay-up were assembled in its appropriate lay-up level and stacked on top starting with the woven roving and the chopped strand mat. Another layer of woven roving and chopped strand mat were added followed by the foam core. Two additional layers of chopped strand mat and woven roving were placed on top of the foam core in an alternating fashion. Chromate sealant tape was used to surround the perimeter of the sandwich structure lay-up in order to seal the vacuum bag later. Segments of plastic tubing were placed at either ends of the sandwich structure to aid in the direction of resin flow from the vacuum pump. A small piece of cotton was added to the tubing closest to the vacuum to increase the bag pressure. The peel ply, flow media, and vacuum bag were then folded over to envelope the entire sandwich structure shown in Figure 29. 


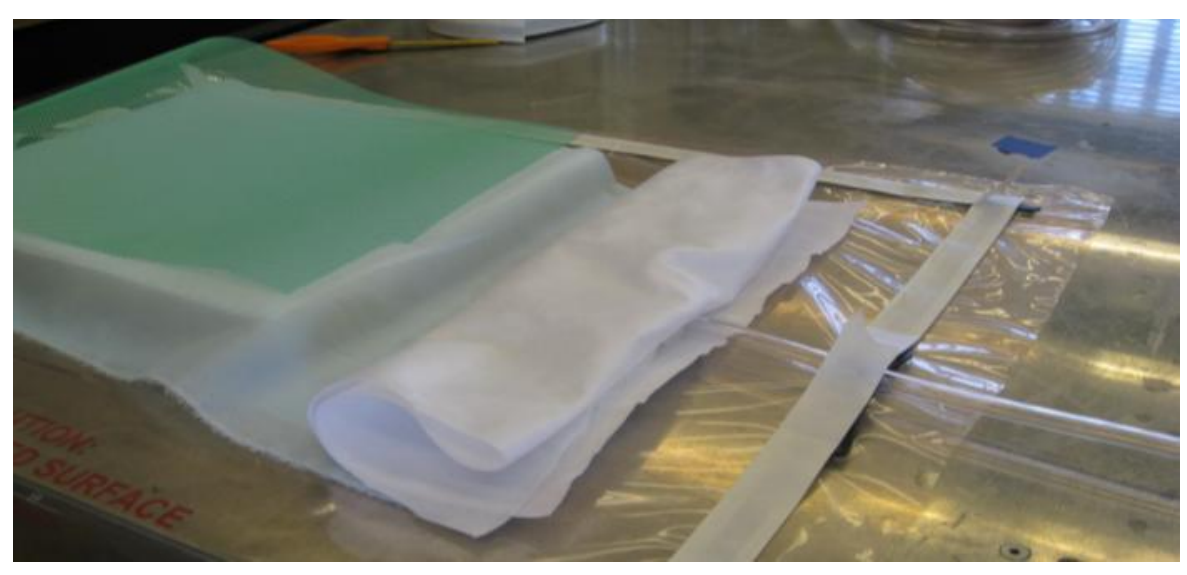

Figure 29 - Stacked VaRTM lay-up before vacuum bagging

The vacuum bag was sealed off using the Chromate sealant tape that was applied to the perimeter of the vacuum bag. Care was taken while sealing the vacuum bag to minimize air leaks. The vacuum end of the tubing was connected to the resin trap and sealed off using another thin strip of sealant tape. A leak check was performed prior to running the resin through the part. To check for leaks, a piece of sealant tape was applied to the resin side of the tube and the vacuum was turned on. If leaks were discovered, then the remaining leaks were sealed off with additional Chromate sealant tape. Caution was also taken to correctly line-up the composite fabric sheets. If the sheets were not correctly place, the applied vacuum pressure would cause the contents of the bag to shift around. After double checking the placement of the composite sheets and leaks, the sealant tape on the resin side of the tube was removed and the tube was closed off using vice grip pliers (shown in Figure 30) 


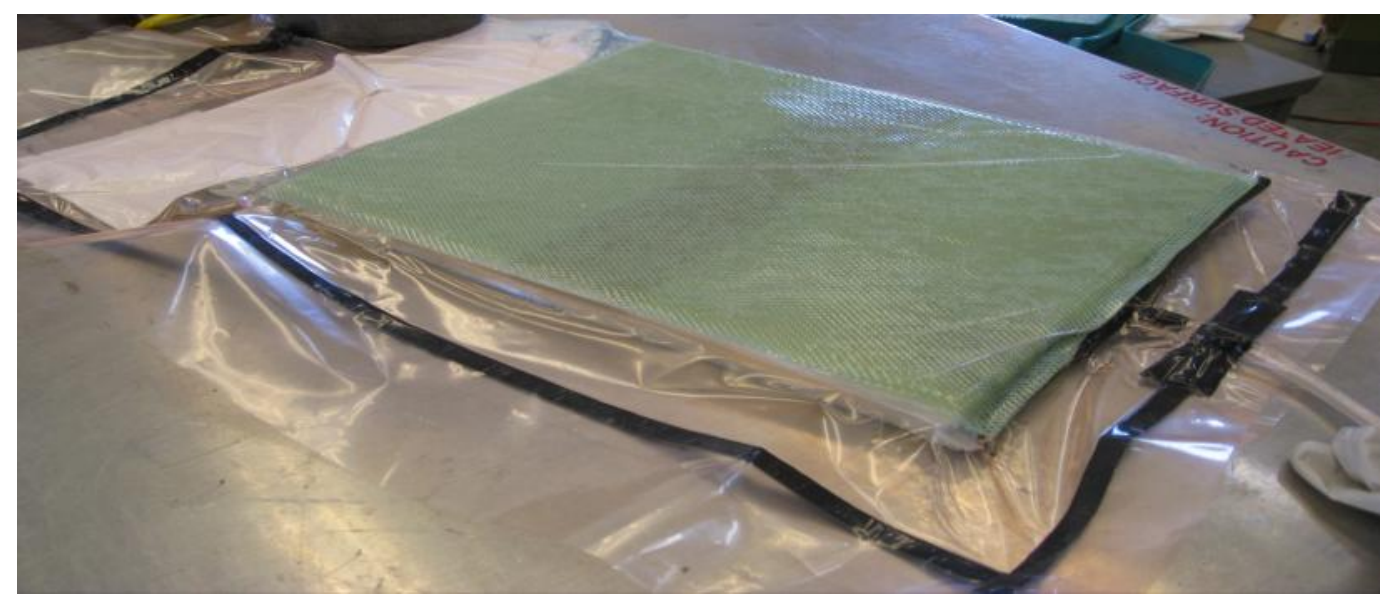

Figure 30 - Vacuum bagged composite sandwich structure after lay-up

West System's 105 Epoxy System and 206 Slow Hardener were used as the matrix for the composite sandwich structure lay-up (shown in Figure 31). The amount of resin and hardener used were determined based upon the weight of the dry fibers. The total weight of the dry fibers was multiplied by 1.5 which allowed extra epoxy to ensure that the fibers were properly saturated. From earlier lay-up experiments it was determined that the total amount of epoxy should be divided into two separate mixing cups in order to prevent the epoxy from curing before it had the chance to travel the entire length of the part. The resin-to-hardener ratio for the resin system used was approximately 3 to 1 .

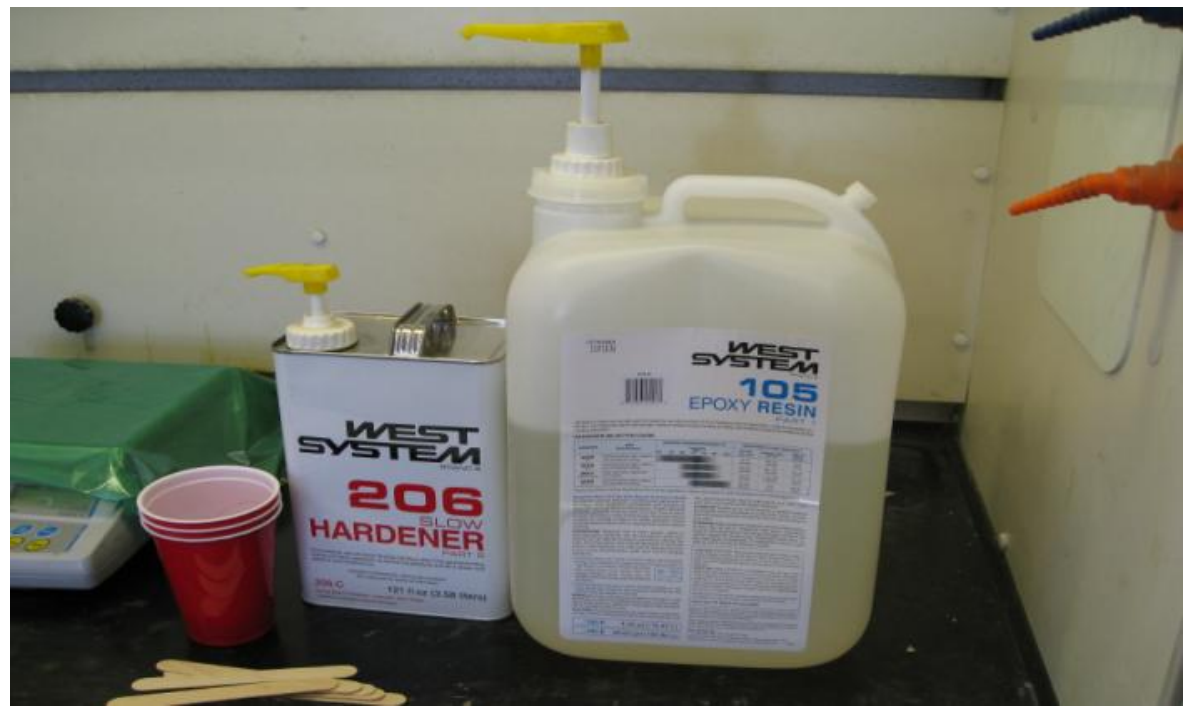

Figure 31 - West System resin and hardener used for lay-up 
The resin and hardener were measured out into two separate cups using a scale. When ready, the two were combined and stirred until fully mixed. The pliers were removed from the resin side of the tubing and the end of tube was placed in the resin cup. Figure 32 shows the resin flowing from the cup through the tubing to the vacuum sealed composite sandwich structure. The pressure from the vacuum pulls the resin across the sandwich structure and through the flow media. The second cup of mixed resin was poured into the $1^{\text {st }}$ resin cup when it was almost empty. After all of the resin had flowed across the sandwich structure then vice grips were used to close off the resin side of the tubing to ensure that the part remains under constant vacuum pressure. Then a flat sheet was placed on top of the sandwich structure and weights were added to evenly distribute additional pressure. The part is left under vacuum pressure overnight for approximately 12 hours.

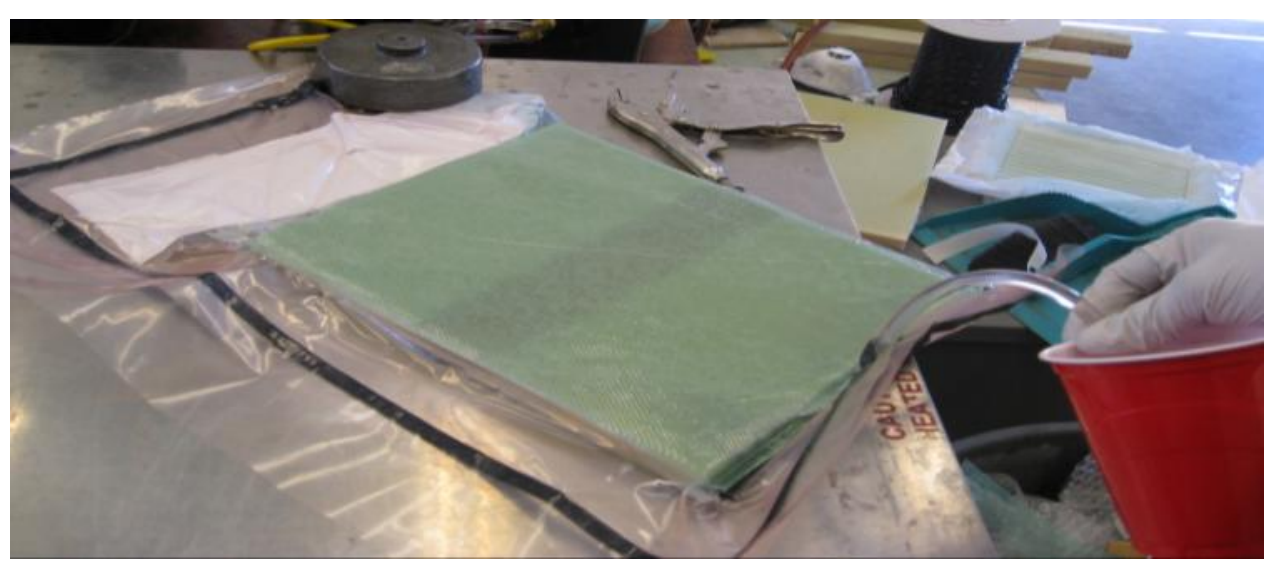

Figure 32 - VaRTM composite lay-ups resin flow

Figure 33 below shows an exploded view of a VaRTM with all of the materials labeled. 


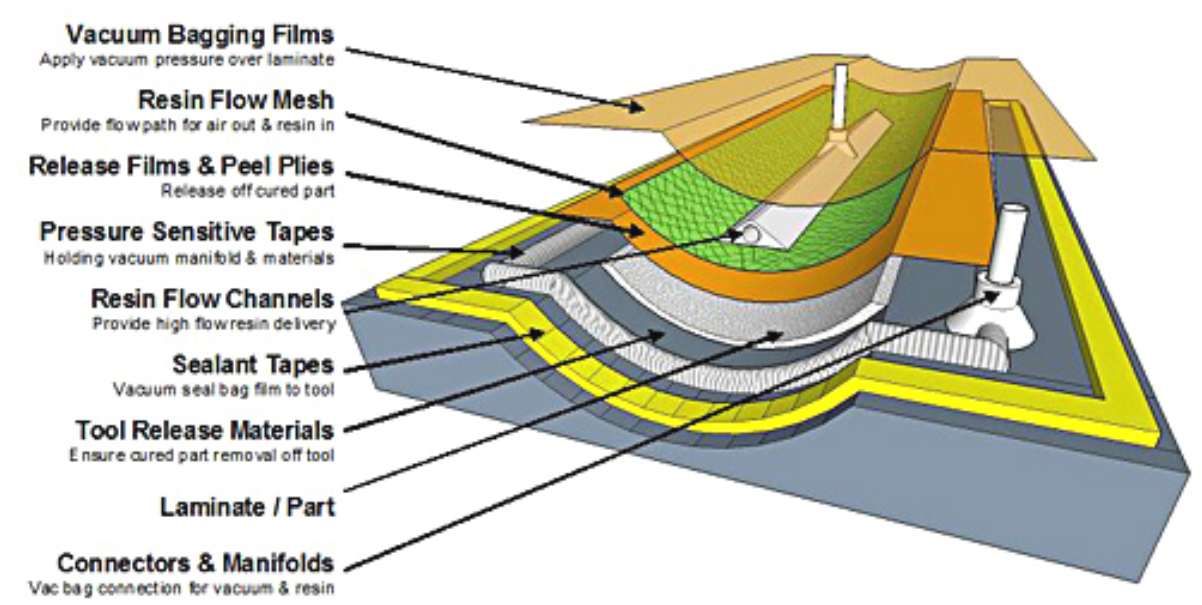

Figure 33 - Composite materials stacked before lay-up ${ }^{22}$

\section{Testing Preparation}

Following the composite sandwich structure curing process (12 hours) the vacuum was turned off and the part was allowed to cure for another 6 hours. The part was removed from the vacuum bag and the peel ply was carefully removed from the sandwich structure. Removing the peel ply also released the flow media and tubing from the part. The tile saw (shown in the Figure 34) was used to cut the sandwich structure into $1.5 \times 6$ inch test pieces. The $6.5 \times 13$ inch pieces were then each cut into $1.5 \times 6$ inch test specimens. Twelve test specimens were produced from one sandwich structure panel.

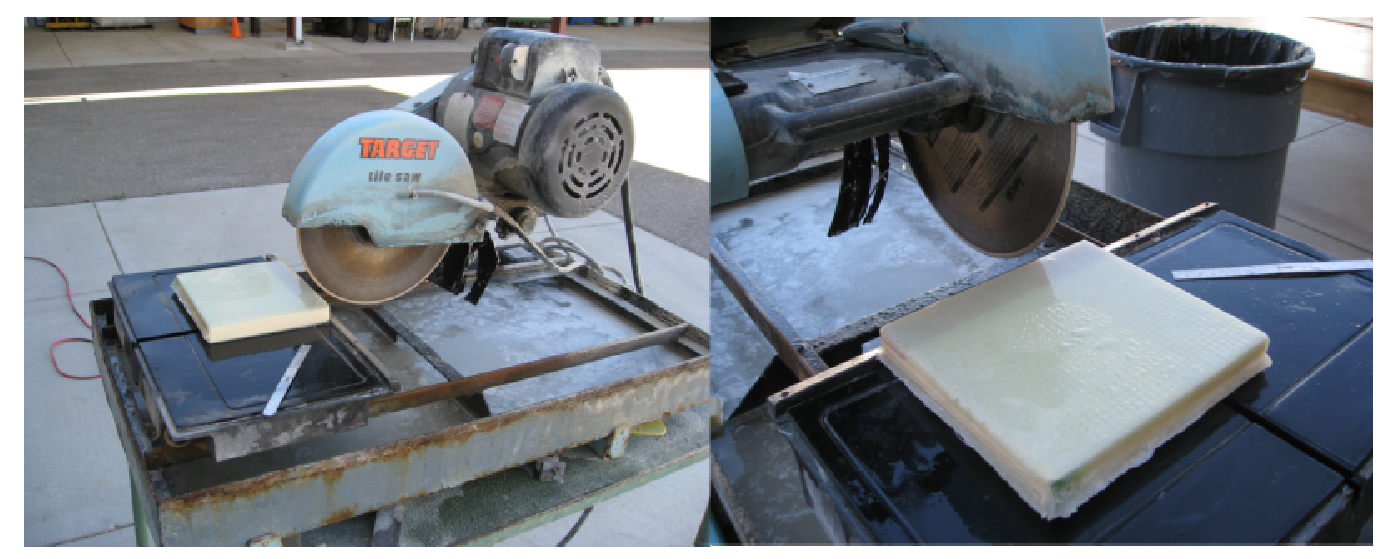

Figure 34 - Tile saw and cut test specimen 
Trimmed test specimens were placed in direct sunlight for approximately one hour to fully dry the test specimens before being labeled. The labeling scheme is shown in Figure 35 below. The numbering scheme was implemented to keep all test specimens labeled in a consistent manner.

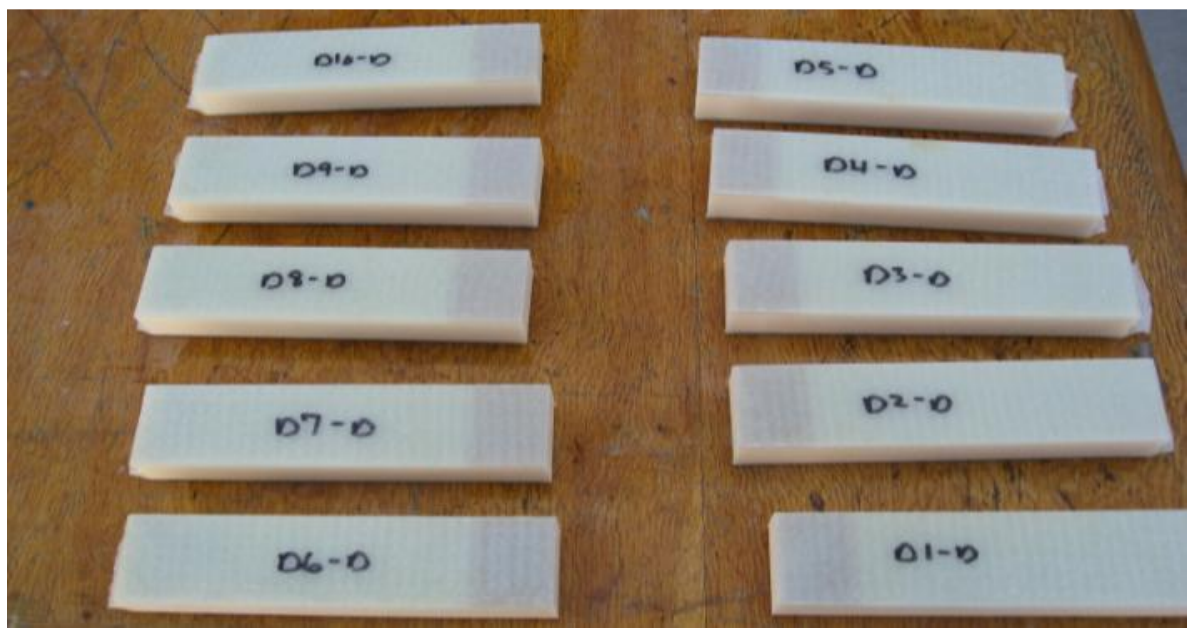

Figure 35 - Test specimen numbering scheme

Load transferring from the Instron machine to the composite sandwich structure was investigated in the previous delamination research. In the research triangular aluminum and steel tabs were used to transfer the load from the Instron machine to the sandwich structures. The triangular tabs worked well because they provided a good bonding area on the composite sandwich but required a tedious manufacturing process because the tabs had to be made using a milling machine. Steel tabs with dimensions of $2 \times 2 \times 0.25$ inch, were much easier to manufacture because no milling was required. However, issues arose with the steel tabs as the 0.25 inch tabs had difficultly bonding to the sandwich structure. Building upon the previous research $90^{\circ}$ aluminum L-brackets were selected. The aluminum Lbrackets have dimensions of $2 \times 2 \times 0.125$ inch with a leg length of 0.5 inch shown in Figure 36 below. The L-brackets were obtained in 8 feet long segments and were then cut into smaller pieces using a jig saw. The 0.5 inch leg length of the tabs provided enough area to bond the sandwich structure and no manufacturing was required. 


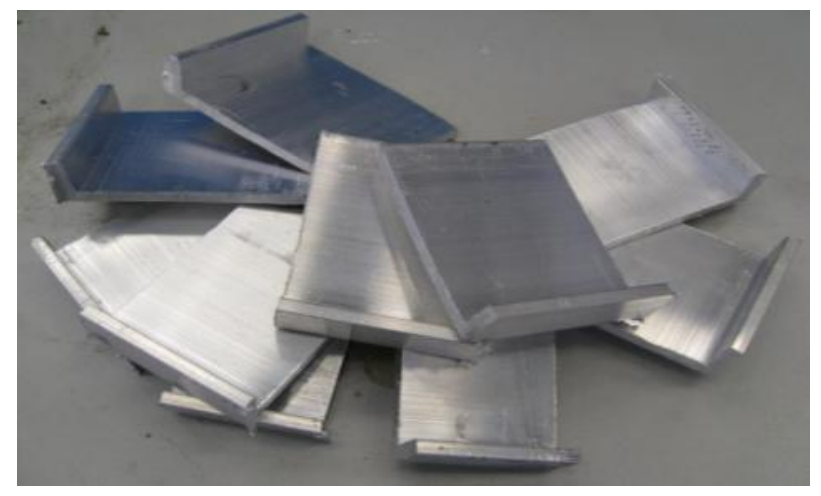

Figure 36 - Aluminum L-brackets

The $90^{\circ}$ aluminum tabs were bonded to the test specimens using Scotch Weld 460 NS structural adhesive. This particular adhesive was selected because it is one of the strongest structural adhesive available with an ultimate shear of $80,000 \mathrm{lb}_{\mathrm{f}}$. The adhesive was applied using a glue gun and a special nozzle that mixed the two part adhesive (shown in Figure 37). The glue gun nozzle mixed the two part adhesive with the appropriate mixing ratio (10:1).

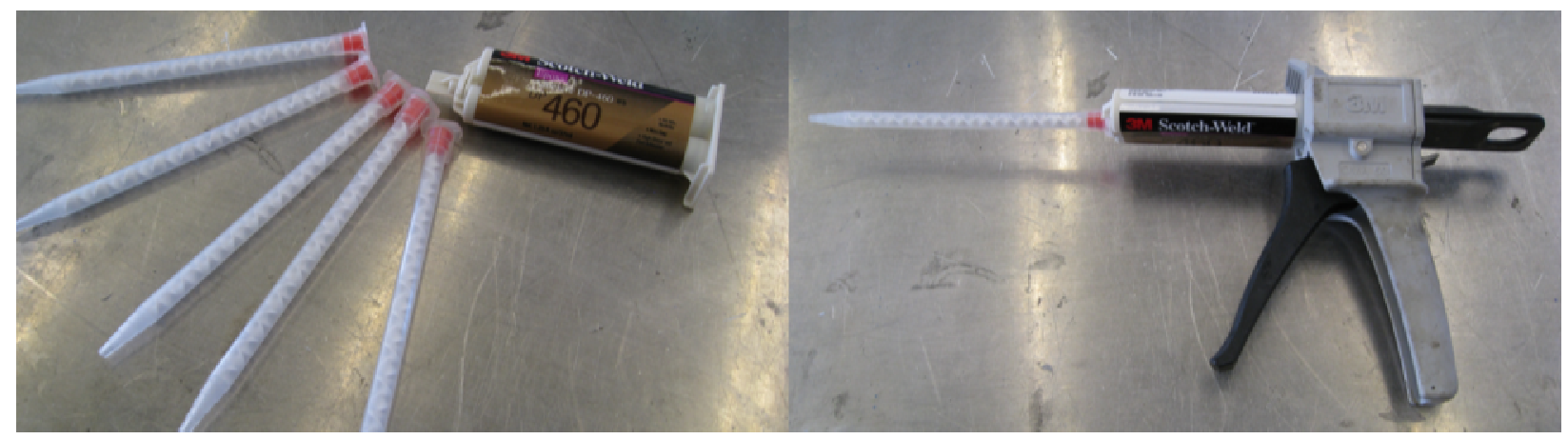

Figure 37 - Structural glue, mixing nozzles, and applicator gun

Tabs were then placed on the edge of a table, as shown on the left side of Figure 38. A thin layer of adhesive was applied to the 0.5 inch leg of the aluminum L-brackets and was evenly spread across the tabs using a popsicle stick (shown in Figure 38). The test specimens were then carefully lined up with the L-brackets and bonded together. A flat piece of plywood was placed on the top of the test specimens and weights are added to apply pressure (shown in the right hand side of Figure 38). The test specimens 
were allowed to cure for approximately 8 hours after which another L-bracket was attached to the opposite side. Test specimens were ready for testing after two L-brackets were attached and fully cured.

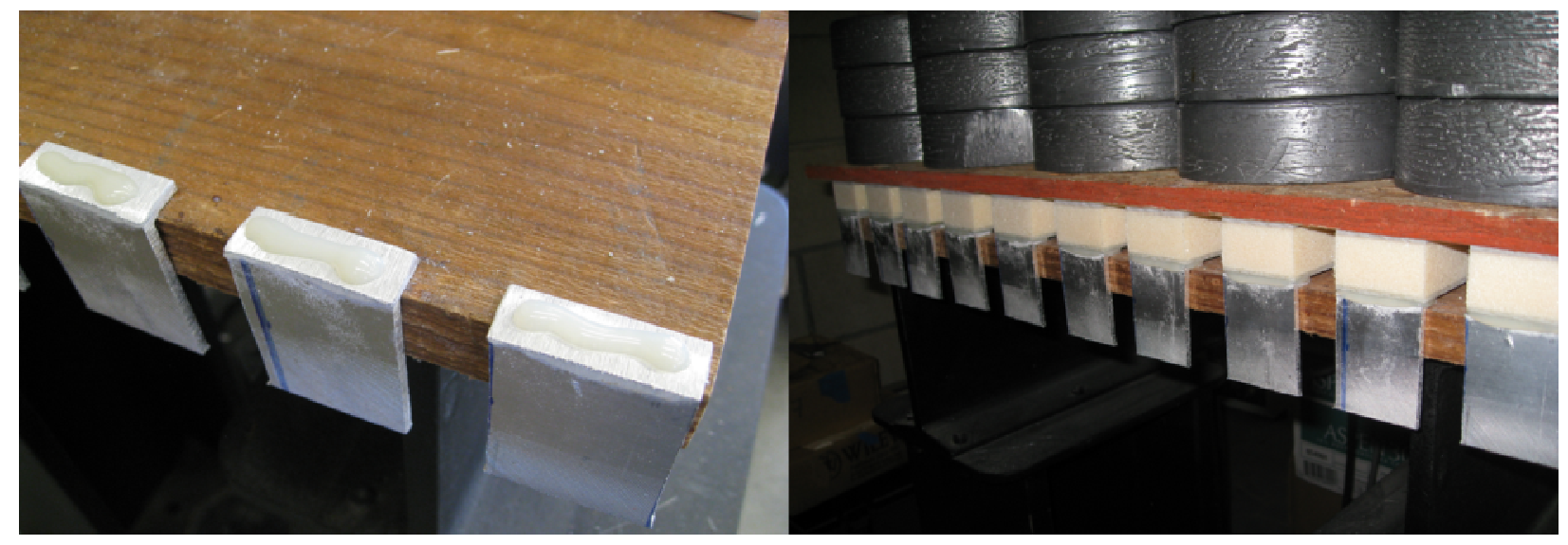

Figure 38 - Structural glue applied to test specimens 


\section{Experimental Procedure and Testing}

The experimental testing of the composite sandwich structures were performed in the Cal Poly Aerospace Structures and Composites Lab. Both the static (monotonic) and dynamic (fatigue) testing were performed using an Instron 8801 machine. Two different machine configurations were used specific to either the high load or low load case. The high load cases utilized a $100 \mathrm{kN}$ load cell which was used to test composite sandwich structures with no initial delamination. The high load Instron configuration is shown in Figure 39.

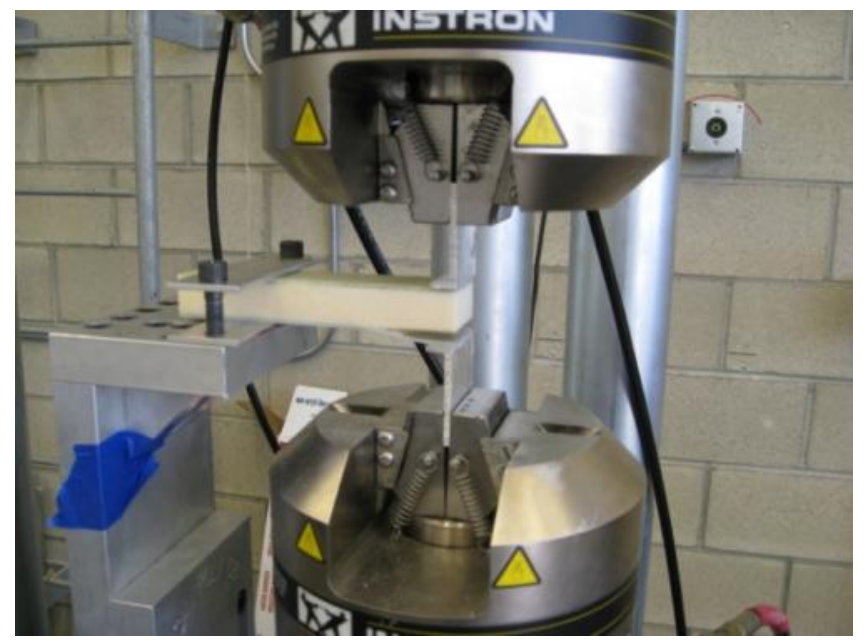

Figure 39 - 100 kN load cell Instron grip configuration

The low force cases used a $1 \mathrm{kN}$ load cell to test specimens with an initial delamination and shear keys. The $1 \mathrm{kN}$ load cell configuration with its appropriate Instron grips is shown in Figure 40. The aluminum tabs on the test specimens were secured into place by closing the Instron grips. The test specimens were also held into place at the back end using a jig as shown in Figure 40. 


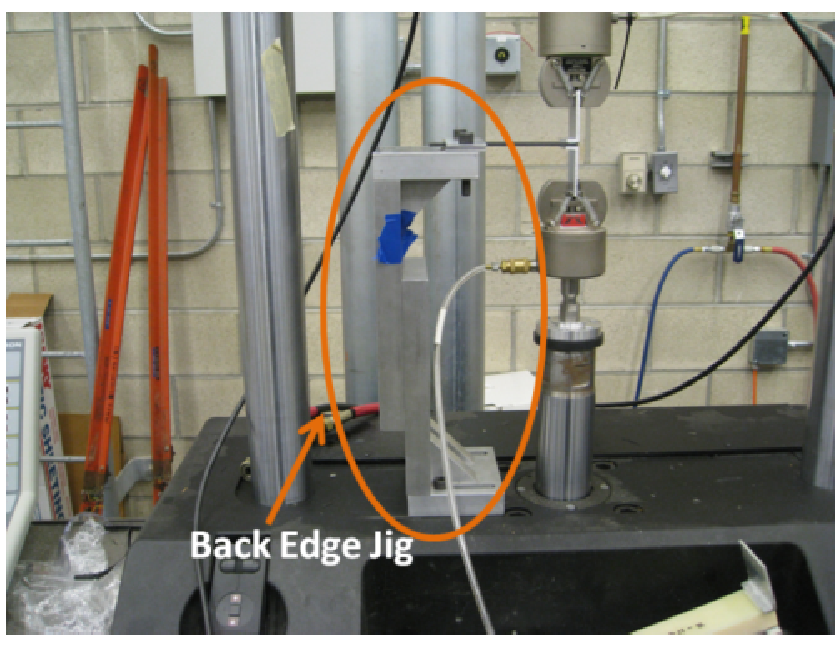

Figure 40 - 1 kN load cell configuration and back edge jig

\section{Monotonic Testing}

Static tests (monotonic testing) were performed on the six different types of test specimens to determine the ultimate loads and failure behavior for each case. The failure loads were required inputs to perform the dynamic (fatigue) testing because the fatigue loading is a function of the monotonic failure. From the previous delamination research the loading rate was investigated under speeds of $0.5,1.0$ and $2.0 \mathrm{~mm} / \mathrm{min}$. It was discovered that slower loading rates introduced difficulties with the delaminated test specimens $^{5}$. For that reason a loading rate of $2.0 \mathrm{~mm} / \mathrm{min}$ was selected. The program used for the monotonic testing was Merlin provided by the Instron. Merlin's failure criteria for testing was that the loading rate for the tested needed to drop by $50 \%$ in order for the tests to stop. Figure 41 shows a screenshot of Merlin before testing, when the inputs are specified and Figure 42 shows Merlin during a test. 


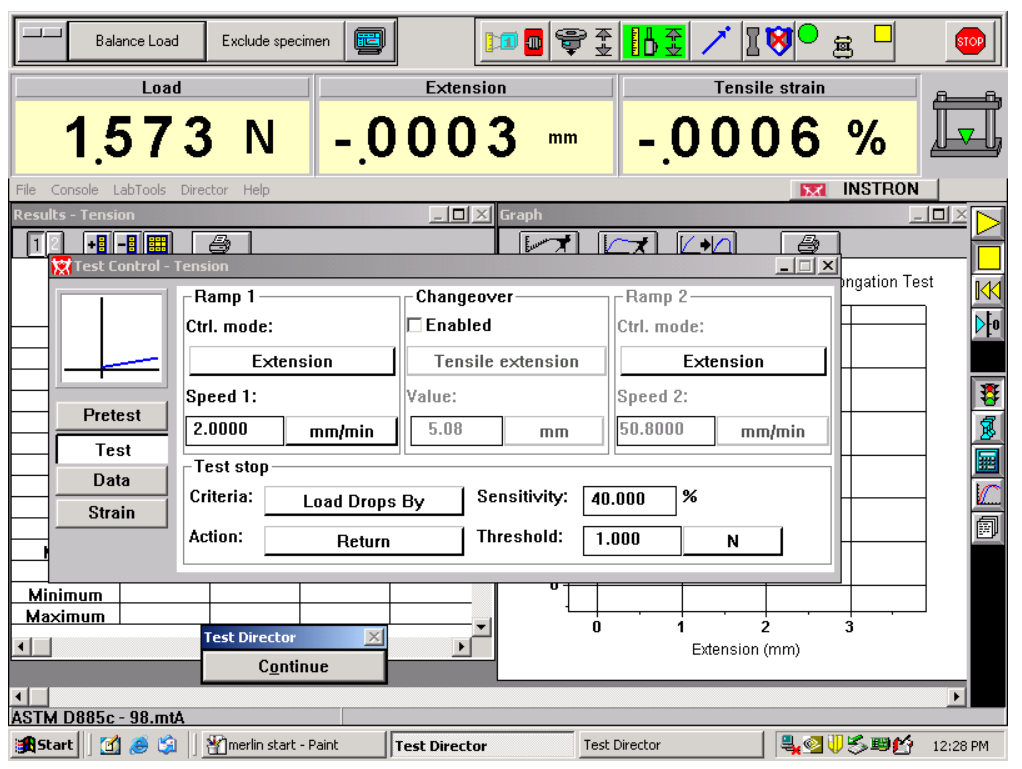

Figure 41 - Inputs for monotonic testing

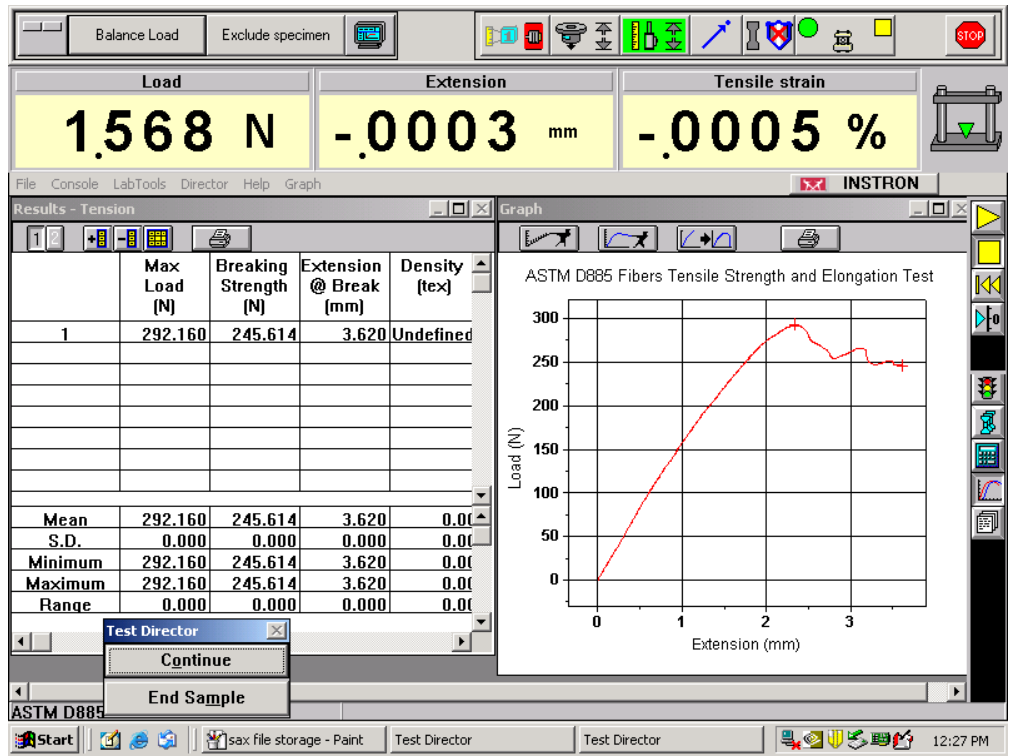

Figure 42 - Merlin screen during testing

\section{Dynamic Testing}

The dynamic testing was performed on the composite sandwich structures to determine the

fatigue behavior. The overall goal of the fatigue testing was to construct a stress vs. number of cycles to failure $(\mathrm{S}-\mathrm{N})$ curve for the following three sandwich structure configurations: 
- No initial delamination

- 0.5 inch initial delamination

- 0.5 inch initial delamination with shear key

The fatigue testing was performed using the Instron program Single Axis MAX (SAX). A sinusoidal cyclic loading was applied to the test specimen from the Instron machine. SAX can either be driven by inputting force or displacement conditions. Force inputs were selected since the monotonic failure characteristics of the sandwich structures were defined in terms of force. The four important parameters that were required inputs into SAX were: frequency, sample rate, mean force, and force amplitude. Figure 43 shows a screenshot of SAX and the input parameters required for testing.

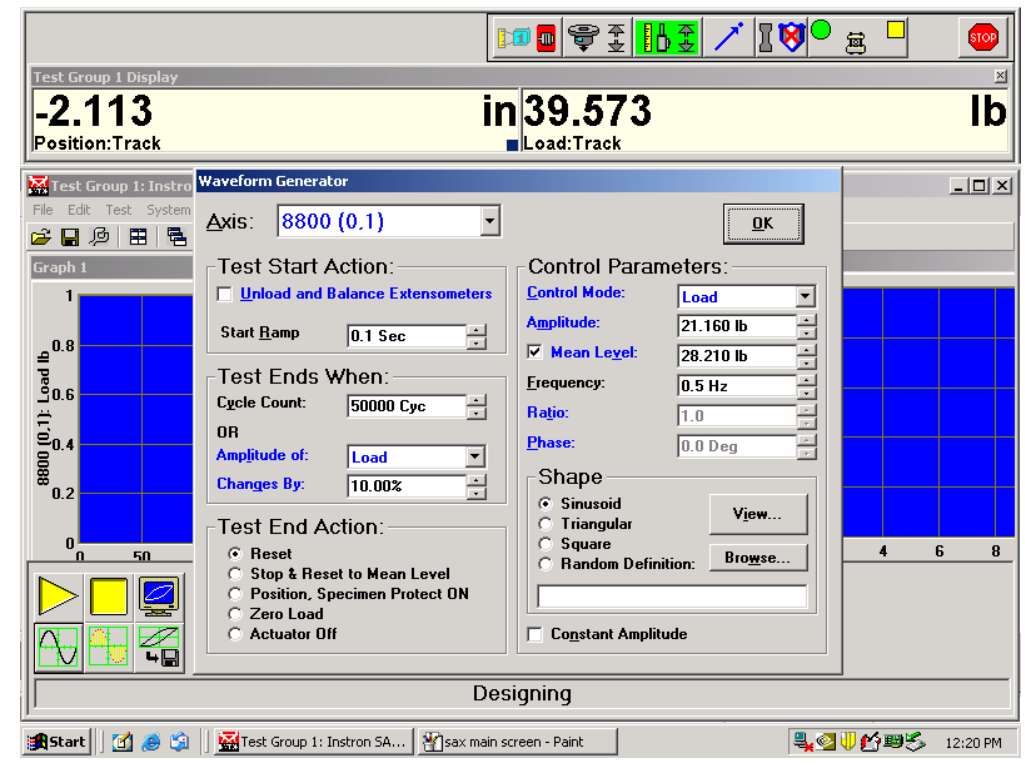

Figure 43 - SAX input parameters

Two important inputs were the force amplitude and mean, which fully defined the sinusoidal wave. Preliminary tests revealed that using the $100 \mathrm{kN}$ load cell put a minimum amplitude requirement of $100 \mathrm{lb}_{\mathrm{f}}$ for the sin wave to correctly track the input force equal to the output force. This was most likely attributed to the notion that the large load cell has a much smaller force tolerance compared to the $1 \mathrm{kN}$ load cell. This requirement was a driving constraint for determining the force amplitude and mean. From 
the monotonic testing it was determined that only the test specimens with no initial delamination could be tested using the $100 \mathrm{kN}$ load cell. For the dynamic testing the ratio of the mean force was kept constant for each of the three different composite sandwich structures. Since the non-delaminated test specimens were tested first they dictated the testing parameters for the delamination and shear key test specimens. A mean force of $40 \%$ of the max failure load was selected because it allowed for a large number of testing loads to be performed using the $100 \mathrm{kN}$ load cell. Figure 44 shows an example monotonic force vs. deflection curve and how the ultimate force was selected from the curve.

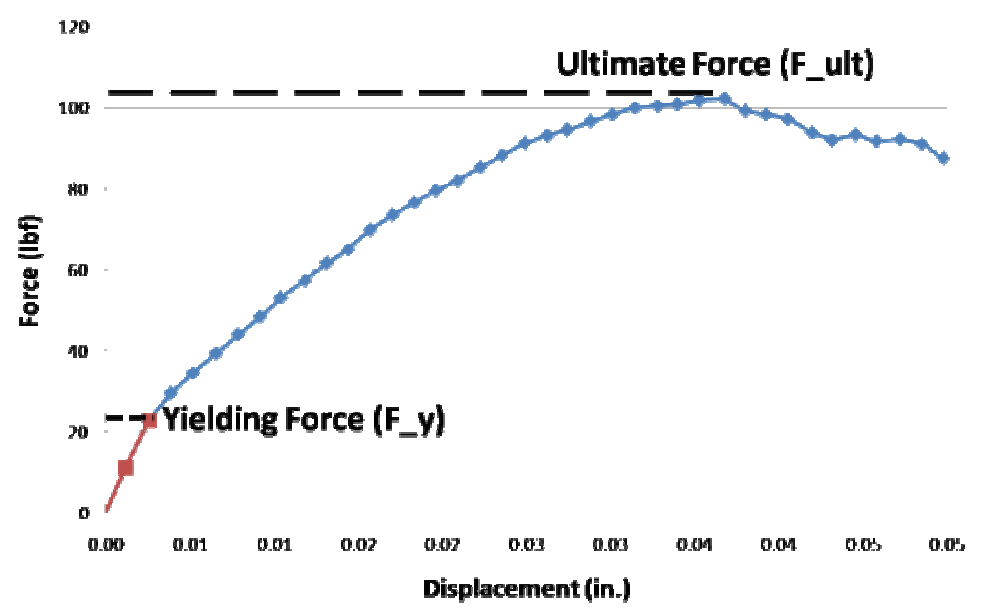

Figure 44 - Monotonic force definitions

Figure 45 shows an arbitrary sin wave force similar to the one applied for the fatigue testing. To construct the stress vs. number cycles to failure curves (S-N) the specimens were tested at the following percentages of the ultimate monotonic failure forces: 70, 65, 60, 55, and 50. The mean force in Figure 45 is represented by the dashed line and was always equal to $40 \%$ of the ultimate monotonic failure force. The force amplitude was varied throughout the testing for the different failure force percentages listed above. Example force inputs for an arbitrary case are shown in Table 1 below. 


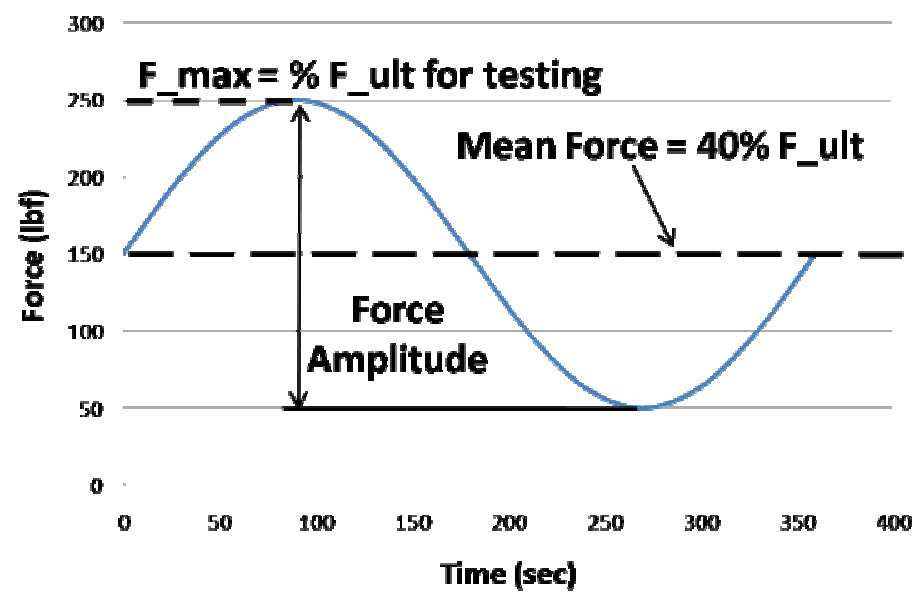

Figure 45 - SAX input definitions

Table 1 - Example input forces

\begin{tabular}{|c|c|c|c|c|}
\hline $\mathbf{F}_{\text {ULT }}$ (lbf) & $\mathbf{F}_{\text {MEAN }}$ (lbf) & Testing \% & $\mathbf{F}_{\text {MAX }}$ (lbf) & $\mathbf{F}_{\text {AMP }}$ (lbf) \\
\hline 550 & 220 & 0.7 & 385 & 330 \\
\hline
\end{tabular}

The two other inputs into SAX are the frequency that the machine operates at and also the sampling rate. A frequency of $10 \mathrm{~Hz}$ was chosen in an effort to speed up the testing process since fatigue and particularly low force fatigue takes a considerable amount of testing time. The chosen frequency was deemed "not too unrealistically high" to adversely affect the results to the point they would be irrelevant. During the initial testing and calibration phase of the fatigue research, the sample rate was varied. The sample rate not only had an effect on the number of data points stored, but it also affected how the sin wave was applied to the test specimens. A small sample rate had the advantage of data storage but the sin wave would correctly track input equal to output. A sample rate of $0.1 \mathrm{kHz}$ was selected because it was the minimum sample rate that allowed for a correct and smooth sin wave to be input.

To mitigate manufacturing defects on data scatter it was determined that the monotonic failure loads would be determined from each sandwich structure made. Each manufactured sandwich structure yielded 12 test specimens so 2 test specimens were used to determine the failure loads for that 
particular lay-up batch. This method was used to provide more reasonable test results and present a distinct trend in the data. 


\section{Monotonic Testing}

\section{Experimental Results}

In the previous delamination research the load transferring from the test specimens to the Instron grips was investigated. Initially, two triangular tabs were attached to the sandwich structure using structural glue to either side of the test specimens. Though quite effective in evenly transferring the load, the triangular tabs required a lot of time to manufacture. Rectangular steel tabs with a 0.25 inch thickness were used to test . The steel tabs produced sufficient results but it was difficult to get a strong bond to the test specimen's surface. For this research $90^{\circ}$ aluminum brackets with leg lengths of 0.50 inches were used. These aluminum tabs provided a sufficient area for bonding and were durable enough to be used in multiple tests.

\section{$\underline{\text { No Initial Delamination }}$}

Figure 46 shows the failure stiffness $\left(\frac{F_{u l t}}{\text { width }}\right)$ plotted vs. the vertical displacement of the specimen with no initial delamination. Failure stiffness values were plotted instead of stress because the stress associated with the vertical deflection corresponds to the stresses in the epoxy. The epoxy has a very small thickness which in turn would make the stress level large. Figure 46 shows that the monotonic test data for the specimens without delamination all behaved similarly as indicated by the similar data points produced. 


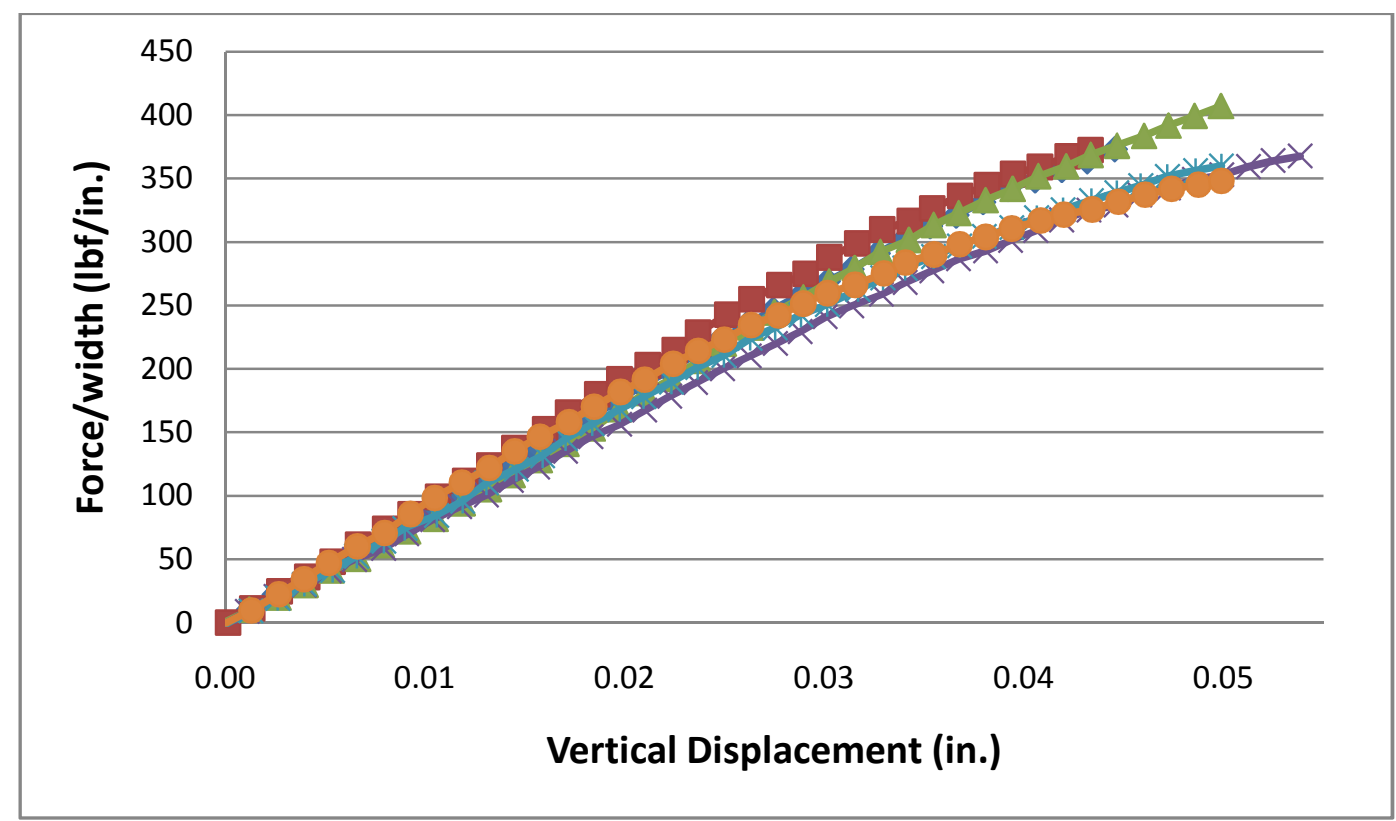

Figure 46 - Monotonic test data without delamination (all data)

The curve plotted in Figure 47 is the average of the six test runs shown in Figure 46. The data was averaged because there were very similar trends (force and displacements), and also as an aid to easily convey the material response of the composite sandwich structure. The test specimens with no initial delamination have a material response dominated by linear elastic behavior (denoted by the red portion of the curve) but there is a small region where the material response is non-linear elastic (blue region of curve). The maximum stiffness value for the test specimens with no initial delamination was $396\left(\frac{l b_{f}}{i n}\right)$, which corresponded to a maximum vertical deflection of 0.0538 inch The slope of the elastic portion of the curve was $8676\left(\frac{l b_{f}}{i n}\right)$. 


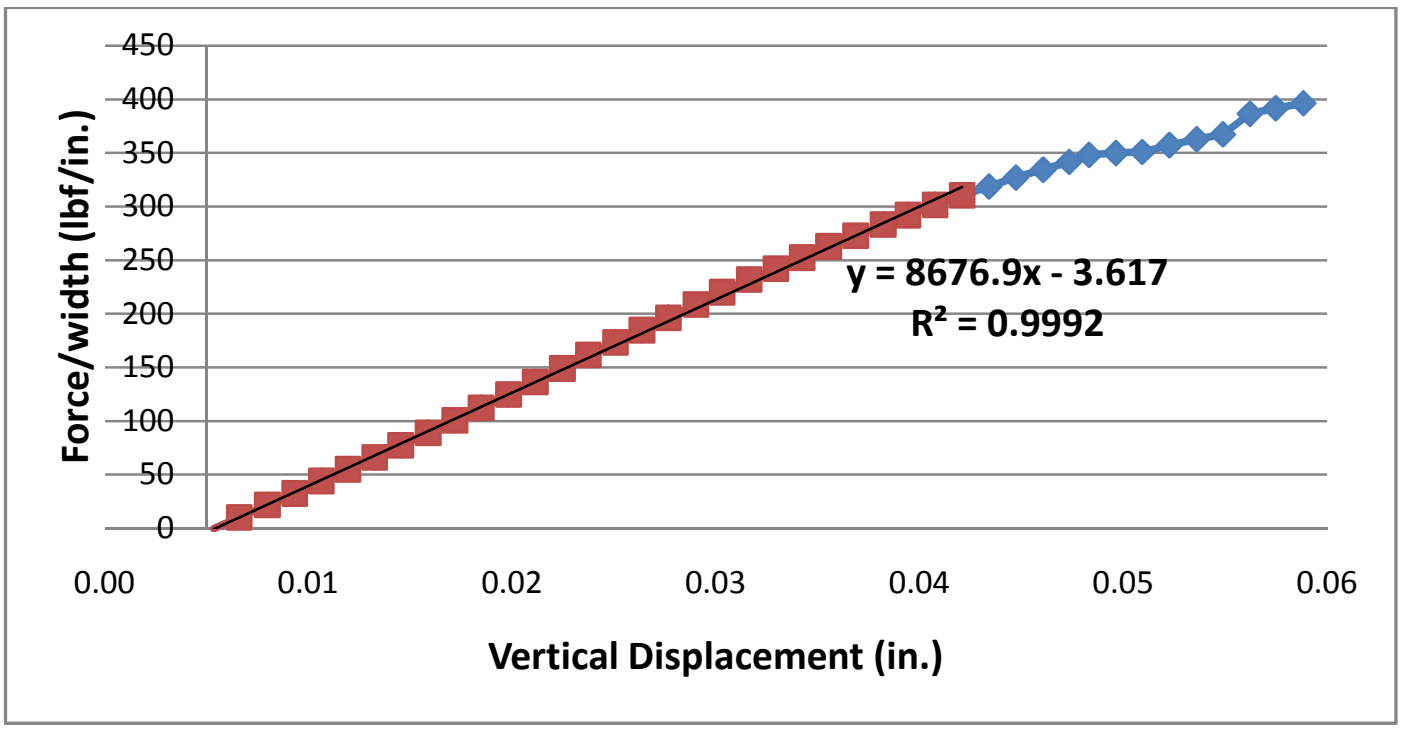

Figure 47 - Monotonic test data without delamination (averaged data)

\section{$\underline{\text { Initial Delamination }(0.5 \text { inch })}$}

The vertical displacement was plotted against the failure stiffness and the results are shown in Figure 48. This data was obtained from 5 specimens with an initial delamination of 0.5 inches and was used to characterize the monotonic failure characteristics.

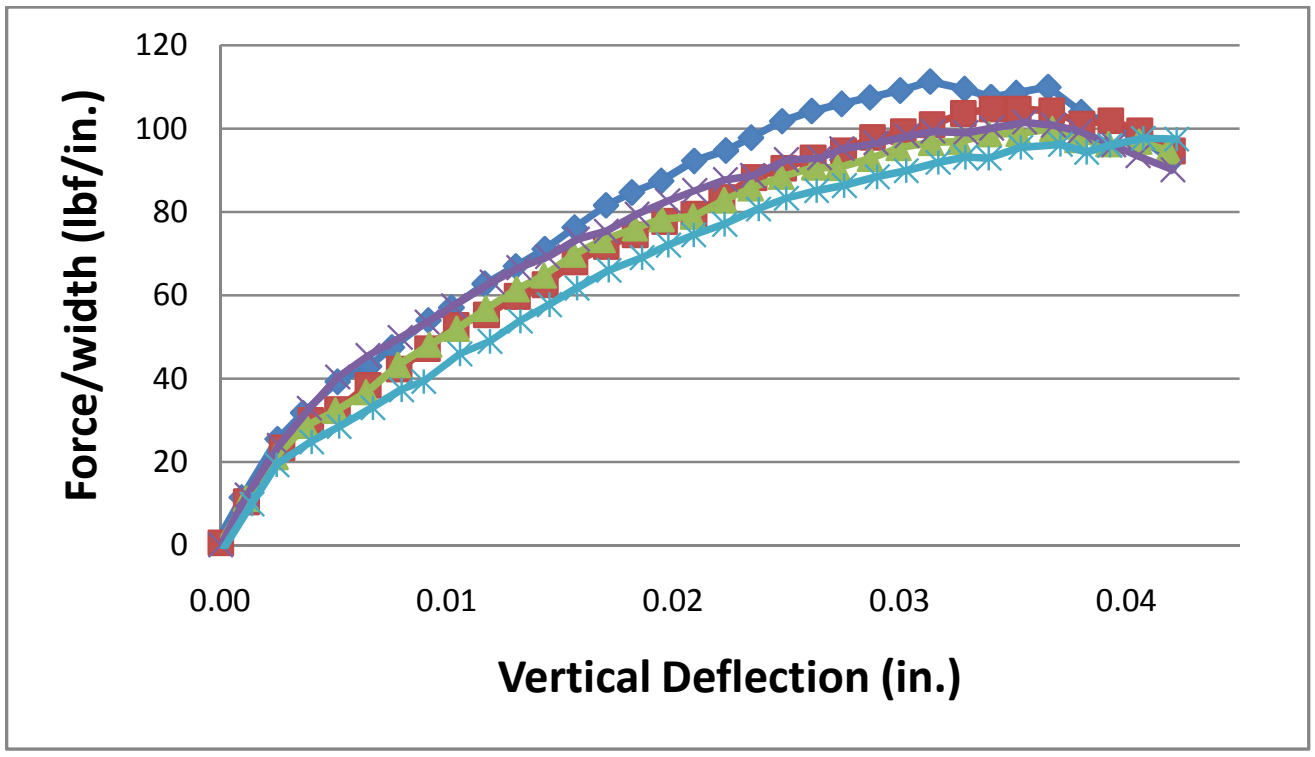

Figure 48 - Monotonic test data 0.5 inch specimen with delamination (all data) 
The curve plotted in Figure 49 is the average of 5 test specimens corresponding to Figure 48. Unlike the test specimens without initial delamination, the 0.5 inch initial delaminated pieces' material response was dominated by plastic behavior (illustrated by the blue line in Figure 49). The response is similar to a ductile metal, such as steel, because of the large region of plasticity. The maximum failure stiffness value for the delaminated pieces was approximately $102\left(\frac{l b_{f}}{i n}\right)$, which corresponded to a vertical deflection of 0.0431 inch.

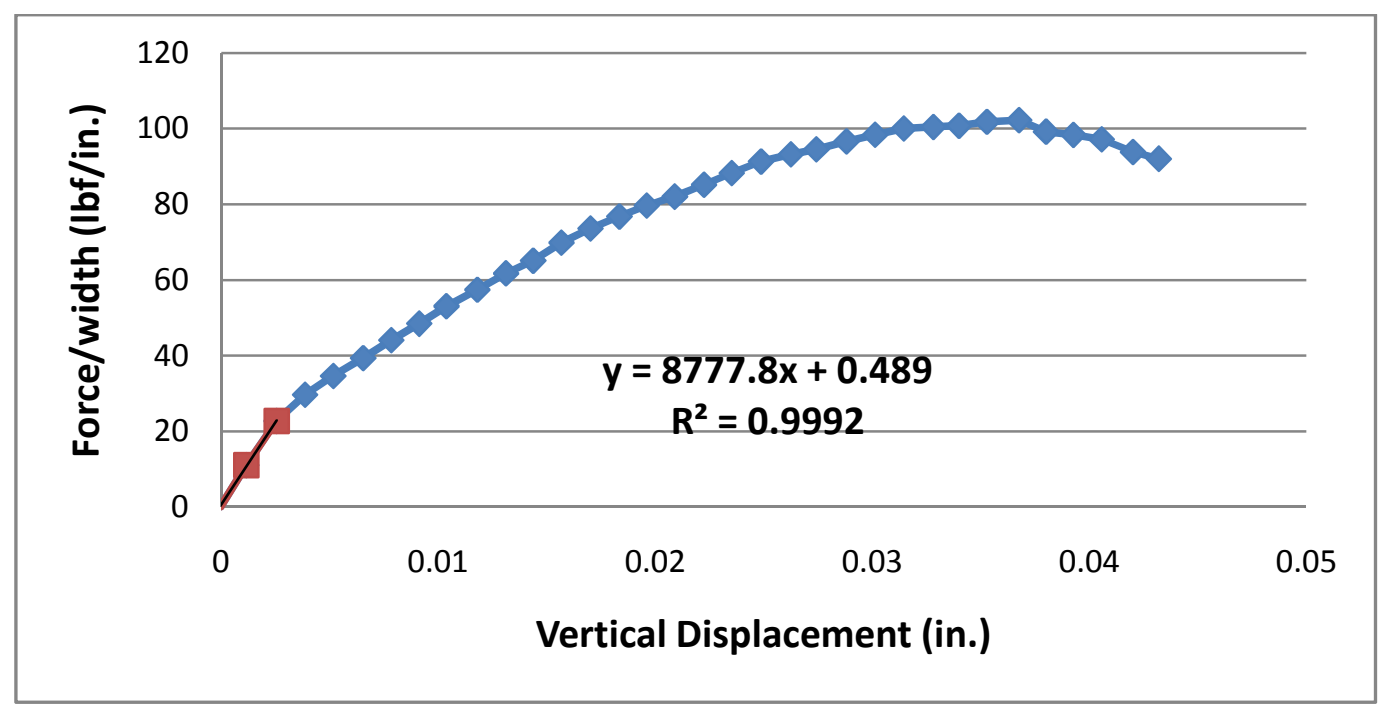

Figure 49 - Monotonic test data for 0.5 inch initial delamination (averaged data)

$\underline{\text { Initial Delamination (1.0 inch) }}$

The vertical displacement was plotted against the failure stiffness (in Figure 50) for the test specimens with a 1 inch initial delamination under monotonic loading. The data for the test specimens with a 1 inch delamination produced a small scatter range, but nothing that was unreasonable. 


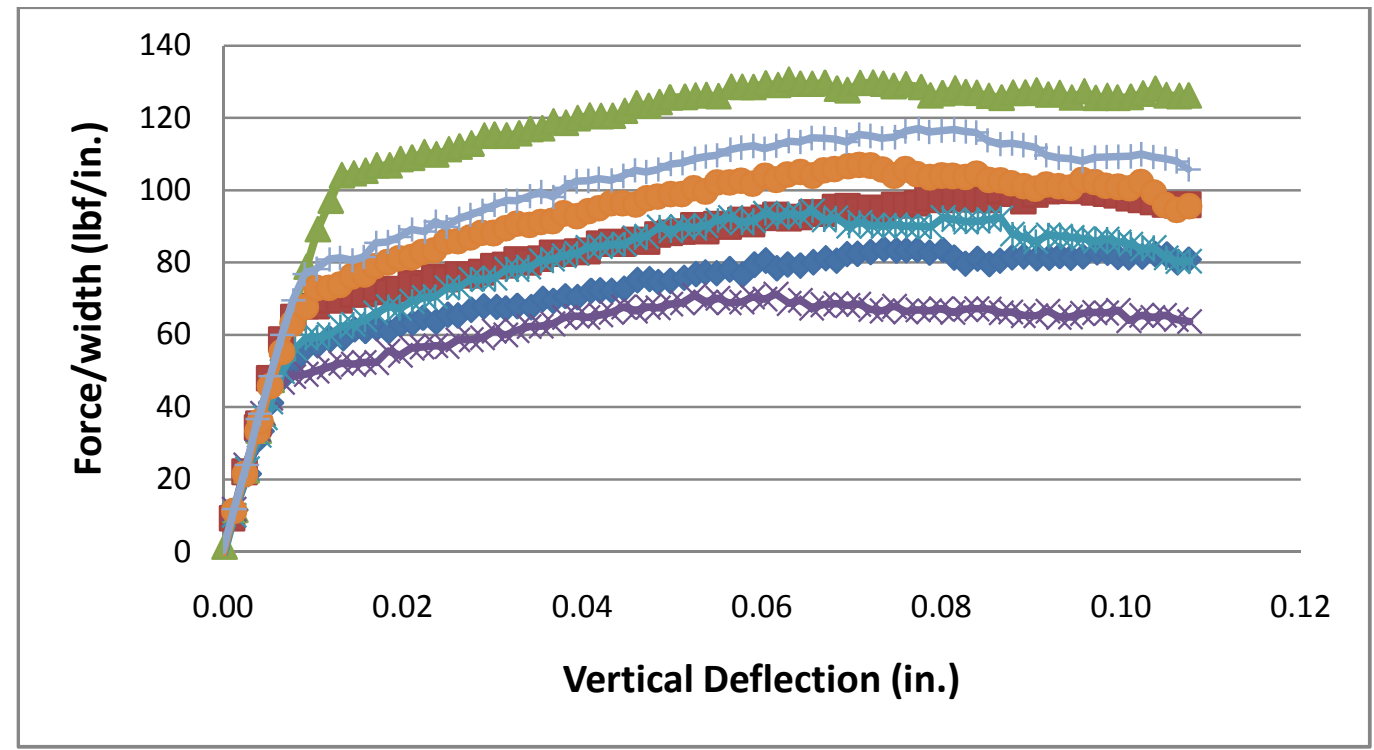

Figure 50 - Monotonic test data for $\mathbf{1 . 0}$ inch initial delamination (all data)

The curve plotted in Figure 51 is the average of 7 test specimens corresponding to Figure 50. The test specimens with a 1 inch initial delamination have material response characterized by a short and steep elastic region followed by a very long plastic region where it gains approximately $40 \%$ of its ultimate strength. The maximum failure stiffness value for the delaminated pieces was approximately $98\left(\frac{l b_{f}}{i n}\right)$, which corresponded to a vertical deflection of 0.106 inch. 


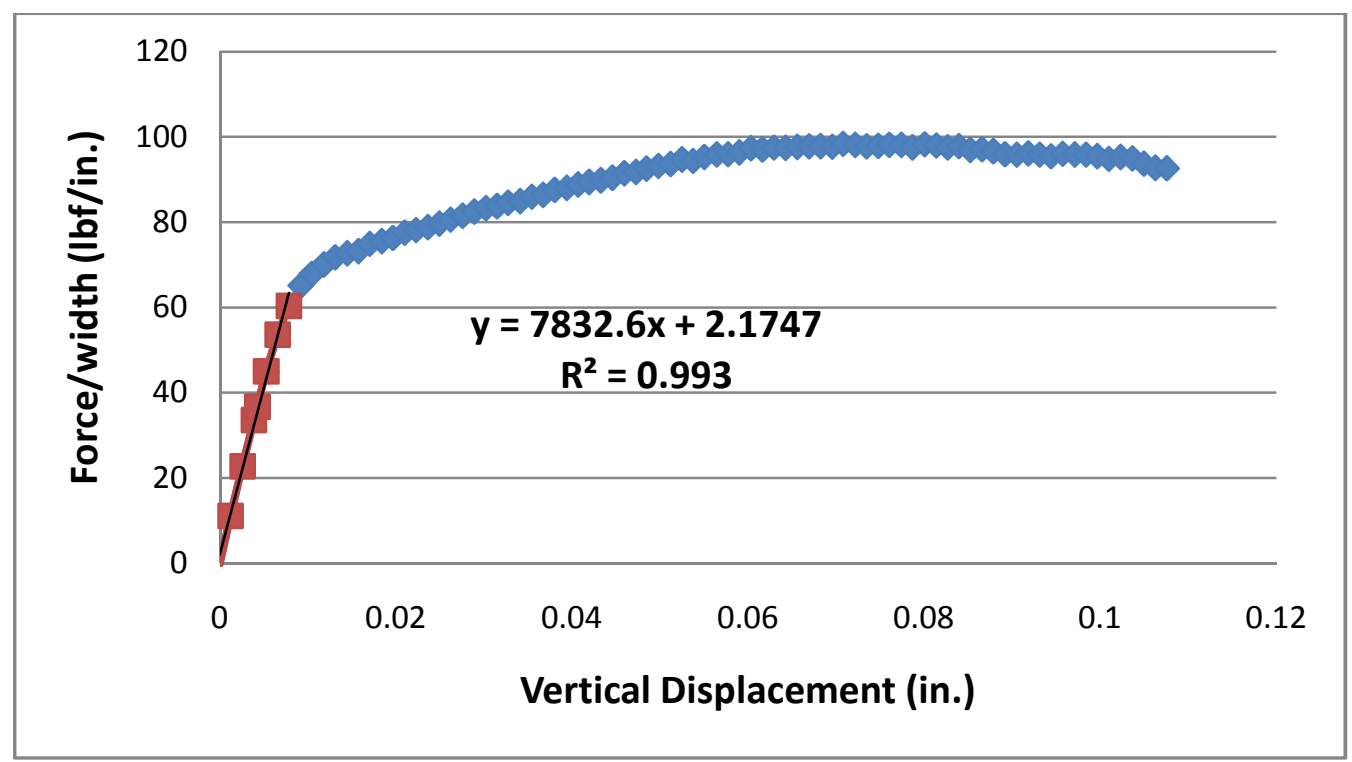

Figure 51 - Monotonic test data for 1.0 inch initial delamination (averaged data)

\section{Data Summary}

Table 2 is a summary of the three sets of monotonic test data values obtained from the sandwich structures without shear keys. All three test sets have relatively similar elastic stiffness values, with the exception of the 1 inch delaminated specimens being a little less. The yield stiffness value of the 0.5 inch initial delamination specimens was significantly less compared to the other two sandwich structure types. One would expect a smaller delamination would correspond a stronger part, with a higher ultimate stiffness, but that was not the case for the yield stiffness. A possible explanation for the weaker yield stiffness for the 0.5 inch delaminated test specimens could be that the 0.5 specimens had a different load path than the 1 inch delaminated specimens. The aluminum tabs used to transfer the load from the Instron machine to the test specimens had a 0.5 inch leg length that got bonded to the upper and lower surface of the specimens. For the 1 inch delaminated pieces the load was not being applied directly axially because the extra 0.5 inch that was not connected to the aluminum tab created a moment. Adding a moment makes the loading conditions no longer purely axial, causing the loading conditions to be mixed modes (Modes I and II). Both the 0.5 inch and non-delaminated pieces had the load applied almost entirely 
axially applied (Mode I). The different loading conditions could also account for the slight differences in the elastic stiffnesses.

Table 2 - Monotonic test data summary

\begin{tabular}{|c|c|c|c|}
\hline Test Type & Elastic Stiffness $\left(\frac{l b_{f}}{i n .}\right)$ & Yield Stiffness $\left(\frac{l b_{f}}{i n .}\right)$ & Ult. Stiffness $\left(\frac{l b_{f}}{i n .}\right)$ \\
\hline No Initial Delamination & 8676 & 310.35 & 396.02 \\
\hline $\begin{array}{c}\text { 0.5 inch Initial } \\
\text { Delamination }\end{array}$ & 8777 & 22.69 & 102.21 \\
\hline $\begin{array}{c}1 \text { inch Initial } \\
\text { Delamination }\end{array}$ & 7832 & 60.32 & 98.34 \\
\hline
\end{tabular}

\section{Monotonic Testing - Shear Keys}

Three different shear key configurations were testing under monotonic loading with the intent of increasing the strength of a sandwich composite structure containing an initial delamination. All of the shear key test specimens had an initial delamination of 1 inch. The initial delamination length on 1 inch was selected because that length yielded the most consistent data from the earlier monotonic testing. The shear key configurations tested were $0,0.5$, and 1 inch.

\section{$\underline{\text { Shear Key }(0 \text { inch }) \text { with Delamination }(1 \mathrm{inch})}$}

The vertical displacement was plotted against the failure stiffness $\left(\frac{F_{u l t}}{\text { width }}\right)$ for the 0 inch shear key placed 0 inch behind the 1.0 inch initial delamination (shown in Figure 52 below). Seven test specimens were used to get the monotonic failure characteristics of the test specimens. 


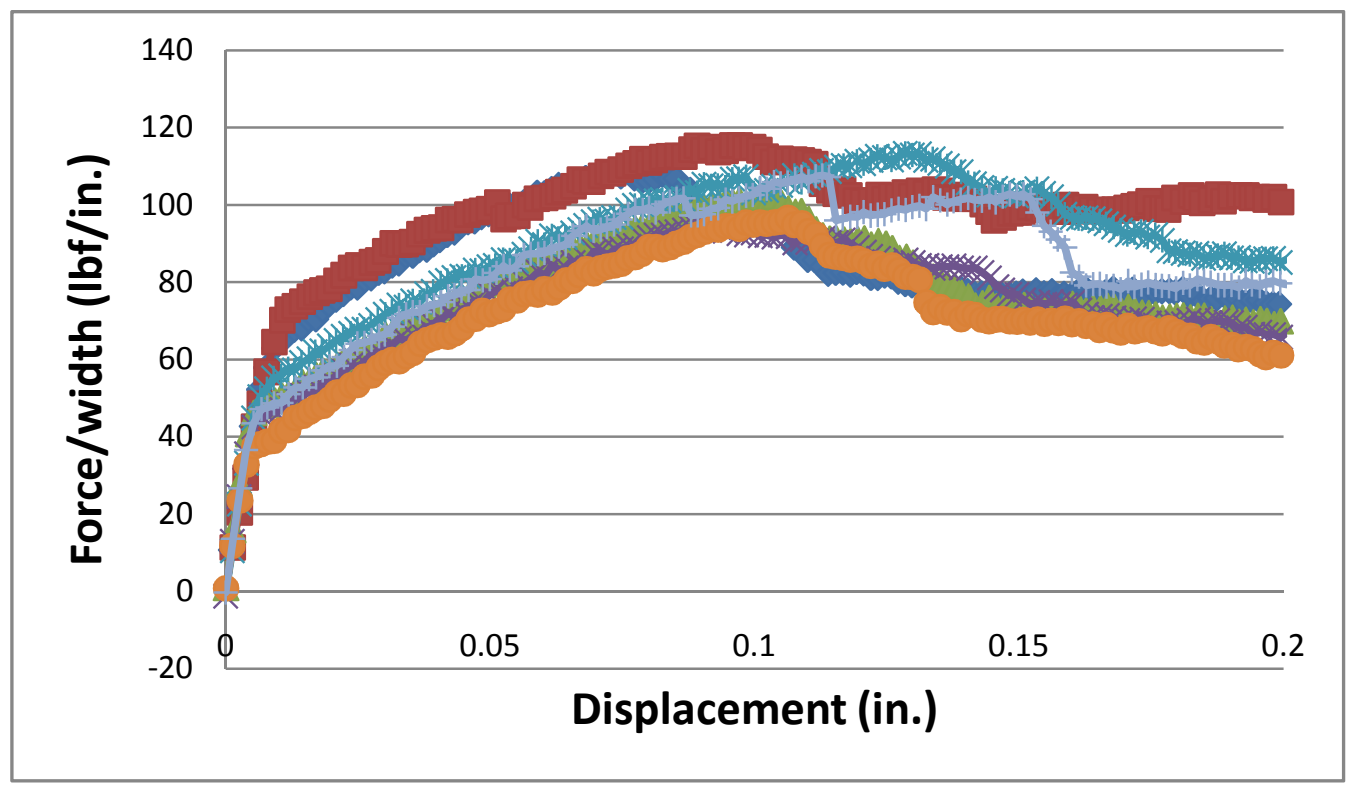

Figure 52 - Monotonic shear key test (0 inch - all data)

The curve plotted in Figure 53 is the average of the data shown in Figure 52. The data was averaged because of the similar trends presented and also to convey the material response of the composite sandwich structure easily. The test specimens with a shear key placed 0 in. behind the edge of the delamination have a material response that is dominated by plastic behavior. A very short elastic response range exists for force/width values less than $45\left(\frac{l b_{f}}{i n}\right)$. The maximum stiffness for the test specimens was approximately $100\left(\frac{l b_{f}}{i n}\right)$, which corresponded to a vertical displacement of 0.0853 inch. 


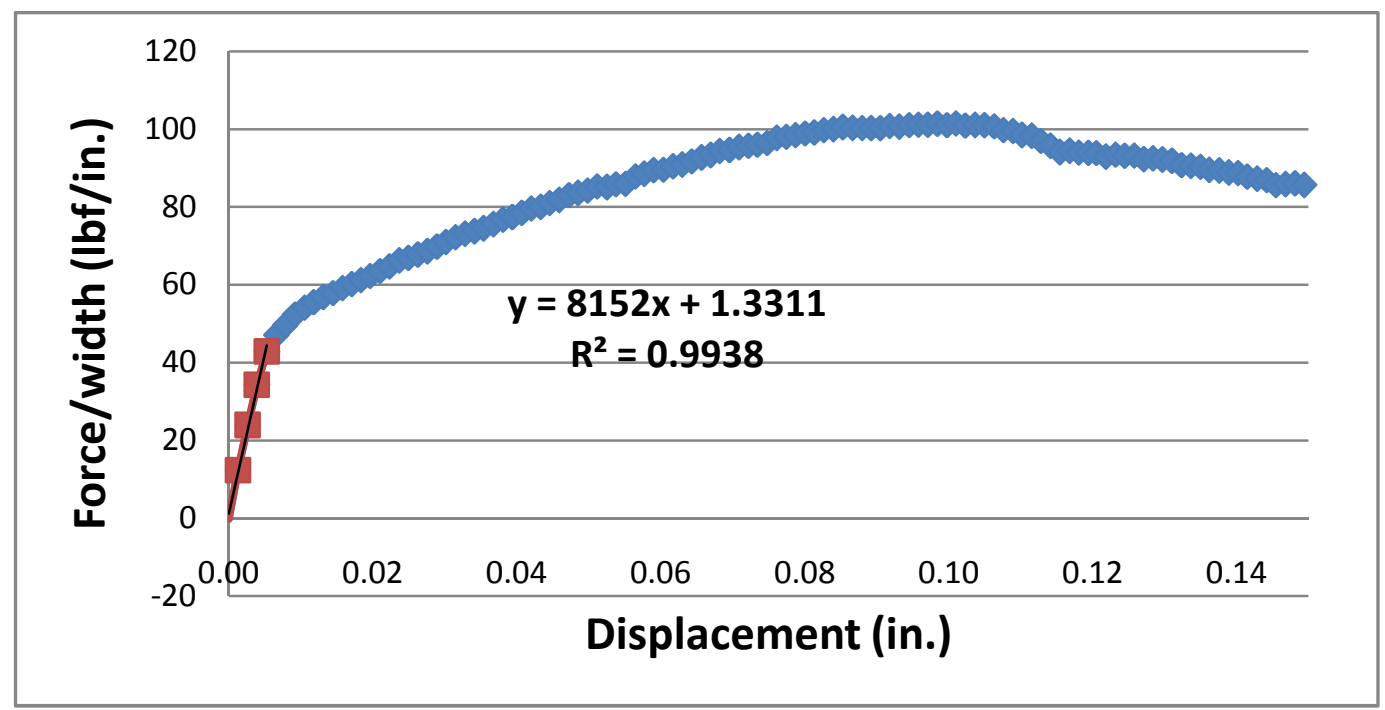

Figure 53 - Monotonic shear key test (0 inch - averaged data)

Shear Key (0.5 inch) with Delamination (1 inch)

Figure 54 shows the vertical displacement plotted against the stiffness for the five test specimens with an initial delamination and a shear key placed 0.5 inch behind it. There as a similar trend produced from the data collected, with the exception of one test specimen that failed prematurely.

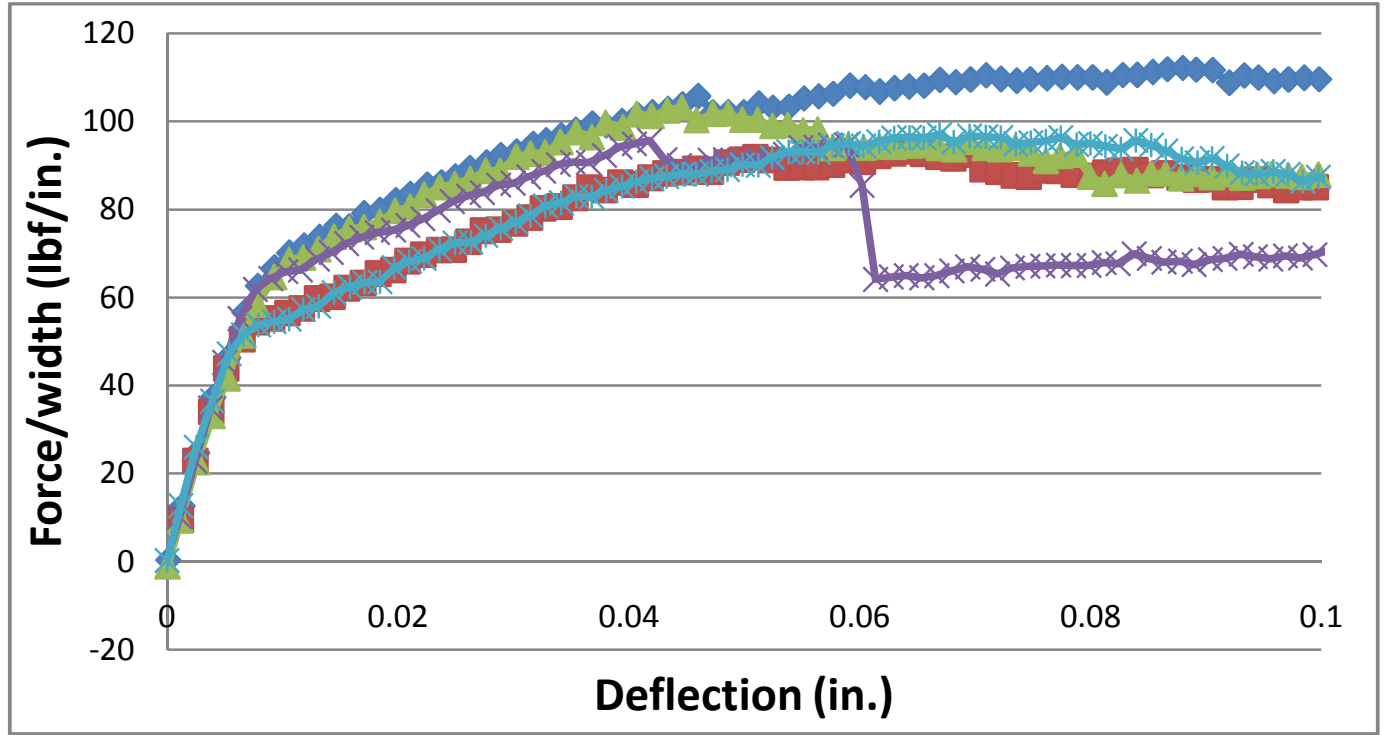

Figure 54 - Monotonic shear key test (0.5 inch - all data) 
The curve plotted in Figure 55 is the average of the data shown in Figure 54. The material response for the 0.5 inch shear key specimens had a large plastic region. A much smaller elastic region was valid for stiffness values less than approximately $53\left(\frac{l b_{f}}{i n}\right)$. The maximum failure stiffness for the shear key test specimens was approximately $96\left(\frac{l b_{f}}{i n}\right)$, which corresponded to a vertical displacement of 0.059 inch.

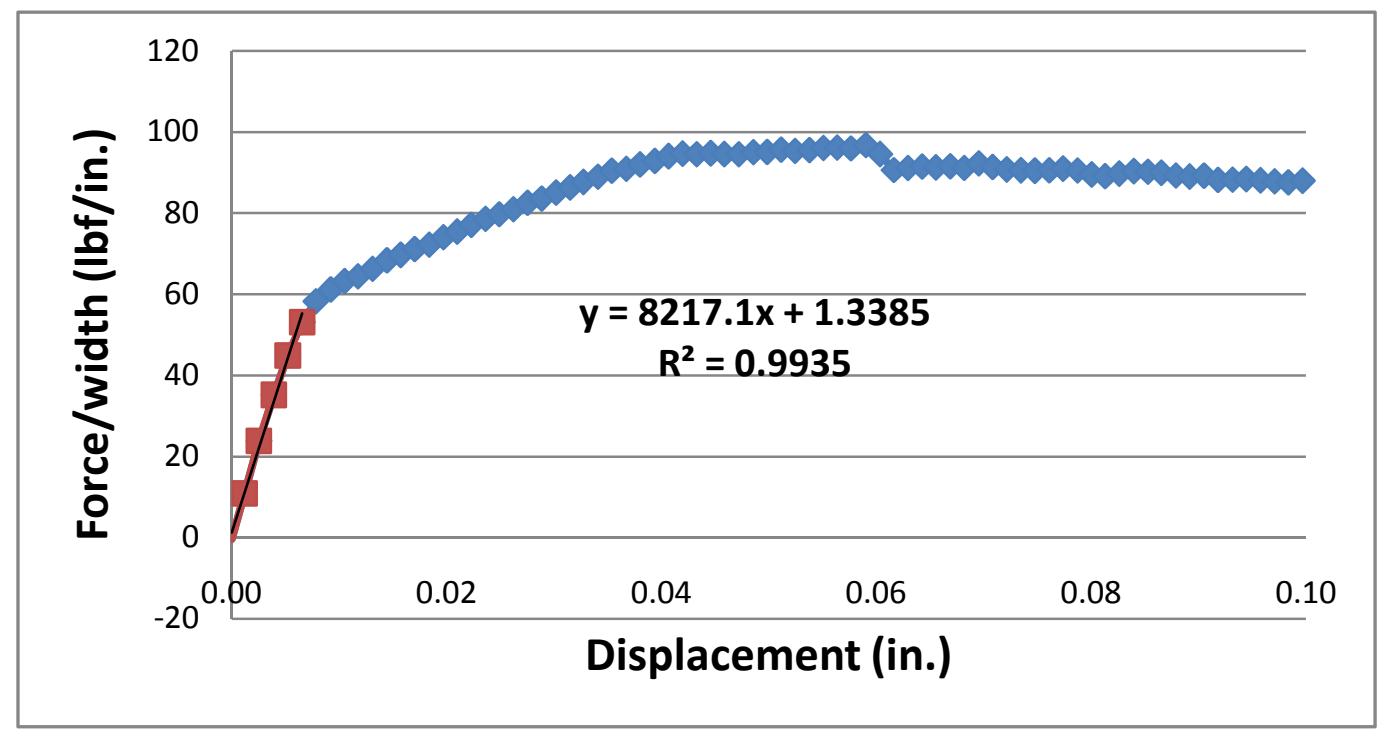

Figure 55 - Monotonic shear key test (0.5 inch - averaged data)

Shear Key (1.0 inch) with Delamination (1 inch)

Figure 56 shows the vertical displacement plotted against the stiffness for the delaminated specimens with a shear key 1 inch behind the edge of the delaminated region. The three test specimens produced a similar trend. 


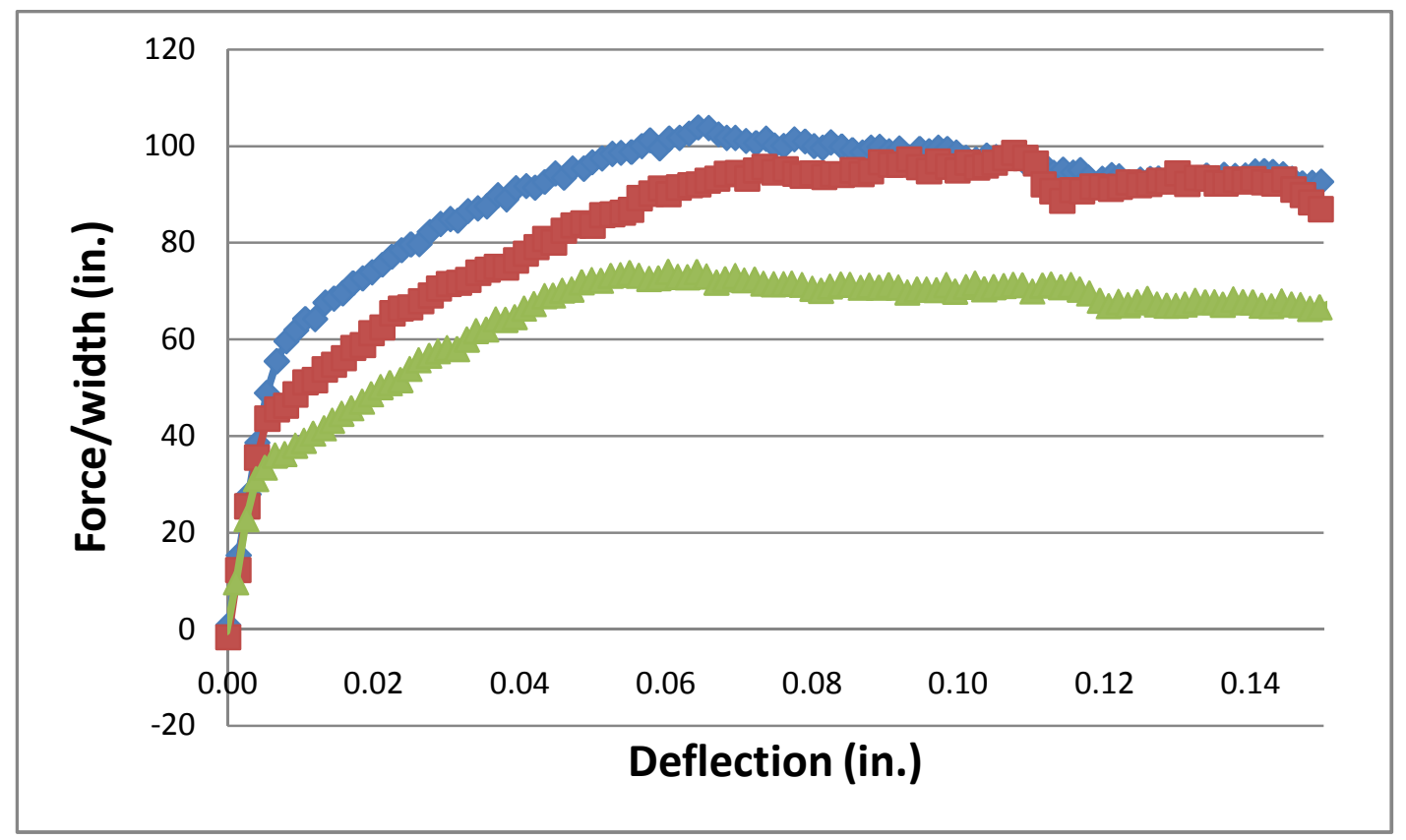

Figure 56 - Monotonic shear key test (1.0 inch - all data)

The curve plotted in Figure 57 is an average of the test data presented in Figure 56. The material response for the 1.0 inch shear keys was largely dominated by plastic behavior. The test specimens have elastic behavior for stiffness values less than $42\left(\frac{l b_{f}}{i n}\right)$. The maximum failure stiffness for the 1.0 inch shear key test specimens is $88.5\left(\frac{l b_{f}}{i n}\right)$, which corresponds to a vertical displacement of 0.0631 inch. 


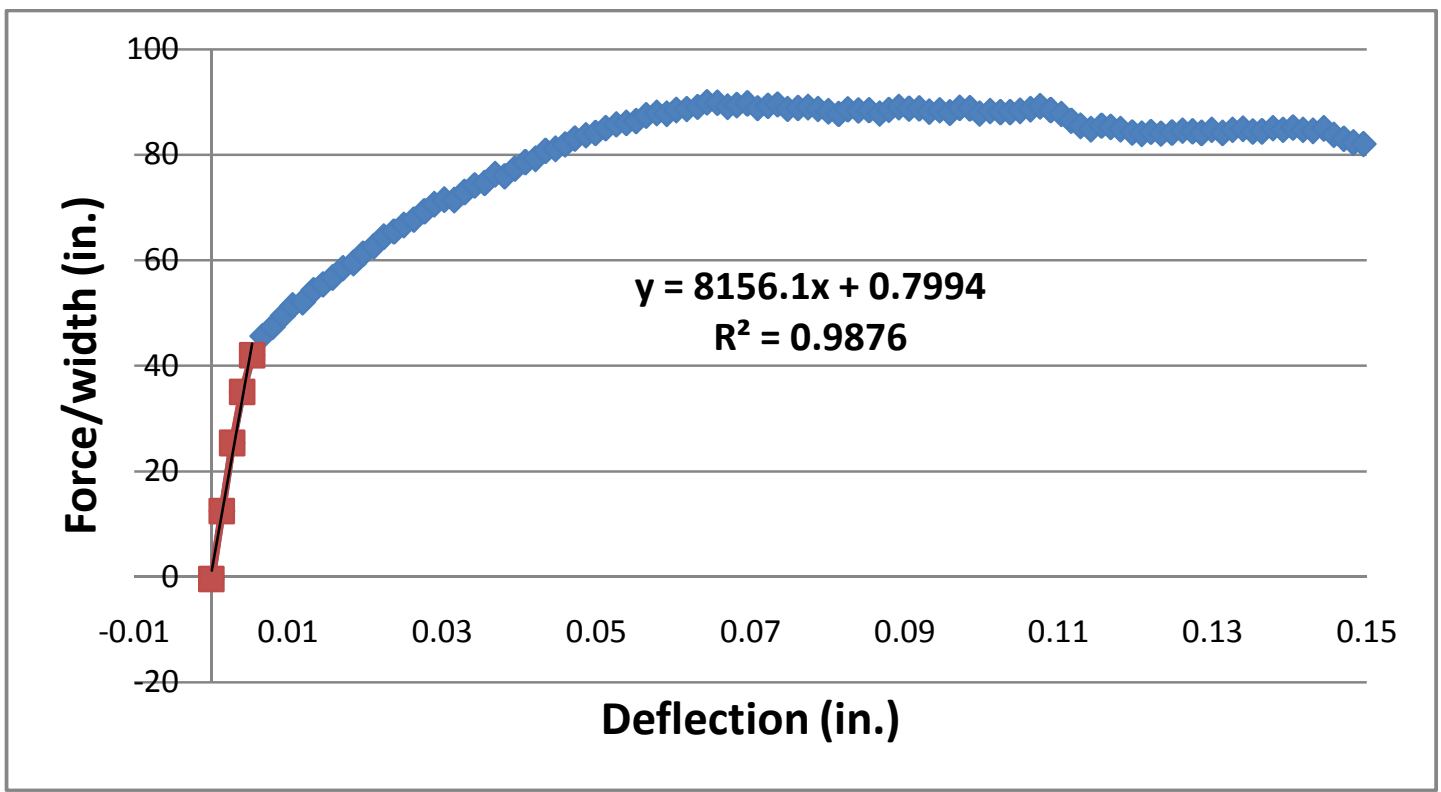

Figure 57 - Monotonic shear key test (1.0 inch - averaged data)

\section{Dynamic Testing}

\section{$\underline{\text { No Initial Delamination }}$}

For the fatigue testing a constant force amplitude with tension/tension load conditions were used. The mean force was selected to be $40 \%$ of the ultimate force, which was determined during the monotonic testing. A sample of one of the load spectrums used during testing is shown in Figure 58. Not all of the data points for the force input were saved due to the large files generated are shown on the curve in Figure 58. When SAX is started, the force initially had to adjust down/up to the appropriate input force and afterwards the curve maintains a constant force amplitude. 


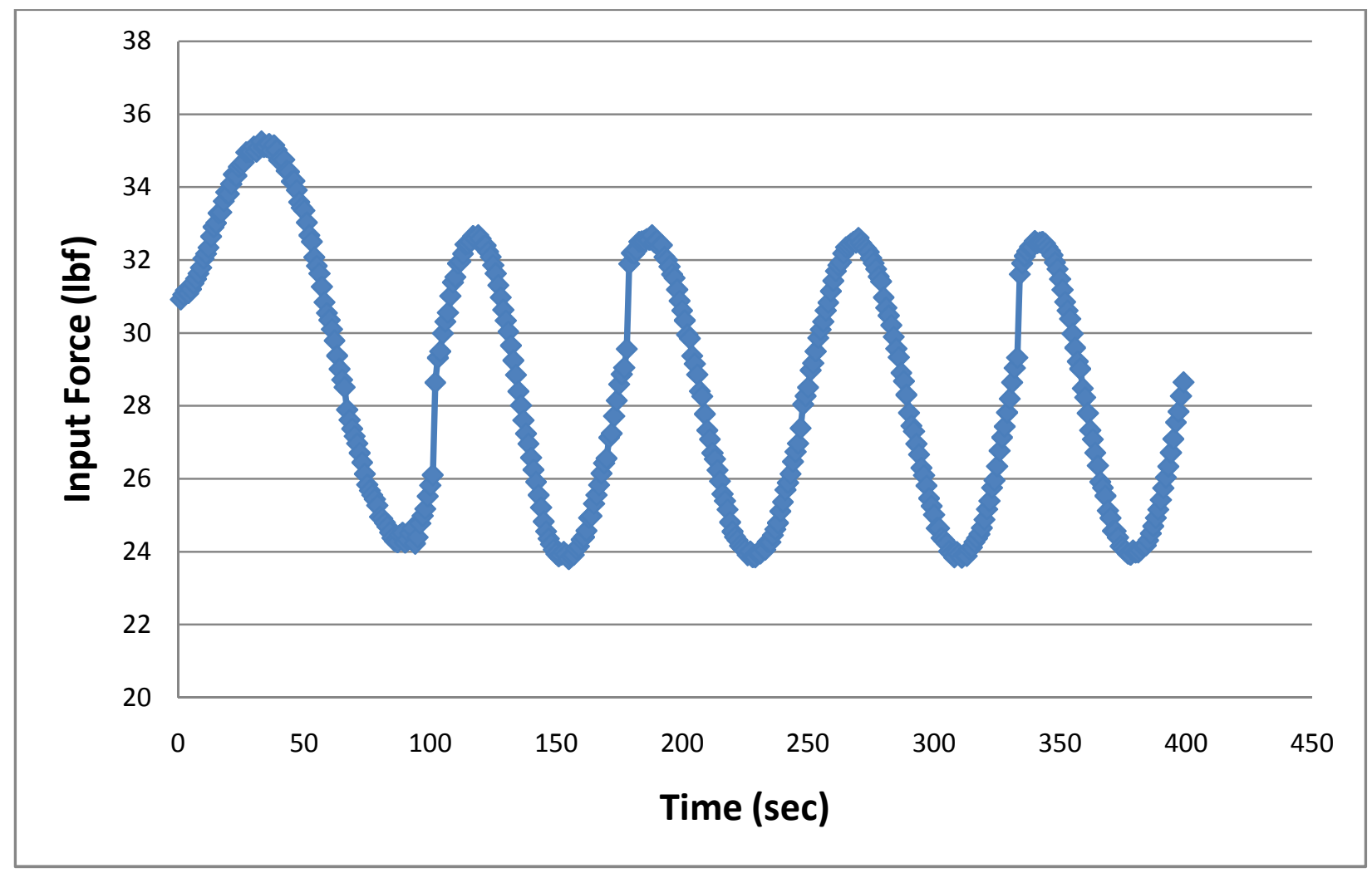

Figure 58 - Sample of fatigue input load

Figure 59 below shows how the input force changed as the test specimens, began to fail due to the origination and propagation of cracks. As the crack starts to propagate the specimens loses stiffness which caused the input force to also decrease. This caused the input force to have a funnel like shape until the failure criteria of a $10 \%$ input force decrease. 


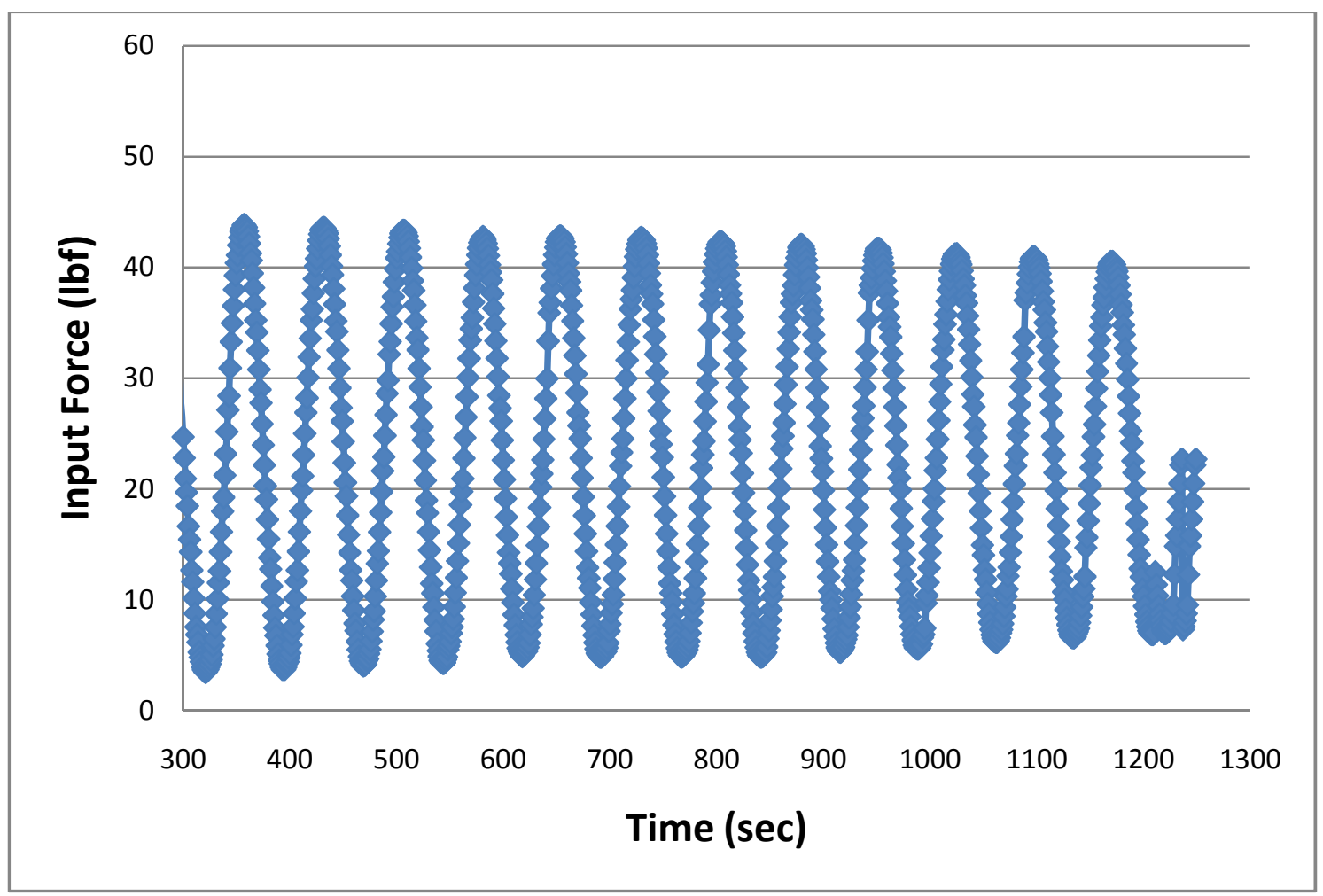

Figure 59 - Sample of load spectrum during specimen failure

Figure 60 shows the fatigue test data for the test specimens without an initial delamination. The data plotted corresponds to the number of cycles to failure vs. the percent of the ultimate monotonic force applied. During testing it was easier to determine the number of cycles to failure for the test specimens under a higher loading rate. 


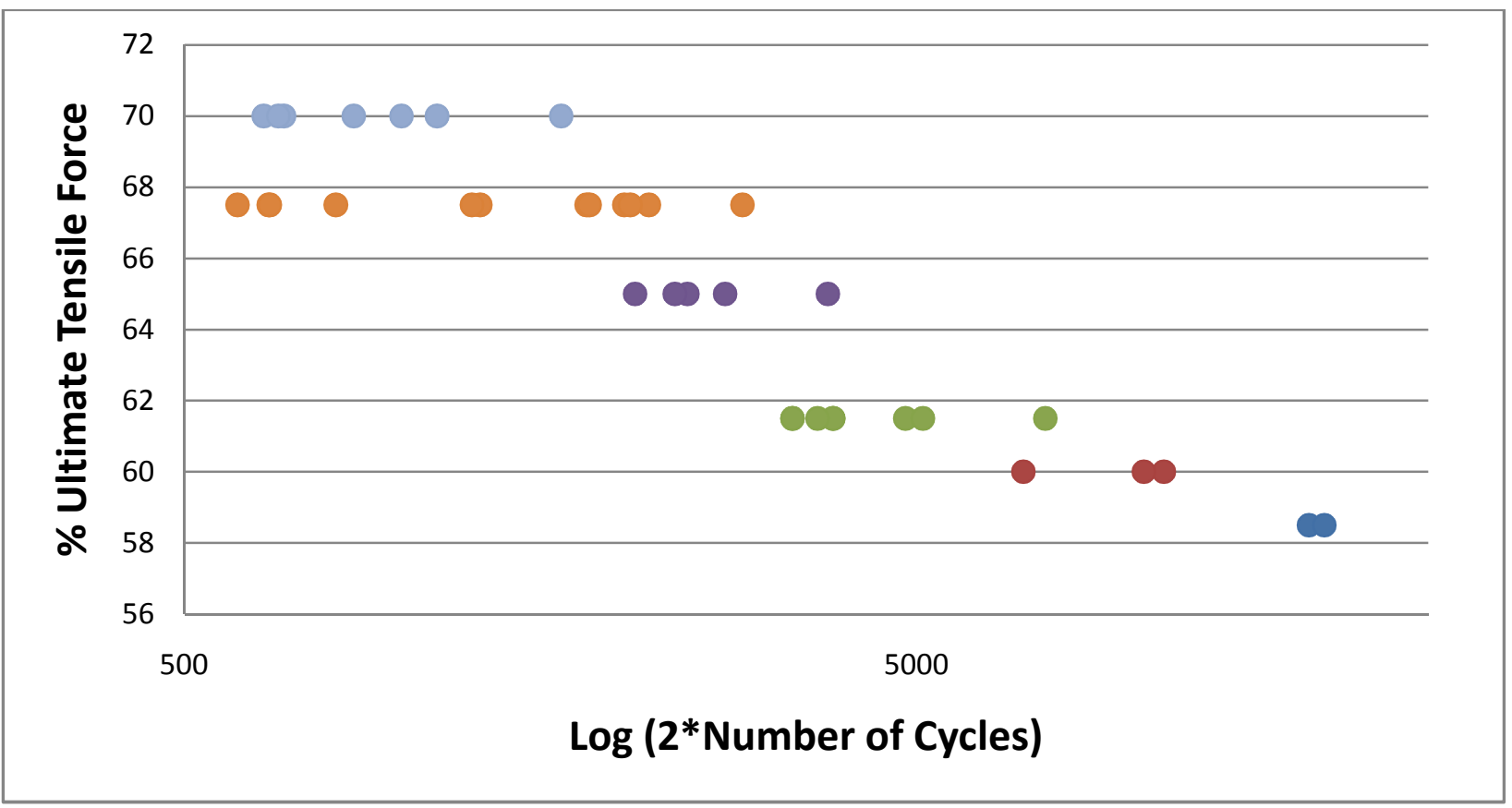

Figure 60 - Fatigue testing no delamination (all data)

The data for the different load rates were averaged and is shown in Figure 61. The graph is plotted on a semi-log scale, helping to illustrate the convergence of the test data. Convergence is believed to be reached because at the higher force loading rates the curve appears to start to level out. The semi$\log$ scale (x-axis) increases confidence that the data is starting to level out and converge at $58.5 \%$ ultimate tensile force and approximately 17,500 cycles to failure. Percentages of the ultimate tensile force greater than $70 \%$ were tested but it was discovered that the specimens would fractured before ramping up to the correct force condition. 
158

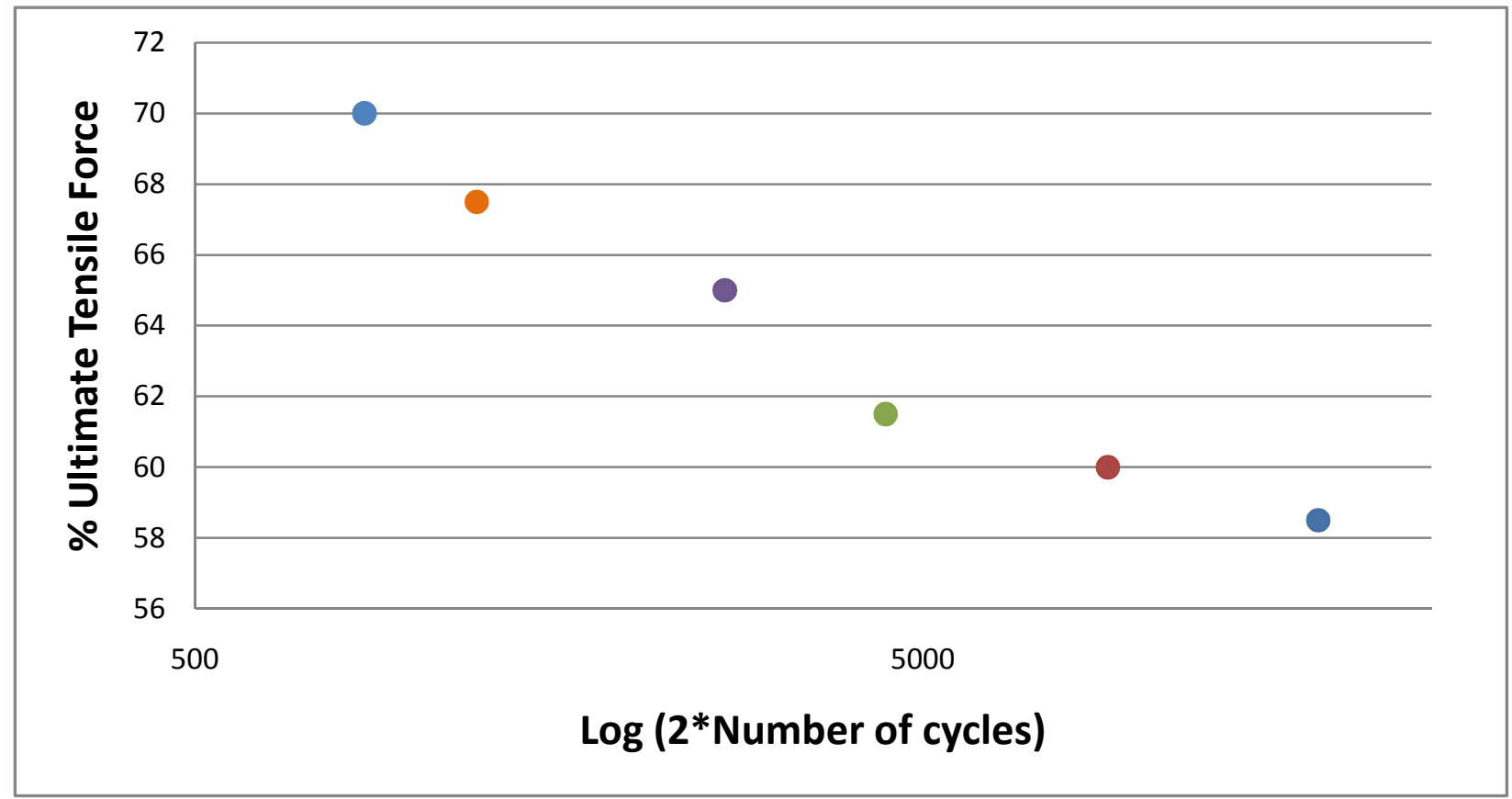

Figure 61 - Fatigue testing no initial delamination (averaged data)

\section{Test Specimens with 1.0 Initial Delamination}

The composite sandwich structures with a 1 inch initial delamination were selected for fatigue testing because the 1.0 inch delamination test specimens had the highest monotonic failure load. The test specimens with delamination were tested using the same method as the test specimens without an initial delamination. Each lay-up batch was tested to get more accurate failure loads. Figure 62 shows the fatigue data points for the test specimens that did not fail prematurely or run out. 


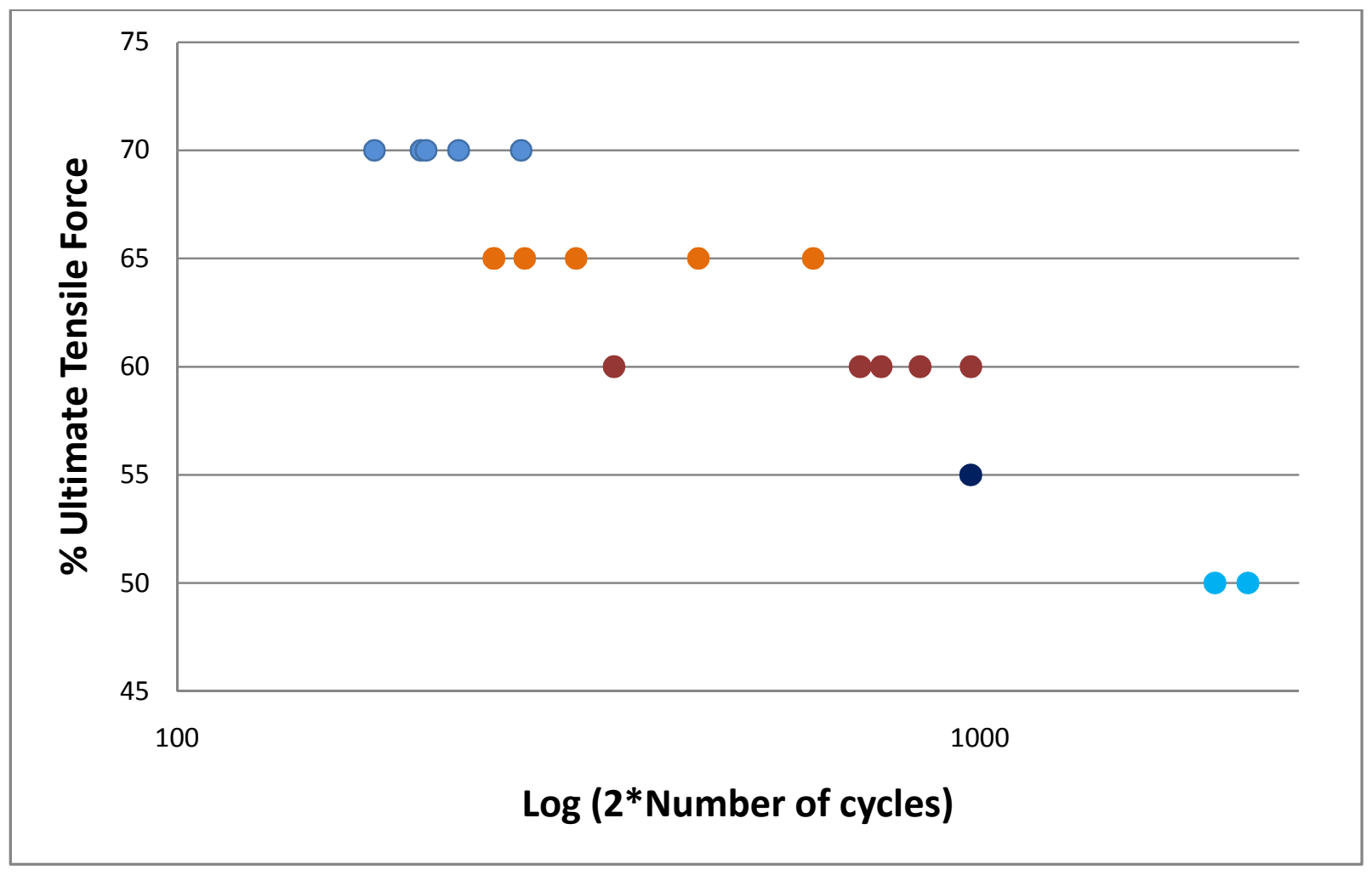

Figure 62 - Fatigue testing 1.0 in. initial delamination (all data)

The data points for each of the different load rates were averaged and is shown in Figure 63. The graph is plotted on a semi-log scale, which helps to illustrate the convergence of the test data.

Convergence is believed to be reached because at the higher force loading rates, the curve appears to level out. Since the data is plotted on a semi-log scale (x-axis) there is further confidence that the data is starting to level out and converge at $50 \%$ of the ultimate tensile force and after approximately 2,000 cycles to failure. Percentages of the ultimate tensile force greater than $70 \%$ were tested but it was discovered that the specimens would fractured before ramping up to the correct force condition could be achieved. 


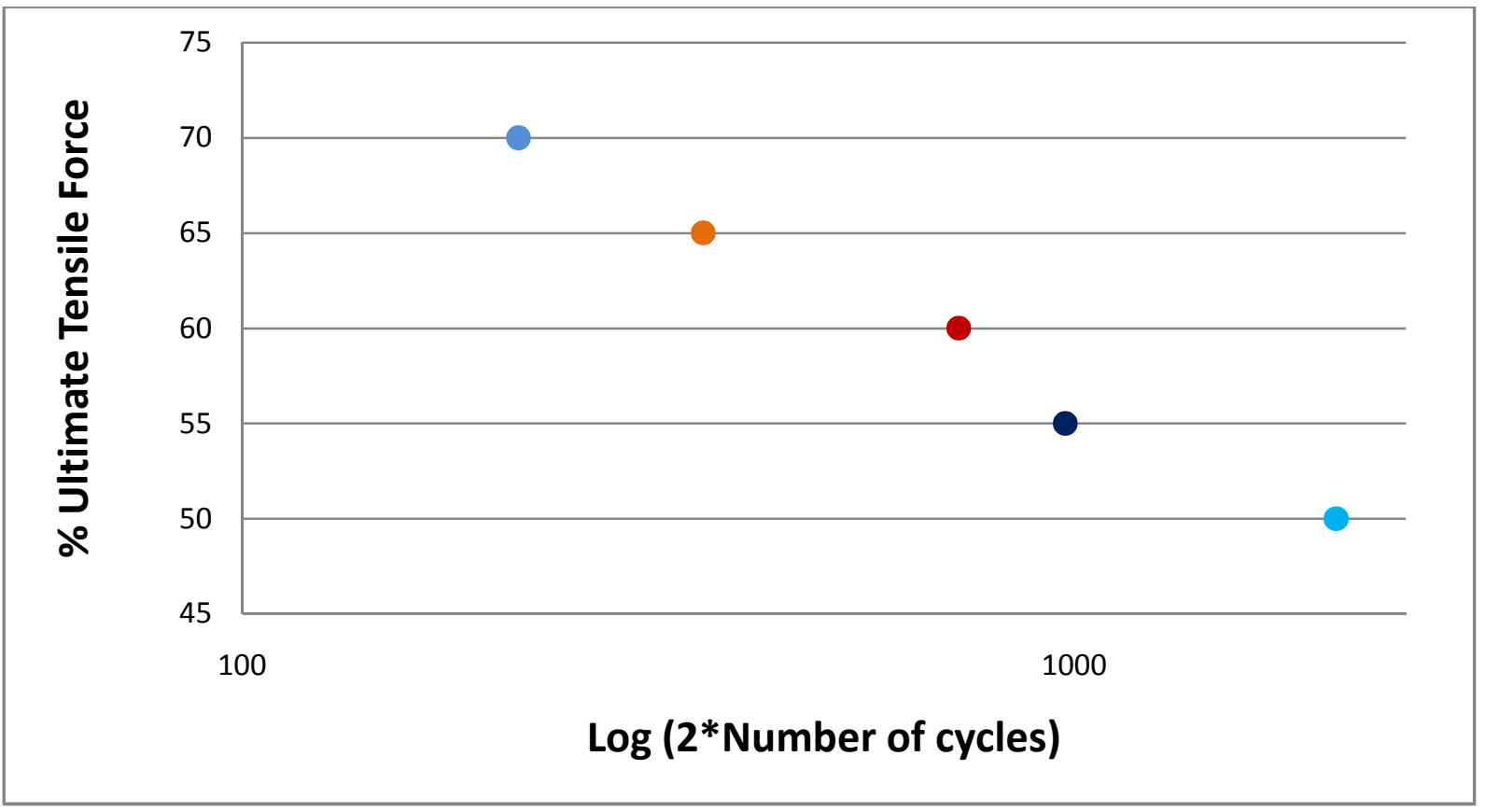

Figure 63 - Fatigue testing 1.0 in. initial delamination (averaged data)

\section{0 inch Initial Delamination with 0 inch Shear Key}

The test specimens containing an initial delamination of 1 inch were tested similar to the test specimens with no initial delamination. Each lay-up batch was tested to get more accurate failure loads. Figure 64 shows the fatigue curve data for the test specimens that were not considered to have failed prematurely or were run outs. The number of cycles to failure was plotted on the x-axis and the $\%$ ultimate tensile force was plotted on the y-axis. 


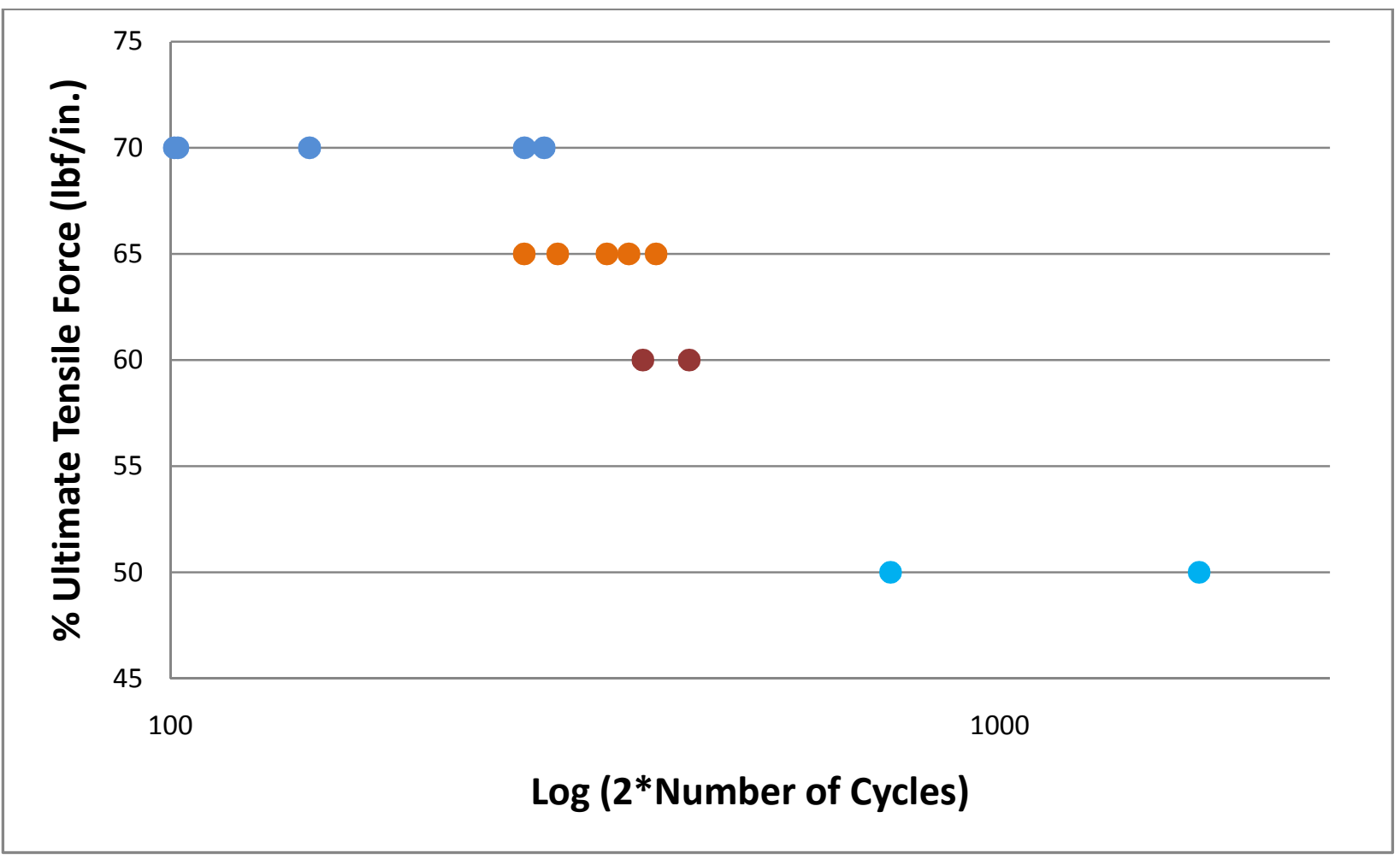

Figure 64 - Fatigue test data 1.0 initial delamination with 0 in. shear key (all data)

The data recorded for the different load rates were averaged and is shown in Figure 65. The graph was plotted on a semi-log scale which helped to illustrate the convergence of the test data. Convergence is believed to be reached because at the higher force loading rates the curve appears to start to level out. Since the data is plotted on a semi-log scale (x-axis) there is further confidence that the data is starting to level out and converge at $50 \%$ of the ultimate tensile force and approximately 1,200 cycles to failure. Percentages of the ultimate tensile force greater than $70 \%$ were tested but it was discovered that the specimens would fractured before ramping up to the correct force condition. 


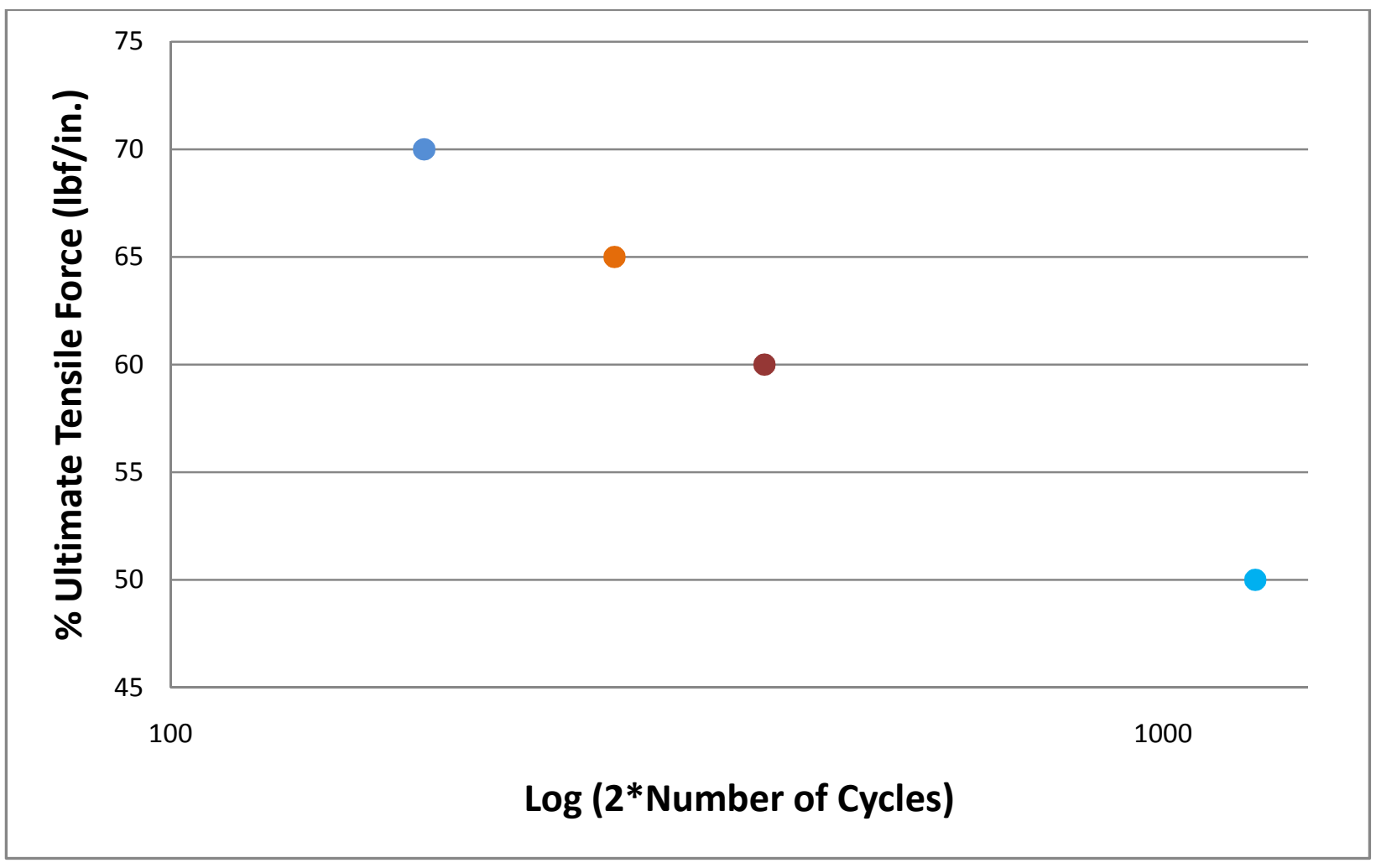

Figure 65 - Fatigue test data 1.0 in. initial delamination with 0 in. shear key (averaged data) 


\section{Numerical Analysis}

\section{Model Geometry}

During the model development it was determined that a 2-D finite element analysis (FEA) would be adequate for the preliminary analyses performed. A longitudinal view of the part was selected for the analysis because it would provide an adequate representation of the stress state longitudinal. The model geometry and coordinate system used for the analysis is shown in Figure 66. The upper and lower fiberglass skins were modeled as a single layer their material properties were determined experimentally. The y-axis runs vertically through the part and the x-axis runs horizontally along the length of the part. Key geometric properties for the analysis are shown in Table 3. A 3-D analysis was not selected because of the high computational cost associated with using solid elements. The delamination model was considered identical to model without delamination except that a seam was added to the region where the upper skin was not connected to the lower skin. The seam represents the piece of non-porous Teflon paper that separates the upper skin from the core.

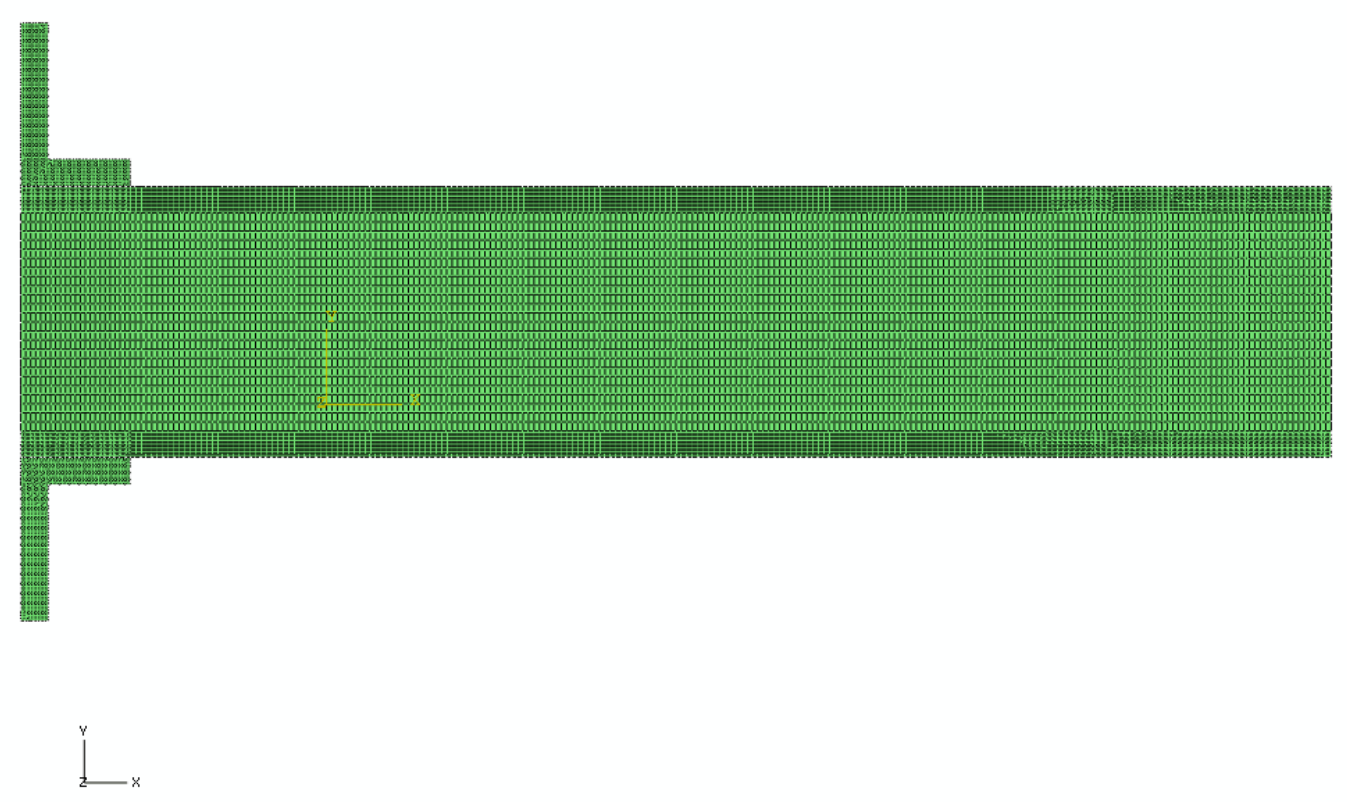

Figure 66 - Finite element geometry for test specimen 
Table 3 - Sandwich structure geometry

\begin{tabular}{|c|c|c|c|}
\hline & $\begin{array}{c}\text { Thickness } \\
\text { (inch) }\end{array}$ & $\begin{array}{c}\text { Length } \\
\text { (inch) }\end{array}$ & $\begin{array}{c}\text { Out of plane thickness } \\
\text { (inch) }\end{array}$ \\
\cline { 1 - 2 } Fiberglass skins (each) & 0.08 & \multirow{2}{*}{6.0} & 1.50 \\
\hline Foam & 0.787 & & \\
\hline
\end{tabular}

\section{Material Properties Development}

Initially during the analysis it was assumed that the constitutive response for both the fiberglass skins and foam core was linearly elastic, homogeneous, and isotropic. In reality that is not the case because both materials are orthotropic and exhibit plastic characteristics. After looking at the initially linearly elastic results it was determined that the plasticity of the foam would need to be model to accurately capture the failure forces. The material properties for the Divinycell foam core were obtained from the manufactures' website ${ }^{23}$ and the tensile (Figure 67) and compressive (Figure 68) stress strain curve were obtained during Dr. Mitra's initial shear key research ${ }^{4}$.

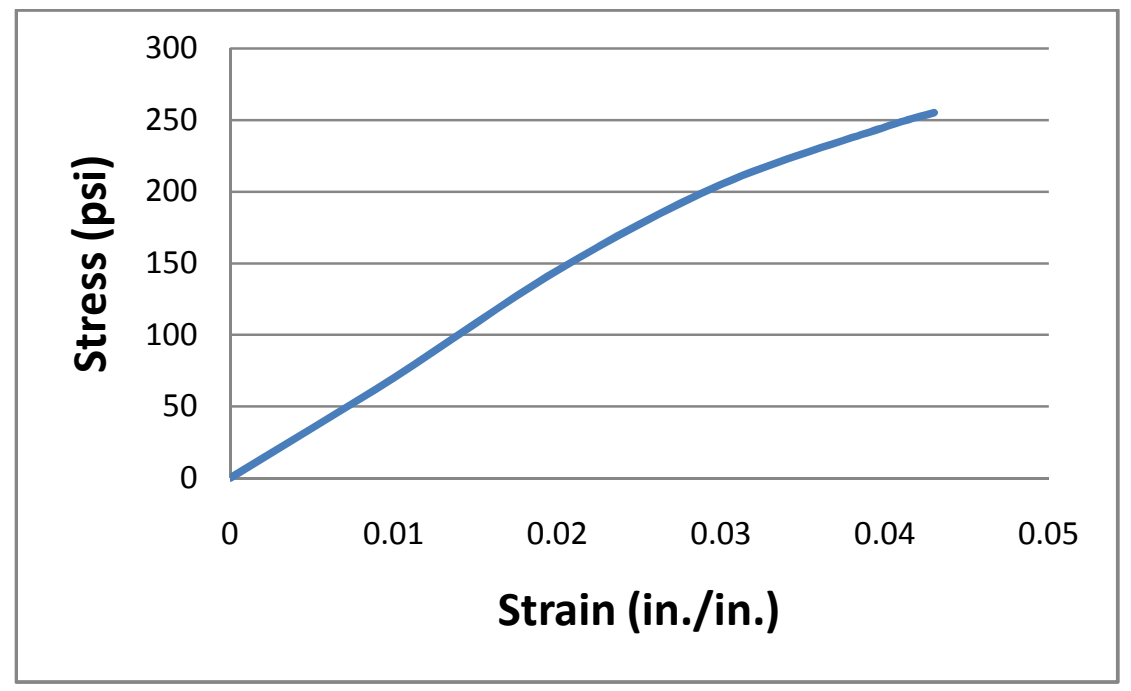

Figure 67 - Tensile response of Divinycell H100 foam ${ }^{4}$ 


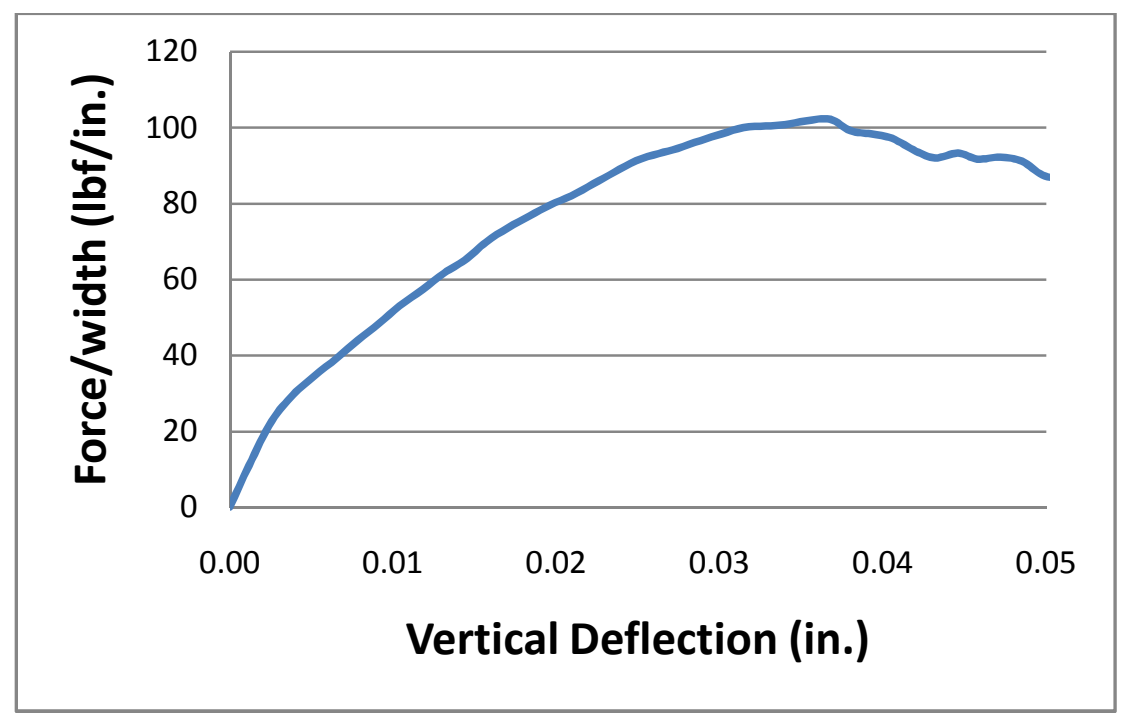

Figure 68 - Compressive response of Divinycell H100 foam ${ }^{4}$

Two different material models were used to represent the non-linear and plastic behavior of the foam after its yield strength was reached. Modeling the foam as a hyperelastic material was the first step in trying to more accurately capture the failure in the foam. A hyperelastic foam model was constructed for the foam by extrapolating data from the tensile and compressive tests for the Divinycell H100 foam. The hyperelastic foam curve used as an input into the material properties in Abaqus/CAE is shown in Figure 69. 


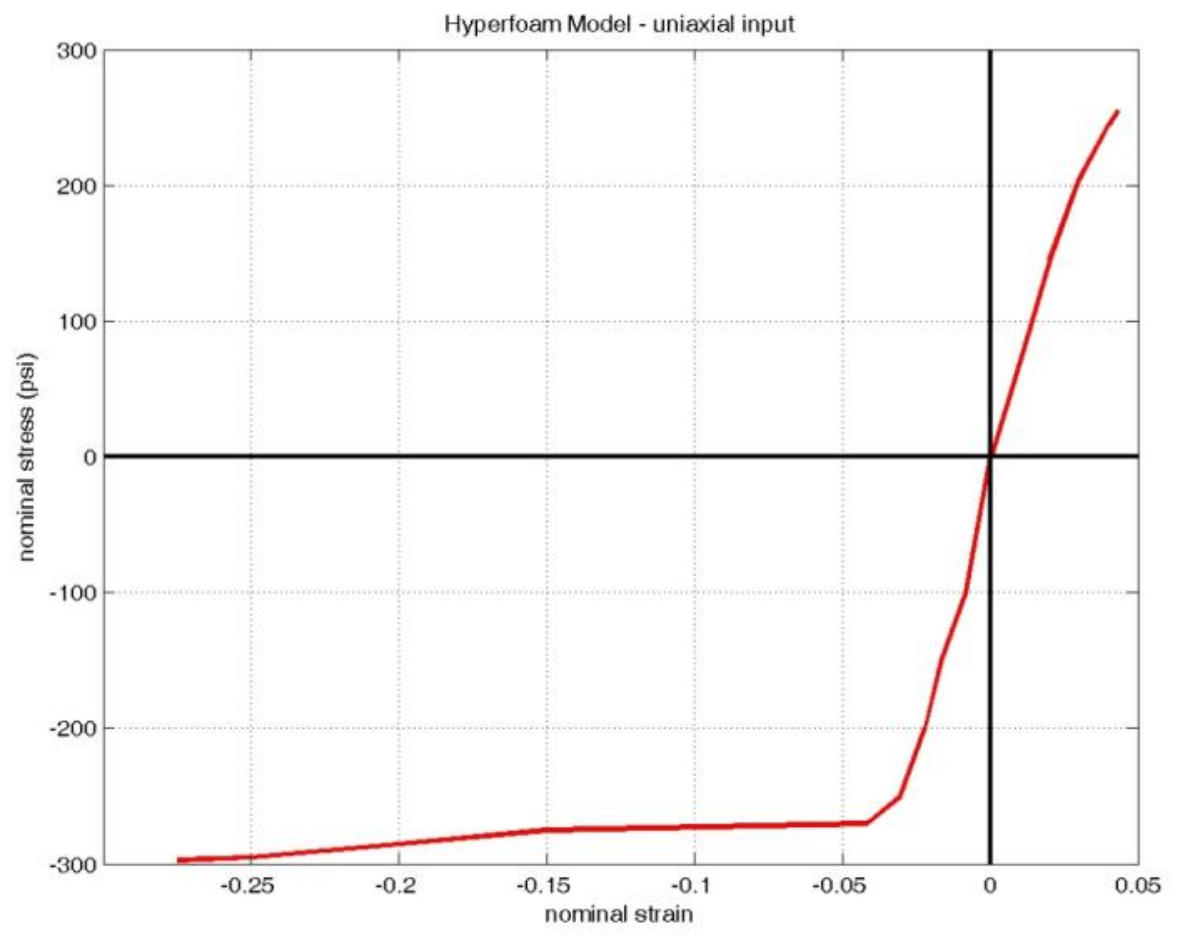

Figure 69 - Hyperelastic foam model

The other foam model used was an expansion of the crushable foam model originally used by Dr. Nilanjan Mitra ${ }^{4}$ during his shear loading research. The crushable foam hardening model used for the analysis is shown in Figure 70. Additional information regarding hyperelastic material properties could be found by consulting the Abaqus User's manual. 


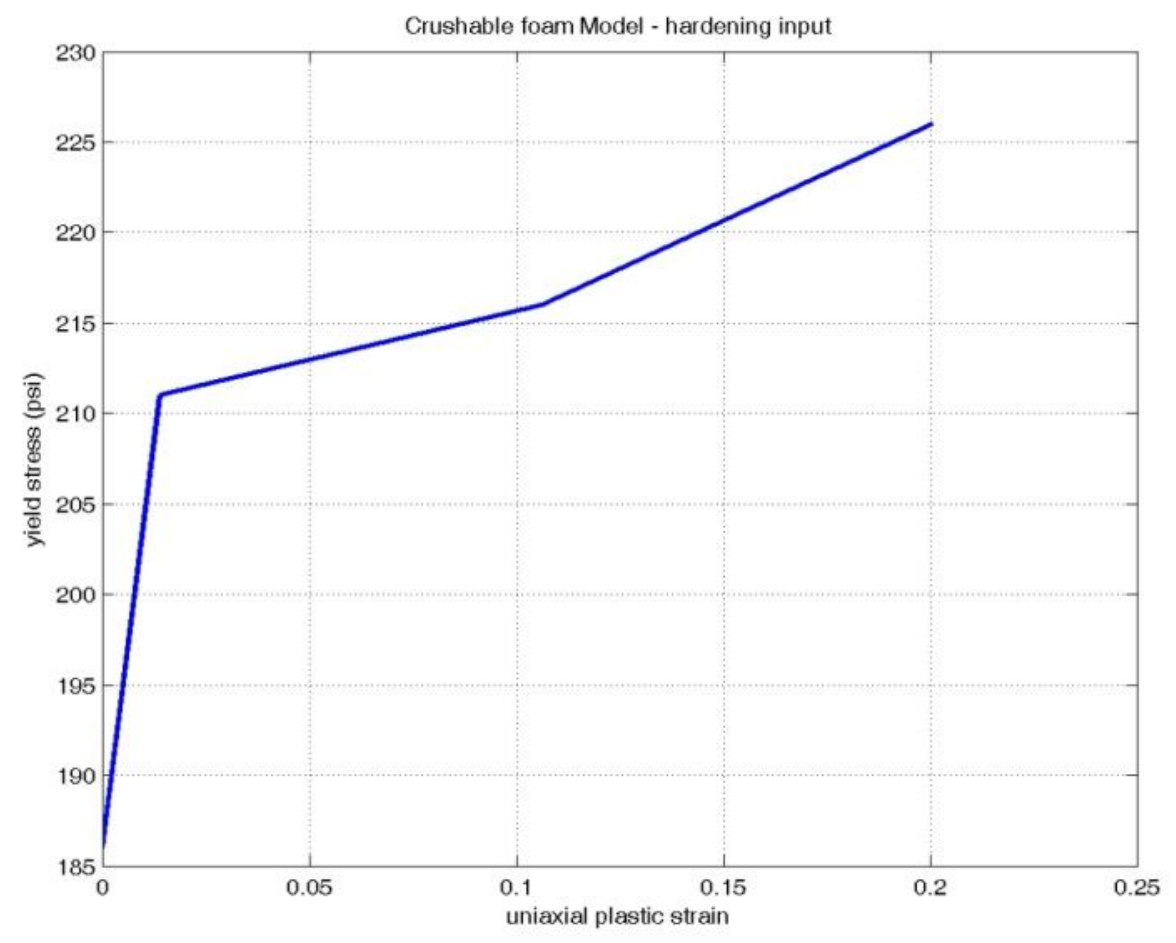

Figure 70 - Crushable foam plasticity model

Material properties from the fiberglass manufacturers were not available so testing had to be performed to determine them. A $120 \Omega$ linear strain gage with a gage factor of 2.1 was added near the middle of the test specimen and two holes were drilled near both the ends of the specimen. One hole was be used to constraint the specimen and the other hole was be used to hand weights off of. The strain gauge was wired up in a quarter Wheatstone bridge configuration using the yellow strain gage box shown in Figure 71. Additional information regarding the crushable foam hardening could be found by consulting the Abaqus User's manual. 


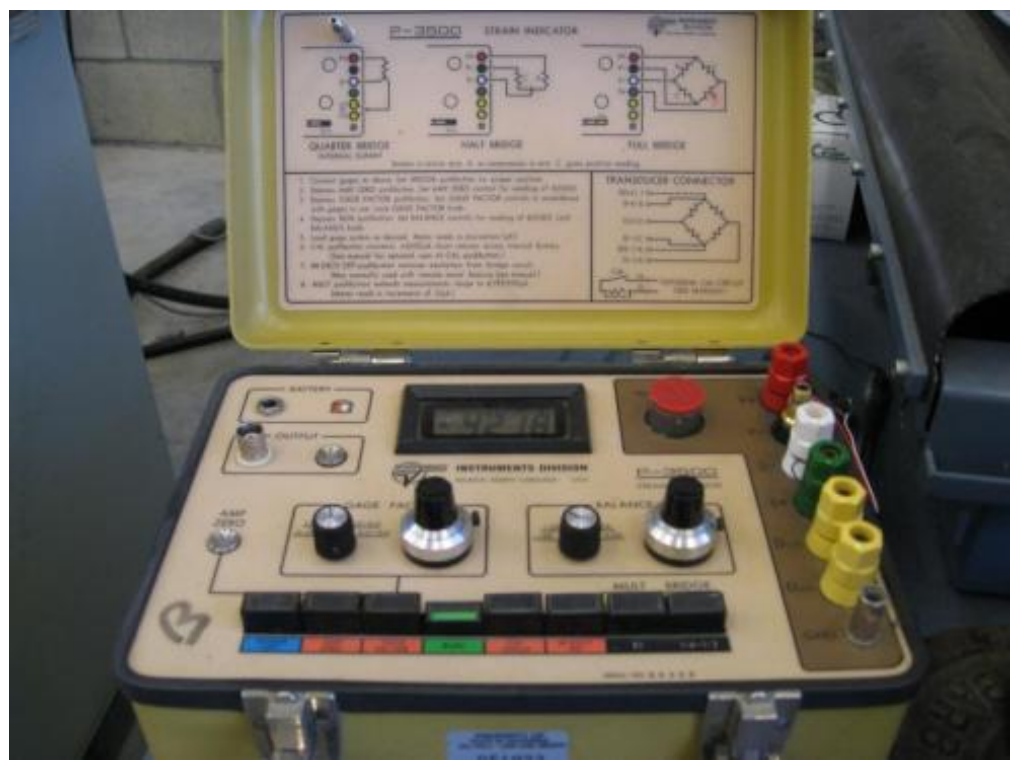

Figure 71 - Yellow strain gage box with 1/4 bridge configuration

An aluminum test specimen was first used to ensure that the method used for the experiment was accurate because the material properties for aluminum were known. Figure 72 shows the aluminum test specimen with a strain gage as well as the boundary conditions used to fix the specimen. Figure 73 shows the jig used to hold the weights during the material calibration.

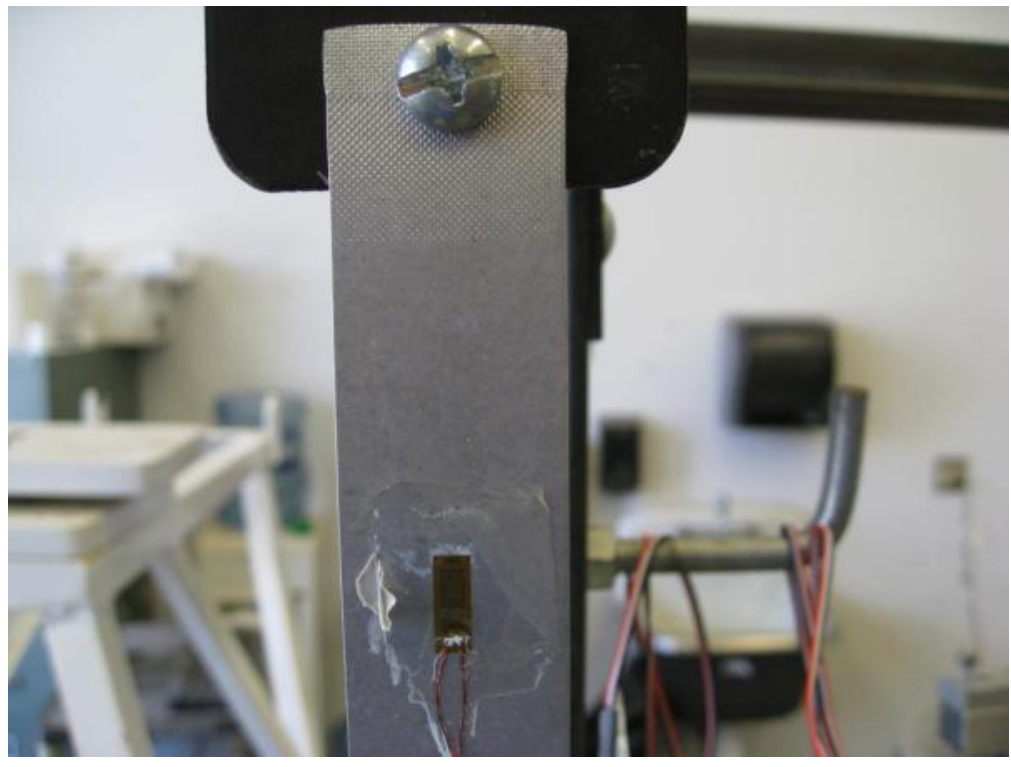

Figure 72 - Aluminum test specimen under tensile load 


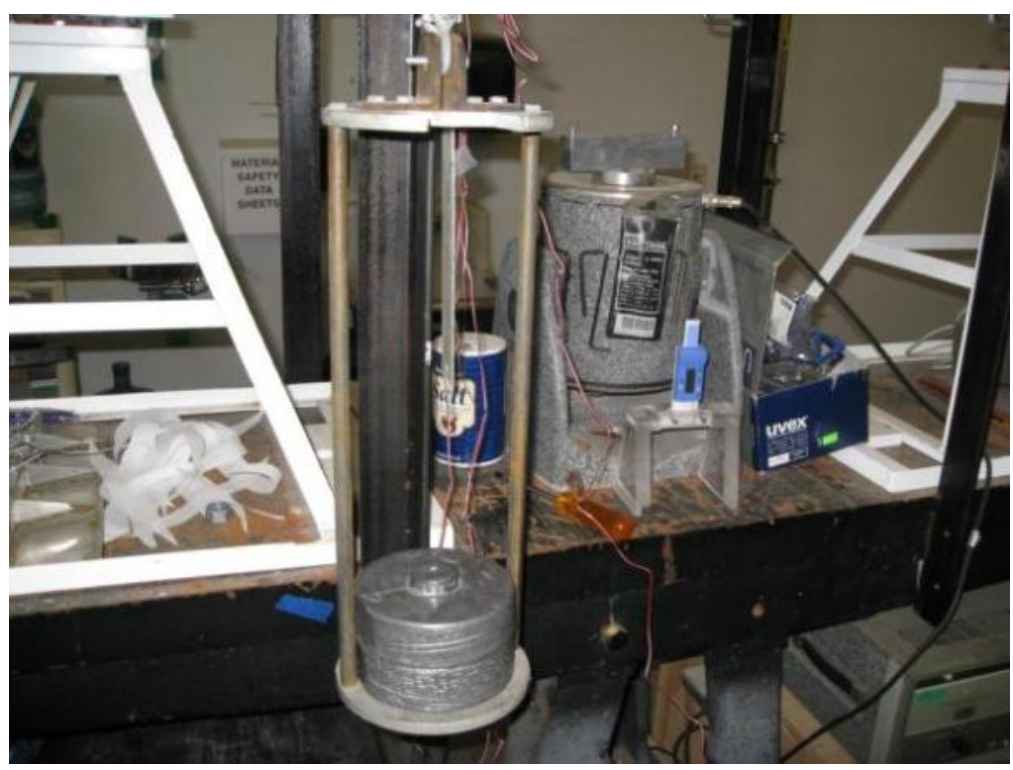

Figure 73 - Applied loading for material calibration

Before any weights or stain readings were recorded, the strain gage box was zeroed. Weights were then added in $10 \mathrm{lb}$ increments and strain readings were recorded. Figure 74 shows the results obtained from the testing for the aluminum and fiberglass skin test specimens. Stress was plotted on the $y$-axis and strain was plotted on the y-axis. Young's Modulus for the aluminum test specimen was experimentally determined to be $9.6 \mathrm{e} 6$ psi which was only $6 \%$ off the known Young's Modulus value of $10 \mathrm{e} 6 \mathrm{psi}$. Young's Modulus for the fiberglass skin lay-up was determined to be 5.7e6 psi. There is also further confidence in the test because the slopes of the lines are straight and there were no jagged points, which generally represent incorrect strain readings. 


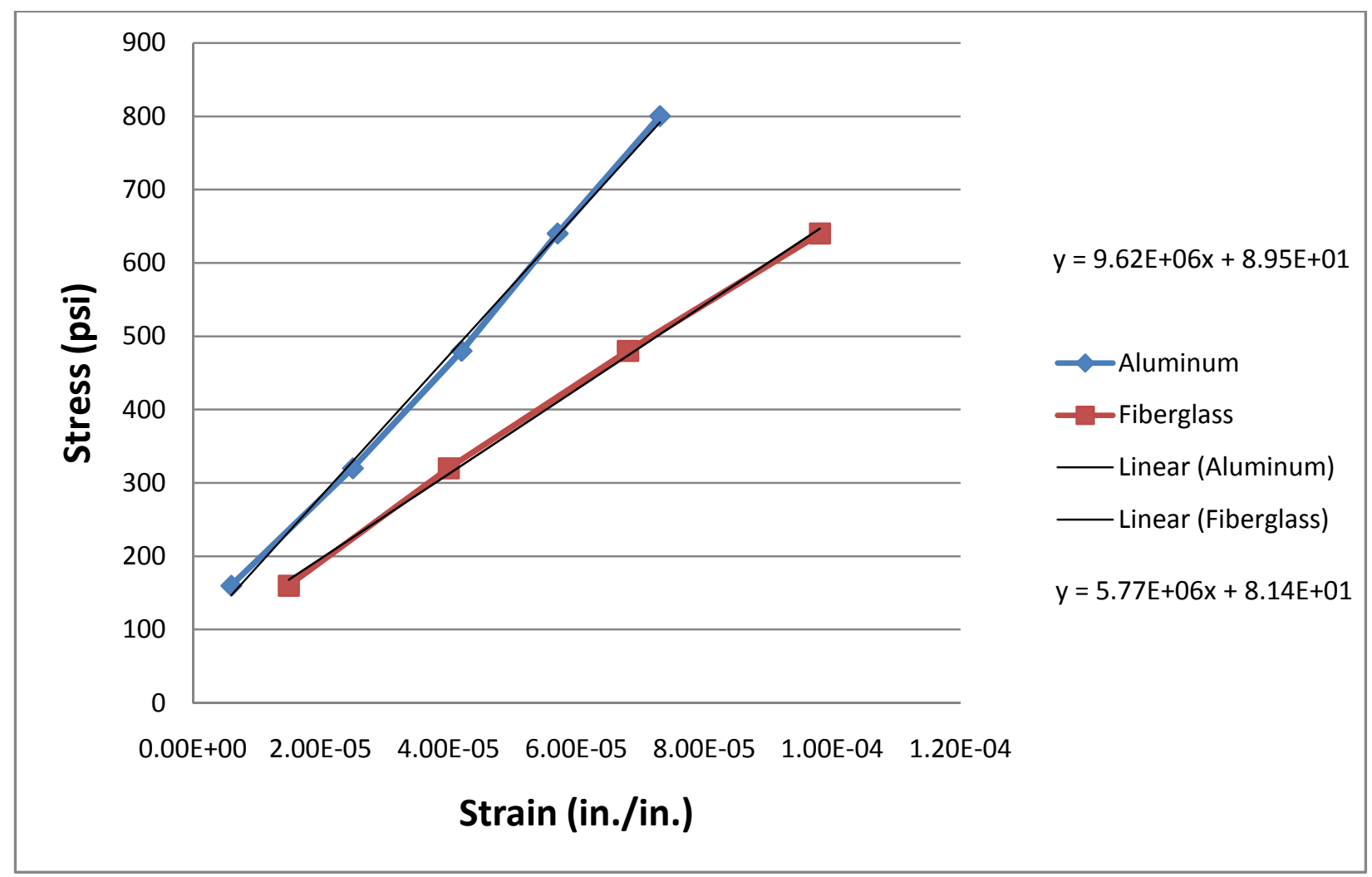

Figure 74 - Material calibration plot

\section{Loads/Boundary Conditions}

The boundary conditions selected for the test specimens with no initial delamination and a 0.5 inch initial delamination analysis are shown in Figure 75. Displacement boundary conditions representing displacement test data were applied to the upper aluminum L-bracket. Both test specimens had the lower aluminum L-bracket fixed (U1=U2=0). The back edge of the test specimens were also fixed using the jig which was fixed to the Instron machine. Figure 75 shows the loads and boundary conditions used for the models. 


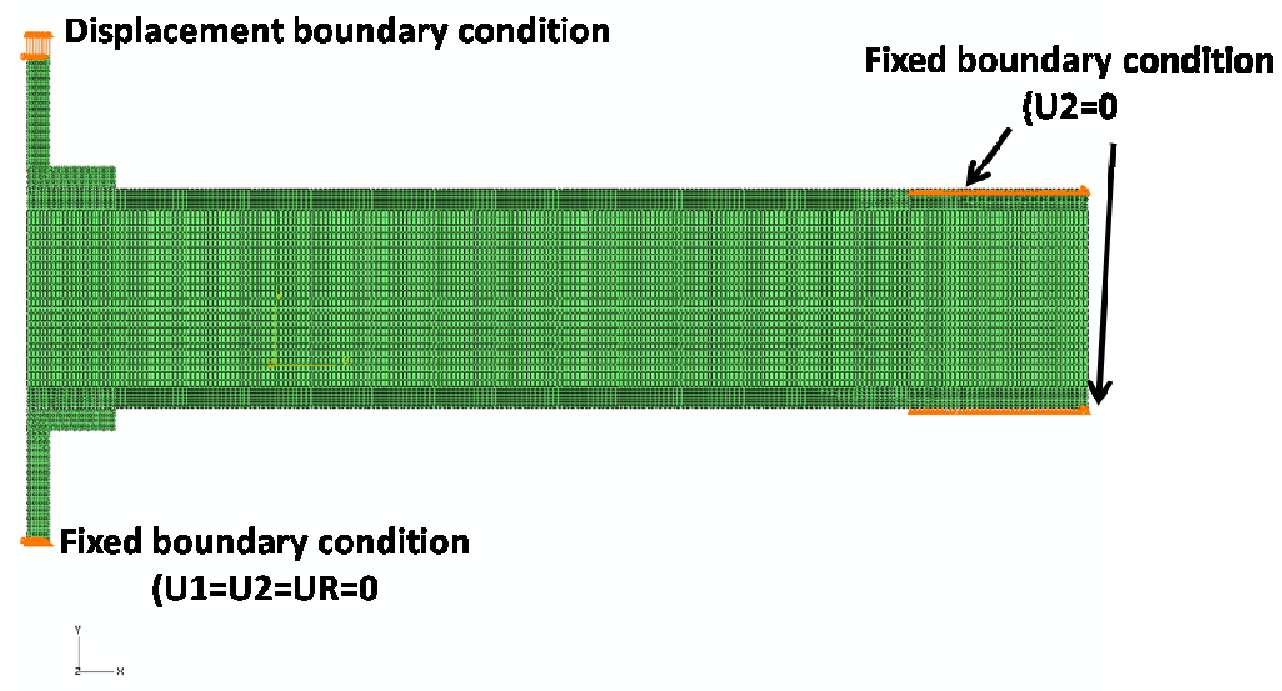

Figure 75 - FEM displacement boundary conditions

\section{Mesh Development}

Shell elements were selected to represent the fiberglass skins and the foam core. The primary reason for choosing shell elements was because stress and displacement were expected to be the same throughout the entire depth of the test specimens. 3-D solid element were not selected because of the high computational costs associated with 3-D elements. The 2-D shell elements should provided a good approximation for the failure loads.

The 2-D shell elements were constructed in Abaqus/CAE by creating a 2-D shell. The skins were made by partioning the 2-D rectangular shell using the thickness of the upper and lower skins. Additional partitions were added to represent the delaminated region where the force boundary conditions were applied.

Linear elements with reduced integration were selected to decrease computation time. It was deemed appropriate that linear elements with reduced integration could be used because the degree of confidence obtained through the mesh convergence study. A quadrilateral structured mesh was assigned to all regions of the test specimens. Plane stress elements were initially selected but modeling issues 
arose when plasticity was adding to the foam, which led to plane strain elements being used. Figure 76 shows the final mesh that was used for the analysis. Table 4 shows the mesh quality used for the numerical analysis.

Figure 76 - Final mesh used for analysis

Table 4 - Mesh quality for final mesh

\begin{tabular}{|c|c|c|c|}
\hline & \% Elems & \# Elems & Average \\
\hline Face Corner Angle $<\mathbf{4 5}^{\circ}$ & 0 & 0 & $90^{\circ}$ \\
\hline Face Corner Angle $>$ 135 & 0 & 0 & $90^{\circ}$ \\
\hline AR $>\mathbf{5}$ & 0 & 0 & 2.08 \\
\hline
\end{tabular}

\section{Analysis}

A non-linear static analysis was selected to simulate the monotonic loading conditions. A static analysis was selected because the monotonic loading conditions represented static testing. A linear static analysis was initially performed because plasticity was not modeled but the initial FEA analysis results needed plasticity to match the experimental data. 


\section{Results}

Figure 77 shows the vertical deflection (U2) contour for the test specimen with no initial delamination. The maximum vertical deflection of 0.03304 inch occurs at the top of the aluminum tab.

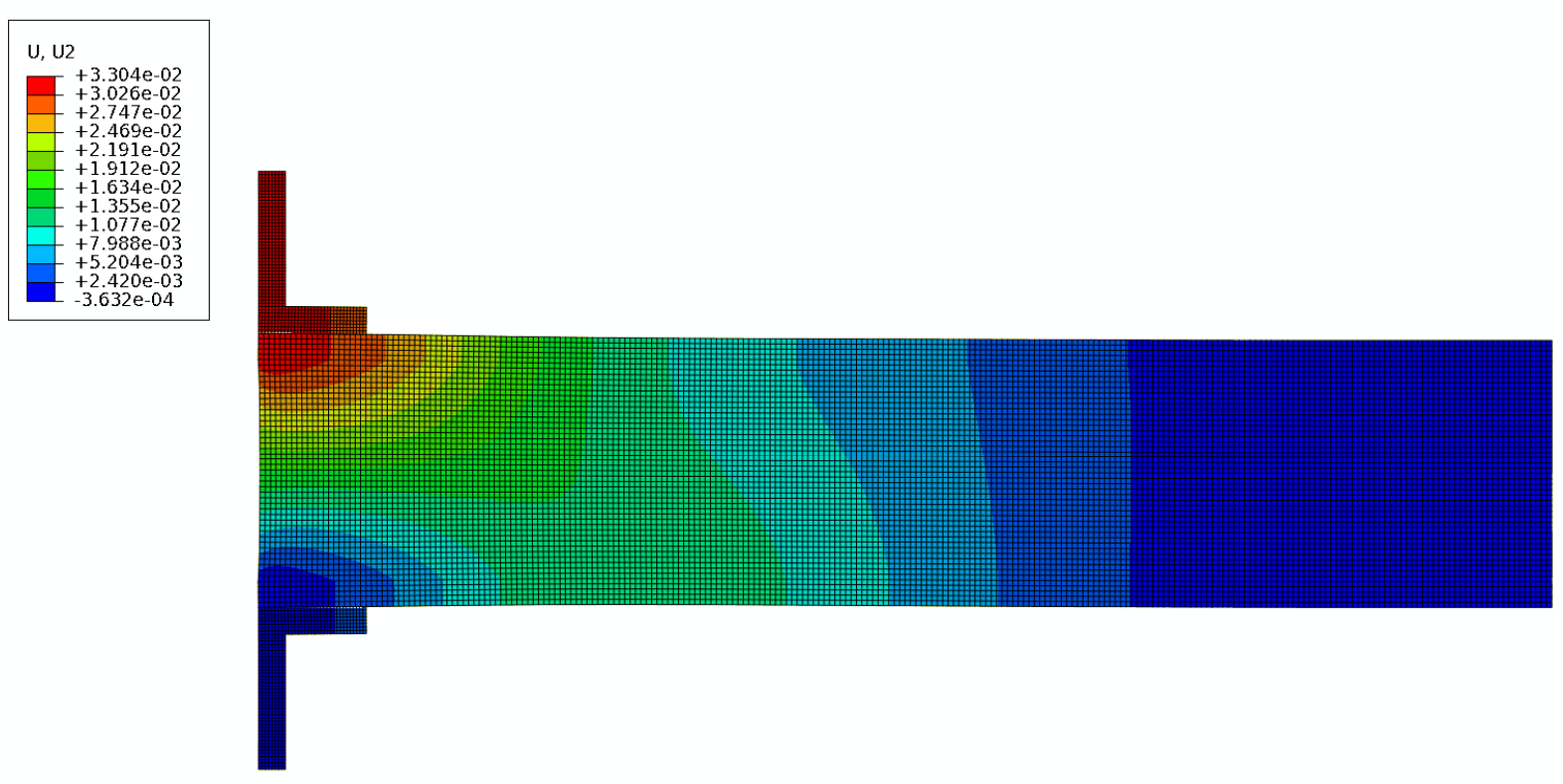

Figure 77 - FEA vertical deflection for test specimen without initial delamination

Figure 78 shows a vertical deflection contour for the test specimen model containing an initial delamination of 0.5 inch. The maximum vertical deflection of 0.03606 inch is shown in Figure 78 at the upper edge of the aluminum tab. The 0.5 inch delamination deflection contour is very similar to the deflection contour in Figure 77 except that there is no seam in Figure 77. 

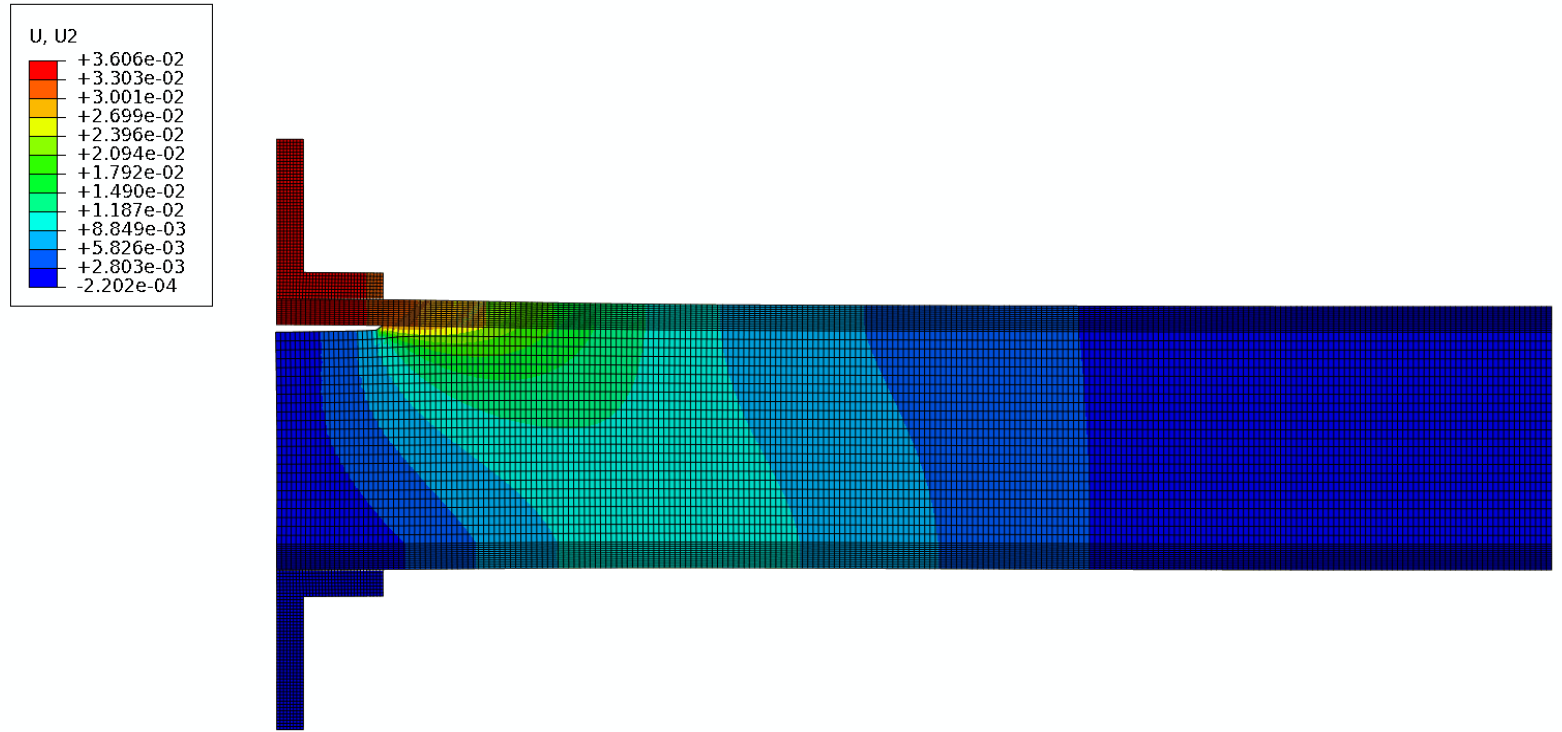

Figure 78 - FEA vertical deflection for test specimen with 0.5 inch initial delamination 


\section{Results and Discussion}

\section{Failure Analysis}

The test specimen stiffness $\left(\frac{l b_{f}}{i n .}\right)$, was used to compare the monotonic test results for the 6 different test specimen configurations. The fracture mode of the specimens was also of importance because it varied depending on the sandwich structure configuration. The composite sandwich structures had three main material elements where failure may have initiated from: the matrix, the fibers, and/or the foam. From a mechanics point of view, the failure should occur in the weakest of the three materials under constant loading conditions. In all three cases, the failures were caused by the development of cracks in one of the three materials.

\section{No Initial Delamination - Cracks in the Foam}

Most of the test specimens with no initial delamination failed due to the formation of cracks in the foam. Figure 79 below shows three pictures of a test specimen with no initial delamination and how they failed under monotonic loading. Cracks in the foam normally originated near the upper or lower surfaces as shown on the left hand side of Figure 79. Cracks then traveled through the foam at an angle, as shown in the middle and right side of Figure 79. The crack stops propagating through the foam when the failure criteria in the Instron machine is reached. These test specimens did not have a symmetric failure on both sides of the foam because the crack traveled across the width of the part as opposed to through the length. It was expected that cracks would initiate in the foam for correctly manufactured test specimens because it was considered the weakest of the three elements. 


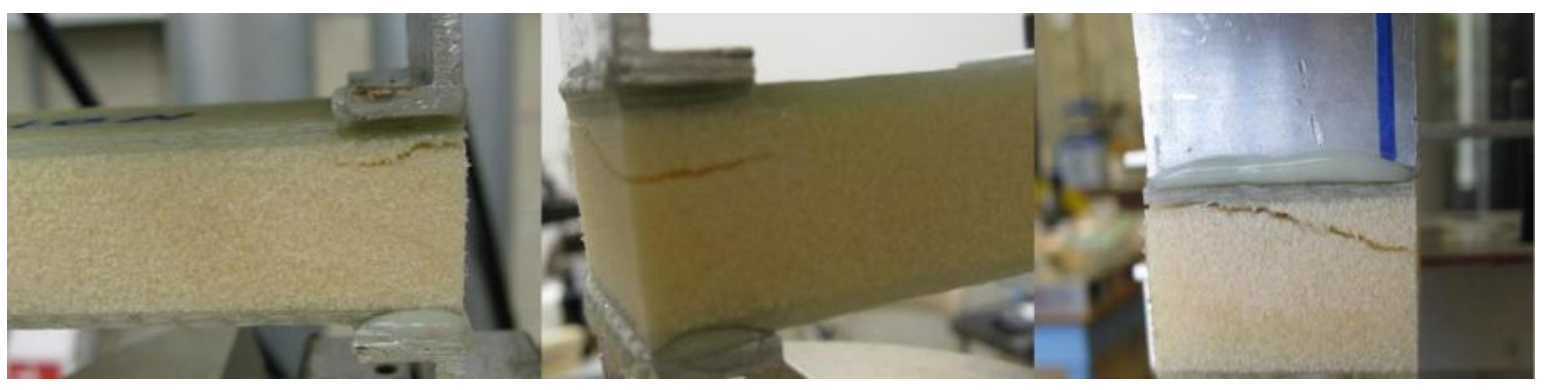

Figure 79 - Monotonic failure of specimens with no initial delamination

\section{No Initial Delamination - Cracks in the Matrix}

The second primary mode of failure in the test specimens was caused by cracks originating in the matrix. Figure 80 shows test specimens that failed due to cracks in the matrix. The picture on the left side shows a crack that started at the top of the test specimen and the picture on the bottom shows a crack that originated on the bottom of the specimen. The majority of the cracks in the matrix originated between the bottom layer of chopped strand mat and the foam. When the specimen failed, the chopped strand mat would delaminate from the foam. The delamination was not smooth because the some of the chopped strand mat would remain bonded to the foam. Cracks in the matrix signified the composite sandwich structure was not properly manufactured because the laminate is a stiffer material than the foam. A possible explanation for the cracks could be traced back to the resin/hardener ratio used during the manufacturing process. The resin/hardener ratio could cause the composite to cure as the resin was running through the part, leaving some of the regions of the lay-up with dry fibers. 


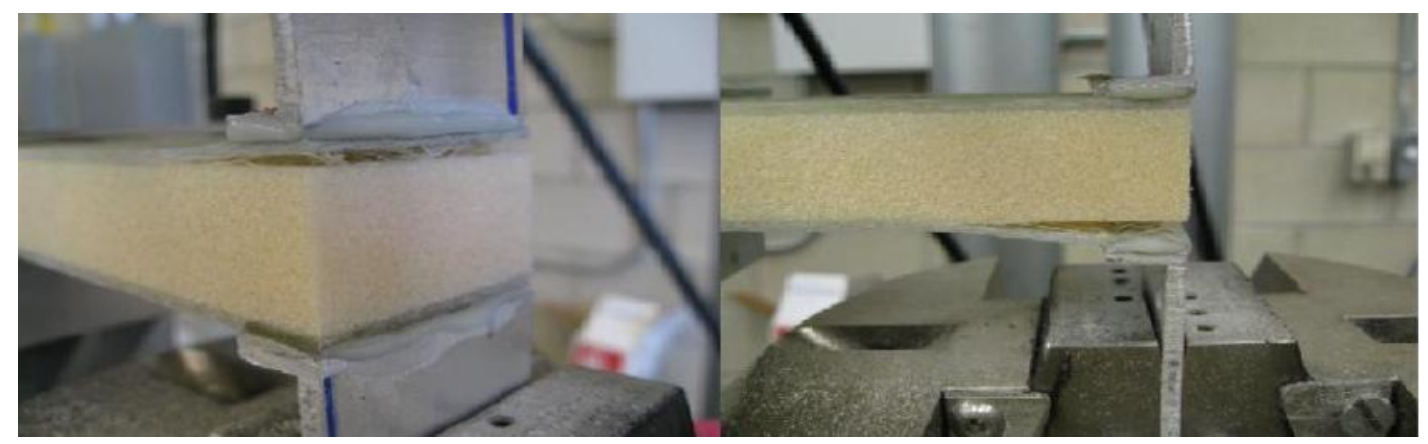

Figure 80 - Monotonic failure of test specimens without initial delamination

\section{$\underline{0.5 \text { inch Initial Delamination - Cracks in the Foam }}$}

All of the test specimens with a 0.5 inch delamination failed due to the propagation of cracks through the foam core. Figure 81 shows 4 pictures of test specimens with a 0.5 delamination that have failed. In all of the specimens tested, the cracks originated at the edge of the delamination and then continued to progress through the foam at various angles. The angles at which the cracks traveled through the foam was the only difference between the failures in the test specimens. Both pictures on the upper portion of Figure 81 failed due to a crack traveling approximately at $0^{\circ}$ from the edge of the delamination. In the two pictures on the bottom of Figure 81 traveled down through the foam at angles of approximately $45^{\circ}$ and $30^{\circ}$. The failures through the foam signified a good bond between the laminate and the foam core. This was also somewhat unexpected because it was predicted that a delaminated piece would exhibit a peeling effect, causing the delamination to separate the laminate from the foam. 

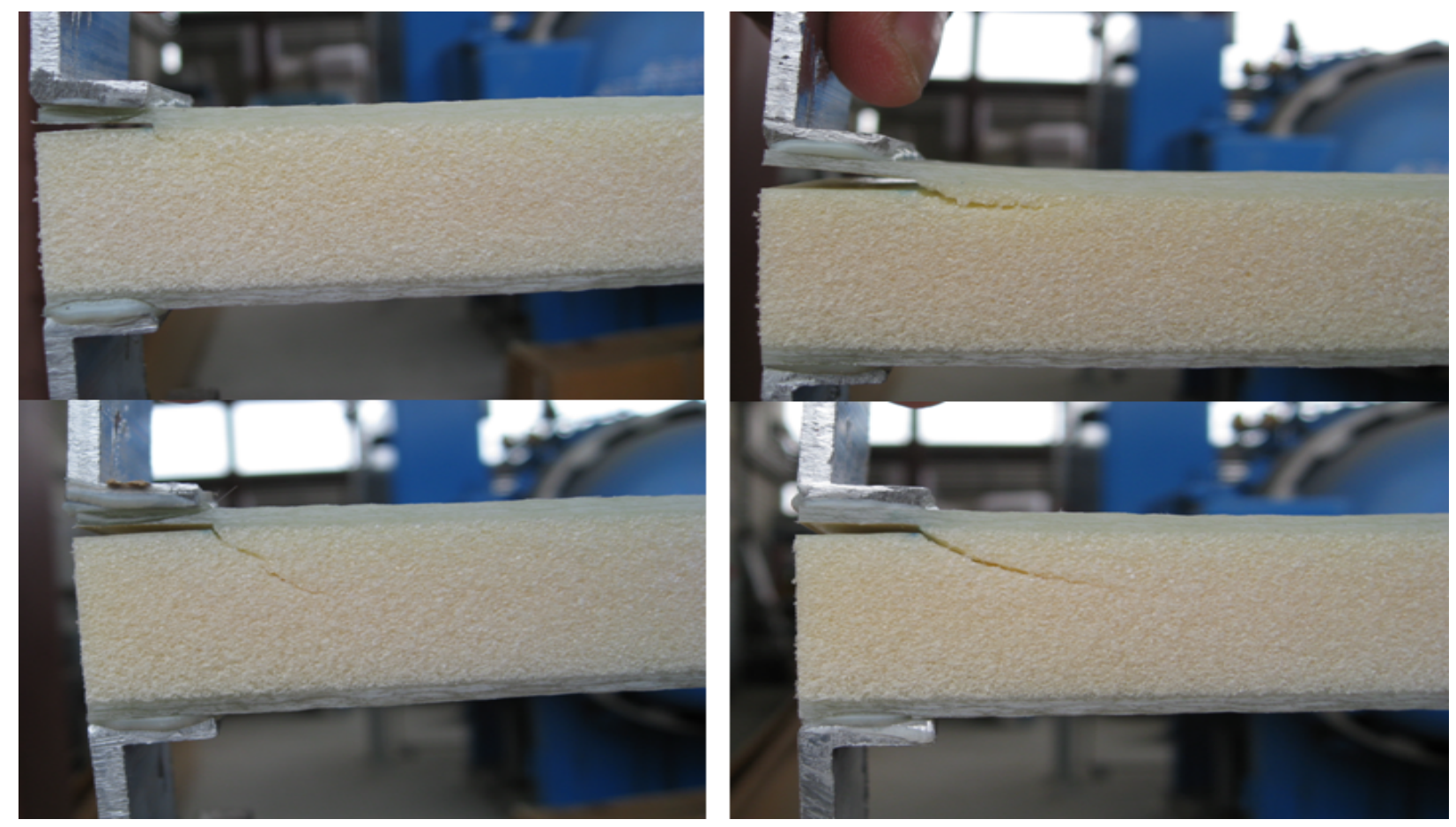

Figure 81 - Monotonic failure of test specimens with 0.5 inch initial delamination

\section{1 inch Initial Delamination - Cracks in the Foam}

The majority of the test specimens containing a 1 inch delamination failed due to cracks

originating in the foam. Figure 82 shows two test specimens that failed due to cracks in the foam core. The 1 inch delaminated test specimens failed in a similar fashion compared to the test specimens with a 0.5 inch delamination. Cracks originated at the edge of the delamination and then traveled downward through the foam, as shown in the upper part of Figure 82. The lower part of Figure 82 shows a test specimen where the crack in the foam initially travels downwards but began to travel back through the foam towards the composite skin. The top picture shows a smooth material transition because the crack travels at a relatively constant angle through the foam. The jagged edges of the crack could possibly represent a test specimen that did not receive a good load transfer from the Instron machine. 


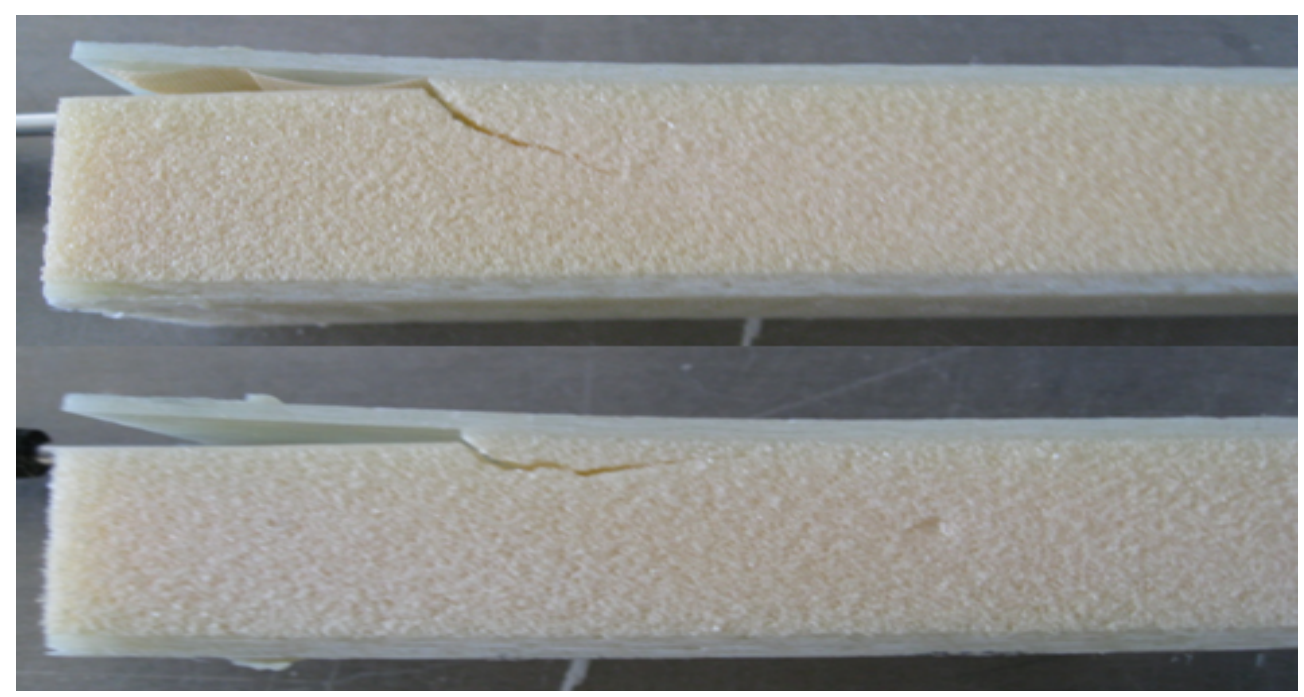

Figure 82 - Monotonic failure of test specimens with 1.0 inch initial delamination

\section{Shear Key Delamination from Foam}

Figure 83 shows a side view of the shear key delaminating from the foam. When the deflection of the laminate got too high, it released the shear key free from the foam and the laminate continued to separate from the foam. When this type of failure was first discovered, the validity of the shear key monotonic test data was called into question. Since the shear keys were delaminated from the foam it appeared that there was not a good bond between the foam and the shear keys. It was later determined that there may have been too much wax applied to the shear key mold and the shear keys didn't have enough surface roughness to achieve a good bond to the foam. Future shear key tests implemented these changes, increasing the strength of the test specimens containing shear keys. 


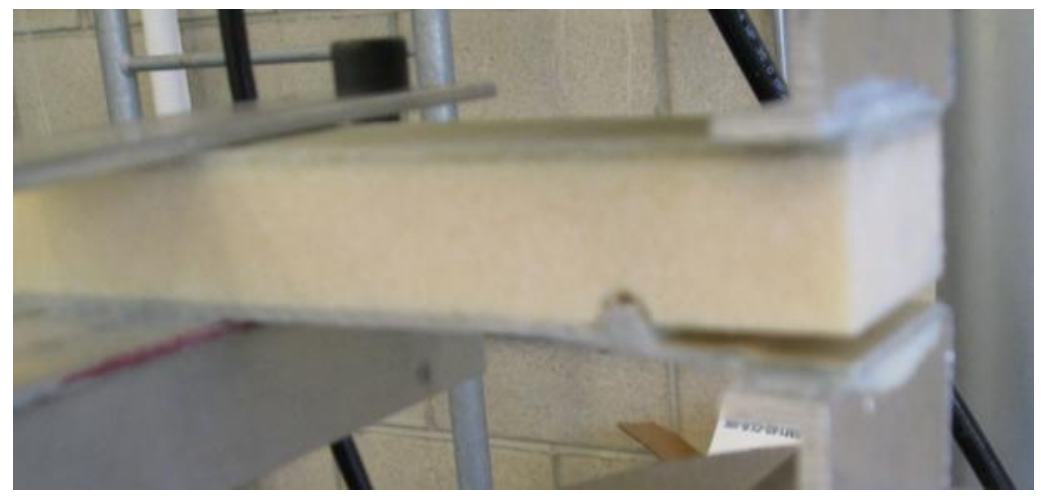

Figure 83 - Monotonic failure shear key delamination

Shear key crack propagating through foam

The majority of the test specimens that produced good data failed due to cracks propagating through the foam. Figure 84 shows a shear key specimen that failed due to a propagating crack. This mode of failure was similar to the failure of the delaminated test specimens with no shear key. The crack originated at the edge of the delamination and then travels through the foam at a slanted angle.

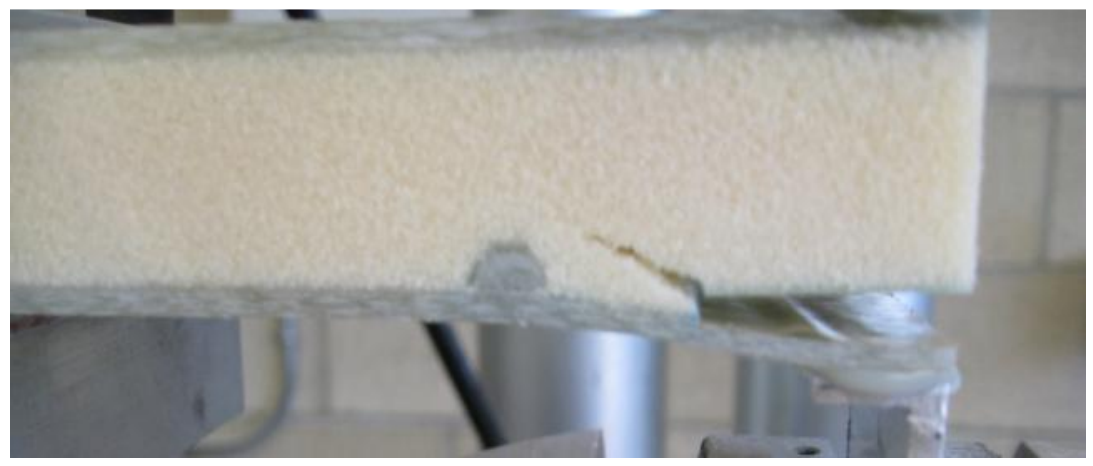

Figure 84 - Monotonic shear key failure due to cracks in foam

\section{$\underline{0.5 \text { inch Shear Key }}$}

The failure models for the sandwich structures with a shear key 0.5 placed inch behind the delamination edge experienced modes of failure similar to the 0 inch shear keys. The primary mode of failure was the origination of a crack at the edge of the delaminated region that travels through the foam. Figure 85 shows the failure caused by cracks in the foam. The image on the right side of Figure 85 shows a crack traveling at approximately a $45^{\circ}$ angle which continues through the entire thickness of the foam. 
This type of crack propagation was the most frequently encountered failure. A secondary type of failure through the foam is shown in the left hand side of Figure 85. The crack initially travels at an angle less than $30^{\circ}$ and then around the shear key as opposed to continuing through the thickness of the foam. This mode of failure was expected with the introduction of shear keys into the sandwich structure test specimens. It was predicted that the shear key would act as a stronger material than the foam, which would drive the crack around the shear key.

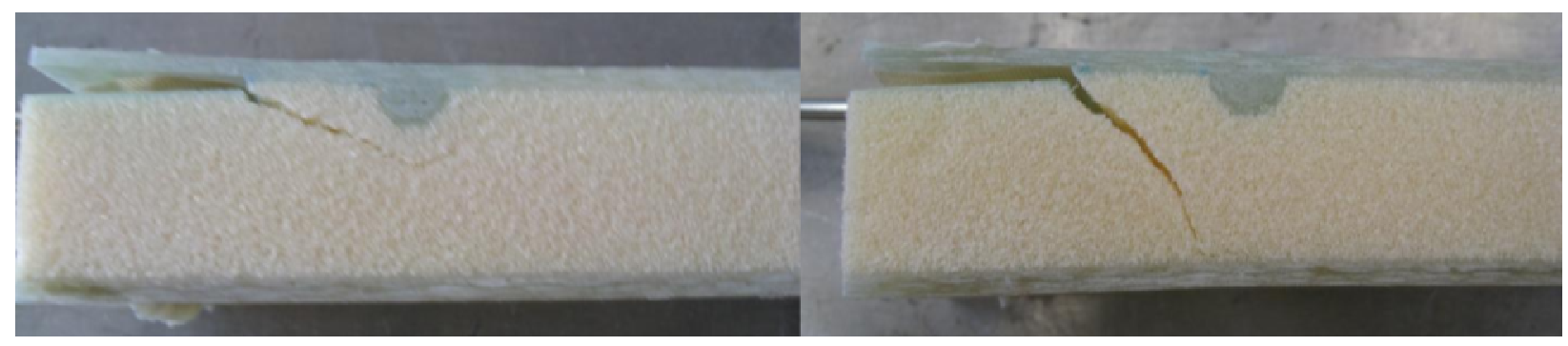

Figure 85 - Monotonic shear key failure (0.5 inch shear key)

\section{Monotonic Failure Analysis - 1.0 inch Shear Key}

The test specimens with shear keys placed 1.0 inch behind the delamination failed in a similar manner to the 0 and 0.5 inch shear keys. The most common failures occurred in the foam and some failures occurred in the matrix. Figure 86 shows a failure caused by cracks originating in the matrix. Cracks in the matrix caused the delamination to propagate along the upper edge, making the upper composite layer separate from the foam core. The shear key had very little effect on these matrix failures because it was located too far away from the failure region. 


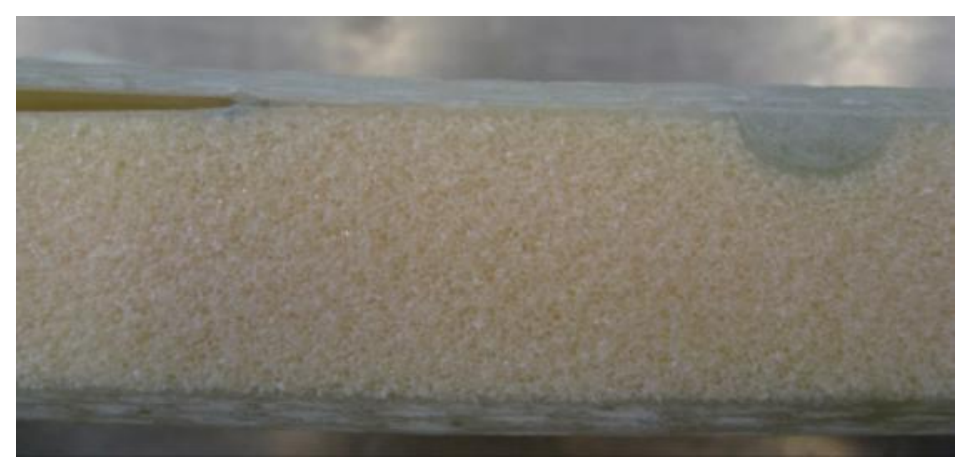

Figure 86 - Monotonic shear key failure through matrix (1.0 inch shear key)

The more common failure for the 1.0 inch shear keys was failure due to cracks in the foam and is shown in Figure 87 below. The failure for these test specimens was slightly different than the other shear key specimens that failed through the foam. Here the crack start at a shallow angle of approximately 10$20^{\circ}$ and goes down through about $1 / 10$ inch through the foam. Then the crack turns slightly and travels at approximately $180^{\circ}$ towards the shear key. Figure 87 shows two failures caused by shallow cracks in the foam.

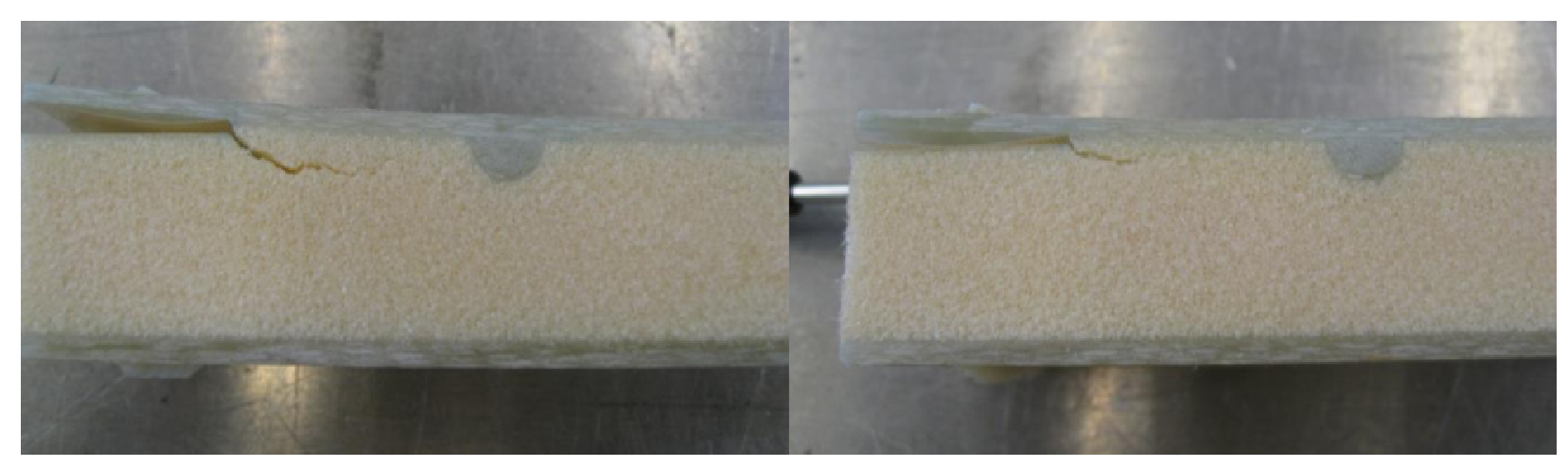

Figure 87 - Monotonic shear key failure cracks in foam (1.0 inch shear key)

The less common type of foam failure in the 1.0 inch shear keys is shown in Figure 88 . The failure starts out the same way as the test specimens depicted in Figure 87 except the crack travels a different path. The crack travels back up through the foam towards the composite layer and stops at the 
edge of the shear key. These results seemed somewhat counter intuitive because the intent of the shear keys was to drive the crack away from the upper skin to help stop the delamination.

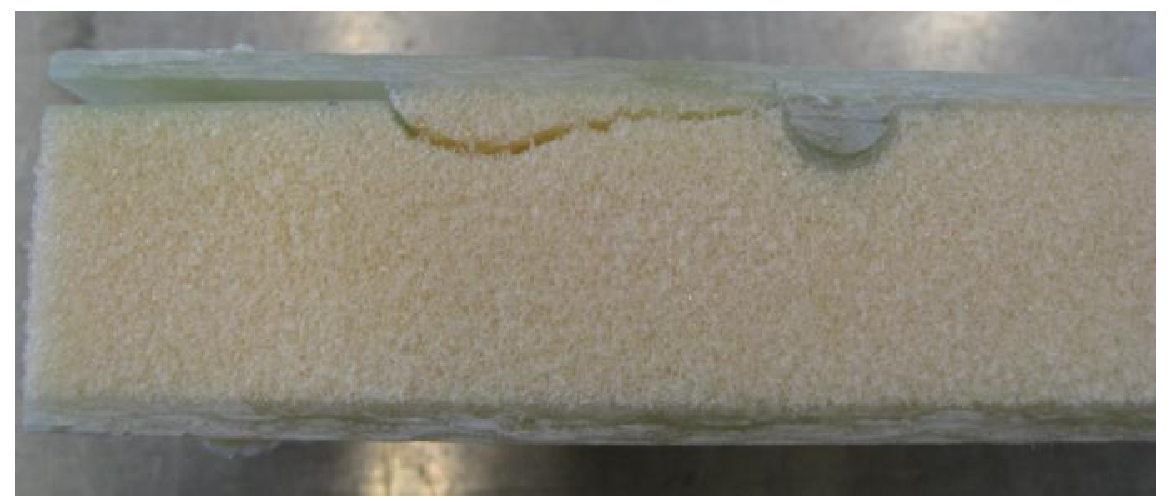

Figure 88 - Monotonic shear key failure type II (1.0 inch shear key)

\section{Dynamic Testing}

\section{$\underline{1.0 \text { inch Initial Delamination Failure Analysis }}$}

The fatigue failures for the test specimens with a 1.0 inch delamination failed very similarly to the specimens tested under monotonic loading with failure. The majority of the test specimens failed due to cracks originating in the foam. A few test specimens failed due to cracks in the matrix. The main difference between the two types of failures was the speed at which the cracks propagated.

Figure 89 and Figure 90 show the crack propagation of one of the test specimens being subjected to an input of $50 \%$ of the — A $50 \%$ load case was selected because it would provide the best representation of the crack propagation because the loading was low, and the crack should move relatively slowly. The left hand side of Figure 89 shows the test specimen after 307 cycles, the point at which it was noted the applied force started to drop from the input force. This signified that a microscopic cracks had begun to develop even though it was not visible. The right hand side of Figure 89 shows the same test specimen after 999 cycles where a small crack is clearly visible near the edge of the 
delaminated region. The angle that the crack begins to travel though the foam was similar to the 1.0 inch delaminated test specimens tested monotonically.

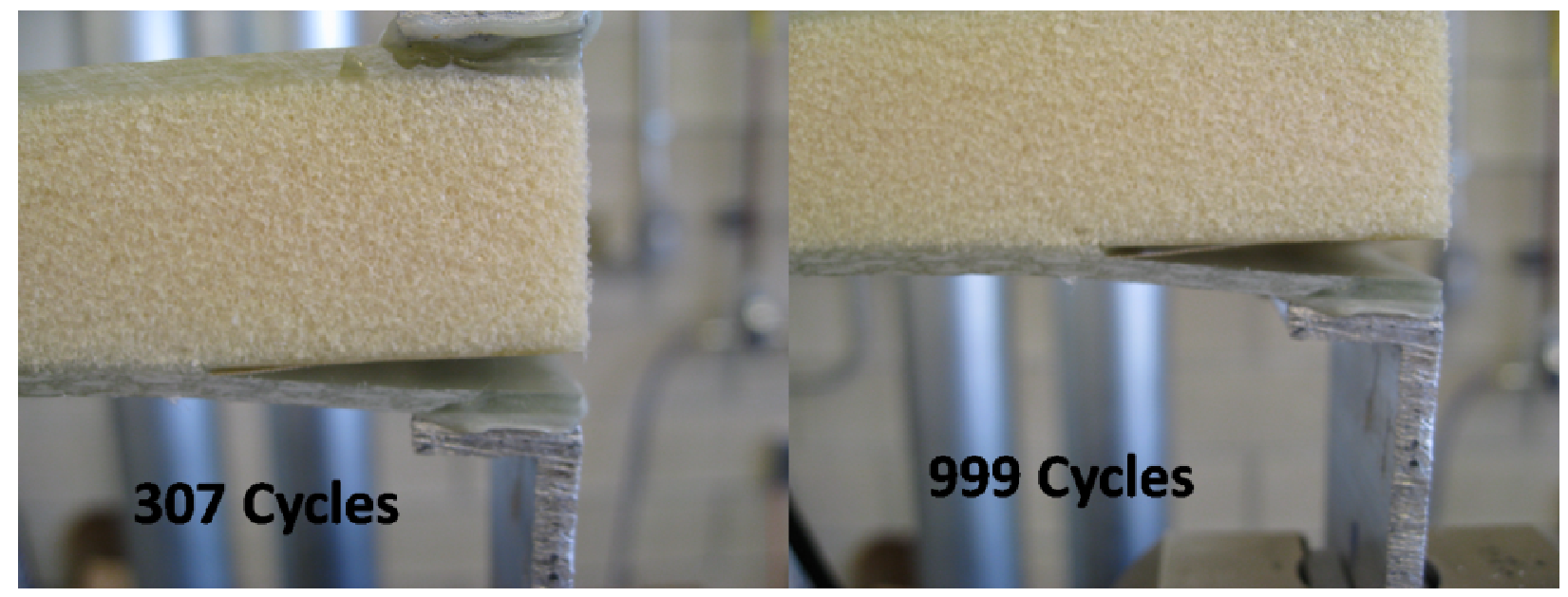

Figure 89 - 1.0 inch delamination fatigue crack propagation through foam

The left side of Figure 90 shows that after 1385 cycles the crack continued to travel through the foam at approximately the same angle that it began. The right side of Figure 90 shows the test specimen after 1963 cycles, which was the point the $10 \%$ load drop failure criteria was met. It uncertain whether or not the crack would continue to travel through the foam at the same angle. In most test the cracks appeared to progress down towards the lower fiberglass skin. This type of failure was similar to the results obtained from the test specimens with shear keys placed 1.0 inch behind the back edge of the delamination. 


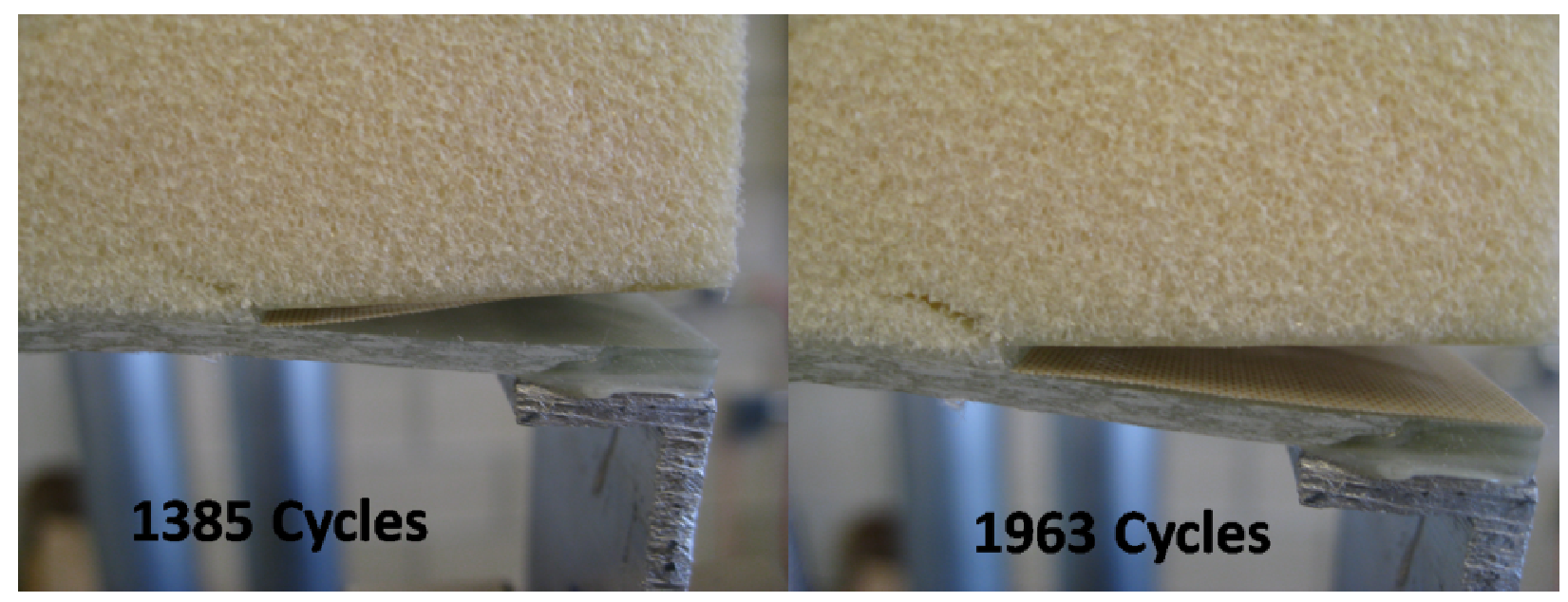

Figure 90 - 1.0 inch delamination fatigue crack propagation type II through foam

The other type of fatigue failure observed for the test specimens with an initial delamination of 1.0 inch was cracks in the matrix, characterized by a delamination that caused the fiberglass skin to separate from the foam core. Figure 91 shows the fatigue crack propagation when failure was caused by cracks in the matrix. The test specimen here was subjected to a loading rate of $55 \%$ of the —— and an easily visible crack was expected, but that did not turn out to be the case. The left side of Figure 91 shows that the skin started to peel away from the foam after only 123 cycles. The same test specimen quickly reached the failure criteria after only 381 cycles. Based on the data obtained from the $50 \%$ loading rate it was determined that this was a premature failure because the crack should have initiated in the foam because the epoxy is a stronger material than the foam. The stiffness of the epoxy is 5 times greater than that of the foam. For the test specimens with an initial delamination of 1.0 inch fatigue failure caused by a crack in the matrix signified a premature failure that was attributed to defects introduced during the manufacturing process. 


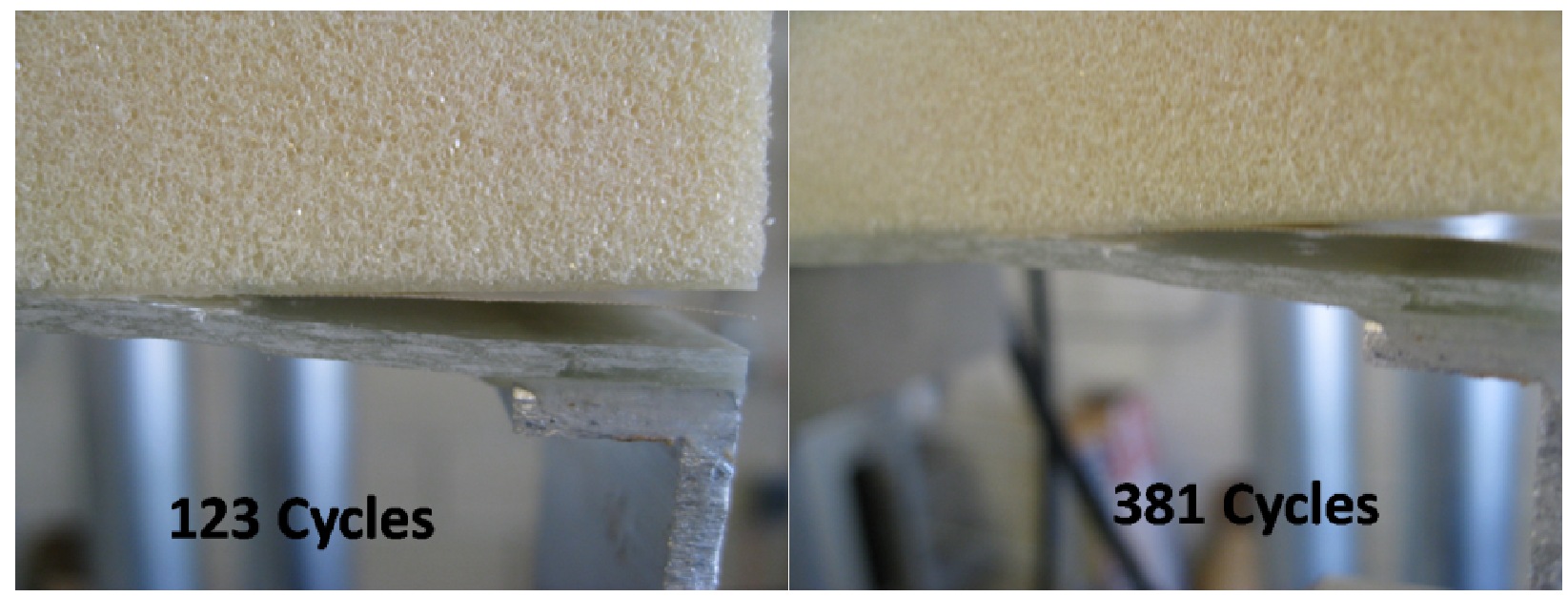

Figure 91 - 1.0 inch delamination fatigue crack propagation through matrix

\section{$\underline{1.0 \text { inch Shear Key Failure Analysis }}$}

All of the fatigue failure for the shear key test specimens were caused by cracks in the matrix. Figure 92 shows a shear key test specimen subjected to $65 \%$ loading with a crack propagating along the upper fiberglass skin. The image on the left of Figure 92 shows the initiation of the crack and the image on the right of Figure 92 shows the final failure.

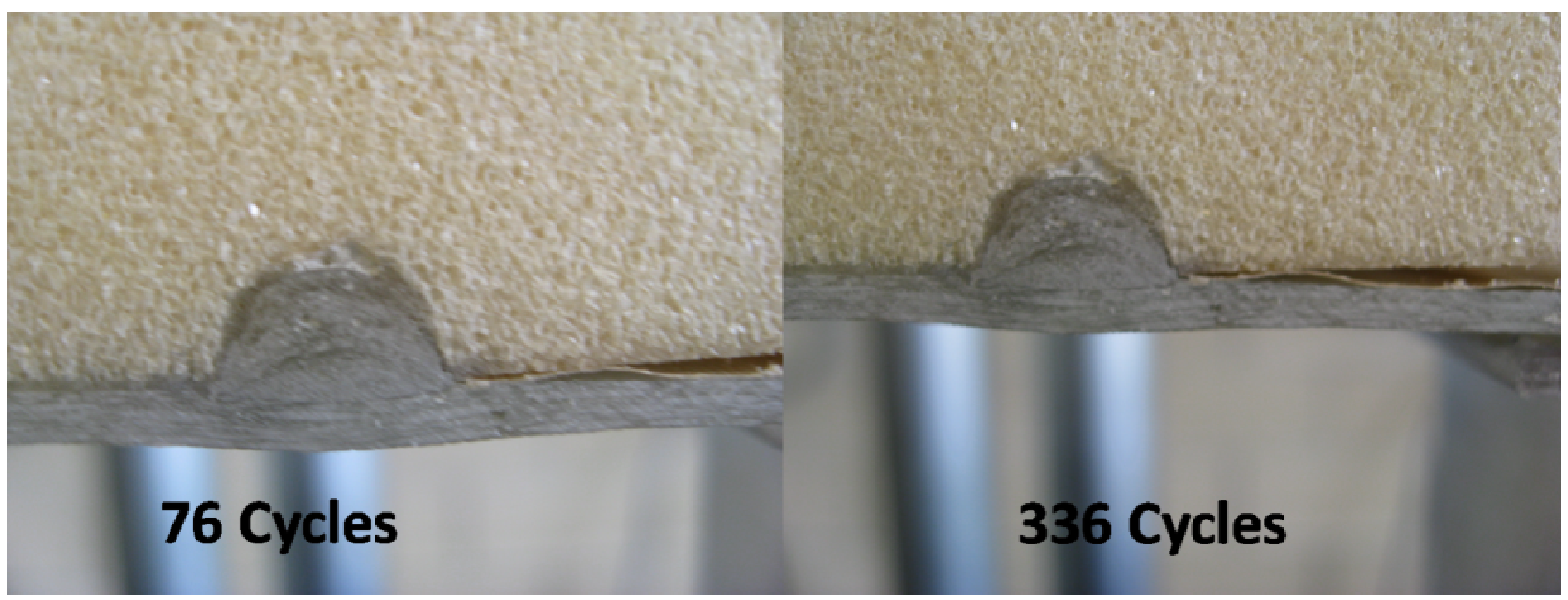

Figure 92 - Shear key fatigue failure analysis 


\section{Monotonic Results Comparison}

Figure 93 shows the monotonic force vs. displacement results for the test specimens with an initial delamination of 0.5 and $1.0 \mathrm{inch}$. Although both delamination lengths reach a similar ultimate $\left(\frac{F_{U L T}}{w}\right)$ of approximately $100 \frac{l b_{f}}{i n .}$ the two curves are very different. The 0.5 inch delamination test specimen only reached a maximum displacement of approximately 0.04 inches where as the 1.0 inch delamination specimens reached a maximum displacement of approximately 0.08 inches.

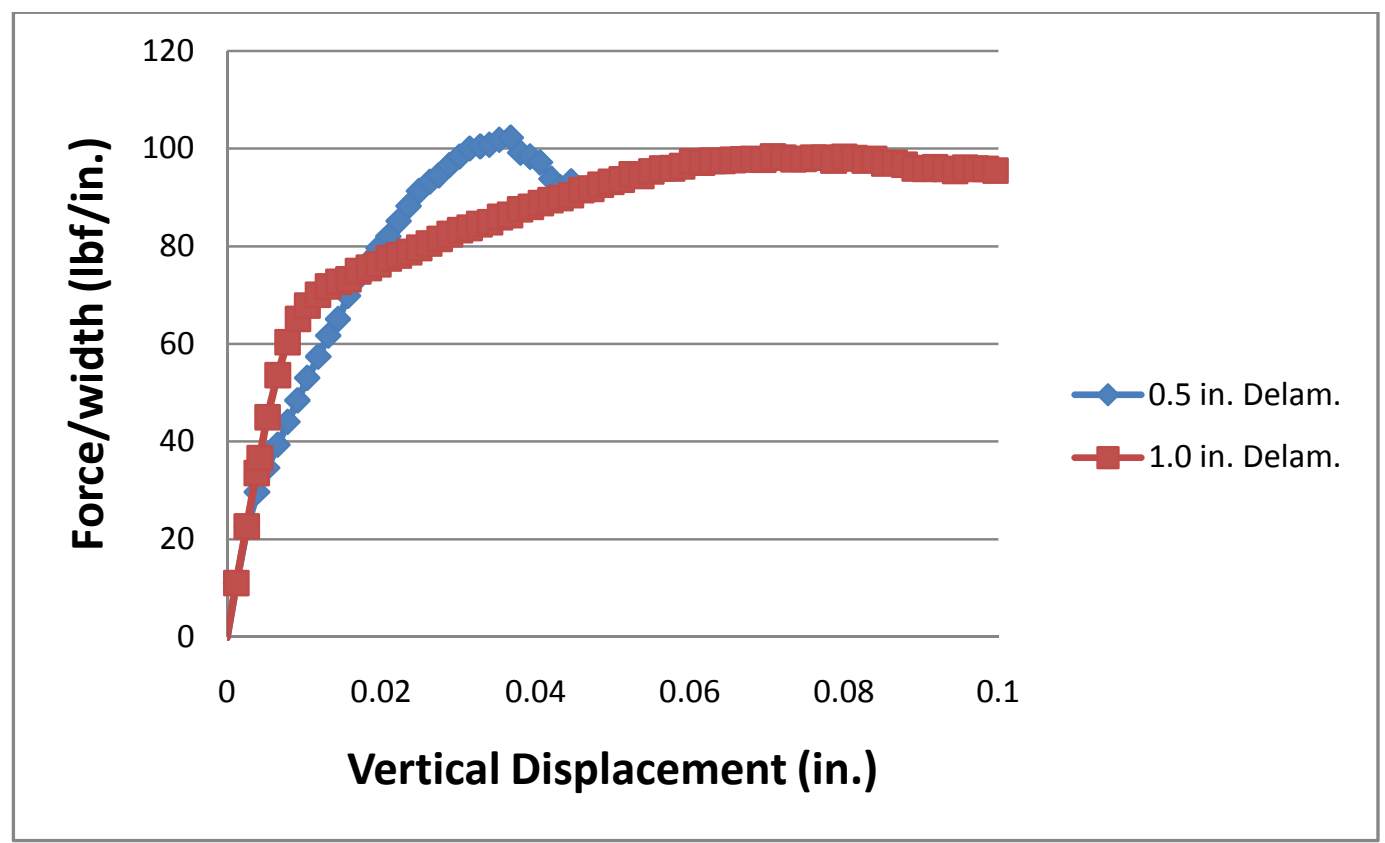

Figure 93 - Monotonic experimental results comparison (delamination)

The large differences can be attributed to the L-shaped aluminum brackets used to apply the load to the specimen from the Instron machine. The brackets had leg lengths of 0.5 inches that was bonded to the upper skin of the sandwich structures. The combination of the 0.5 inch delamination and aluminum bracket create almost a purely vertical pull-up force. The 1.0 inch delamination test specimens are not purely a vertical force because half of the delamination length is not bonded to the aluminum tab. At the free delamination area a moment is created there which causes the 1.0 inch delamination test specimens to 
require more force to initiate the onset of plastic deformation. This can be seen in Figure 93 because the red curve has a much larger elastic region (up to approximately $70 \frac{\mathrm{lb} f}{\mathrm{in}}$ ) than the 0.5 inch delamination pieces which only remains elastic up to approximately $20 \frac{l b_{f}}{i n .}$. For the 1.0 inch delamination test specimen to deform plastically a larger force is needed because the applied forces not only created a pullup force, but also a moment due to the delamination length that was not directly under the aluminum tab.

Figure 94 shows the monotonic test results for the three different shear key configurations as well as the 1.0 delamination case. All four configurations had very similar elastic and plastic deformation. The shear key configurations were characterized by an elastic response up to approximately $55 \frac{l b_{f}}{i n .}$ and afterwards followed by plastic deformation until the ultimate force was reached. The 0 inch shear key reached the highest ultimate force/width value of approximately $100 \frac{l b_{f}}{i n .}$ followed by the 0.5 inch shear key at $98 \frac{l b_{f}}{i n}$ and the 1.0 inch shear key at $95 \frac{l b_{f}}{i n .}$. The 1.0 inch delamination test specimen had a slightly higher ultimate stiffness of approximately $102 \frac{l b_{f}}{i n .}$ and similar elastic response. Figure 94 shows the shear keys had virtually no positive effect for increasing the monotonic failure strength of initially delaminated test specimens which is not entirely unexpected. 


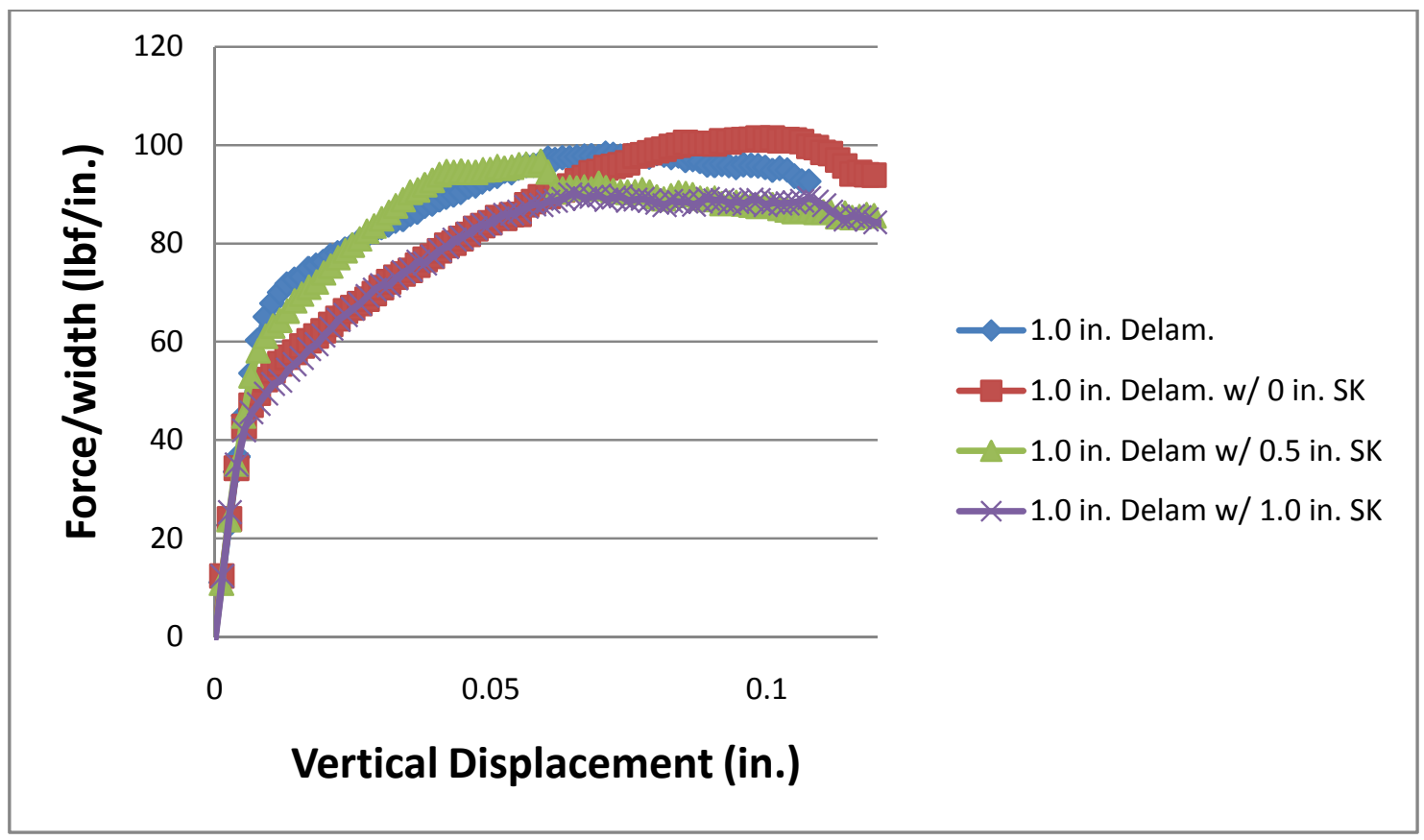

Figure 94 - Experimental monotonic results (shear keys and delamination)

Adding shear keys to initially delaminated test specimens seemed to only add a stress concentration to the test specimens which does nothing to increase the strength of the parts. The stress concentrations do not have a major effect on the test specimen with a 0 inch shear key but as the shear keys get moved further away from the back edge of the delamination the test specimens slowly get weaker. A possible explanation for this is that shear keys are simply additional defects added to the structure. Just as an initial delamination causes the test specimens to fail much sooner than a part without an initial delamination the shear keys have the same effect. By placing the shear key at the back edge of the delamination it essentially combined the two defects together into one which was why the 0 inch shear key specimens were only slightly weaker than the test specimen with only an initial delamination. As the shear keys moved away from the edge of the delamination this created another defect in the part. This explains why the 0.5 and 1.0 inch shear key specimens were weaker than both the 0 inch shear key and the test specimen with only an initial delamination. 


\section{Experimental and Numerical Monotonic Results Comparison}

Figure 95 shows the failure stiffness $\left(\frac{l b_{f}}{i n}\right)$ plotted against the vertical displacement from the experimental and numerical results for the test specimen without an initial delamination. The red curve plotted is the experimental data and the blue and green curves are numerical analysis results using two different material foam models. Both numerical modes closely follow the experimental results for displacements less than 0.015 inches but shortly afterwards the crushable foam models began to deviate from the experimental results and approach a stiffness value of approximately $175 \frac{l b_{f}}{i n .}$. The hyperelastic foam model did a better job of following the experimental data but slowly deviates from the experimental data as the vertical displacement continues to increase. The hyperelastic foam model provided stiffness results within approximately $16.7 \%$ difference compared to the experimental results.

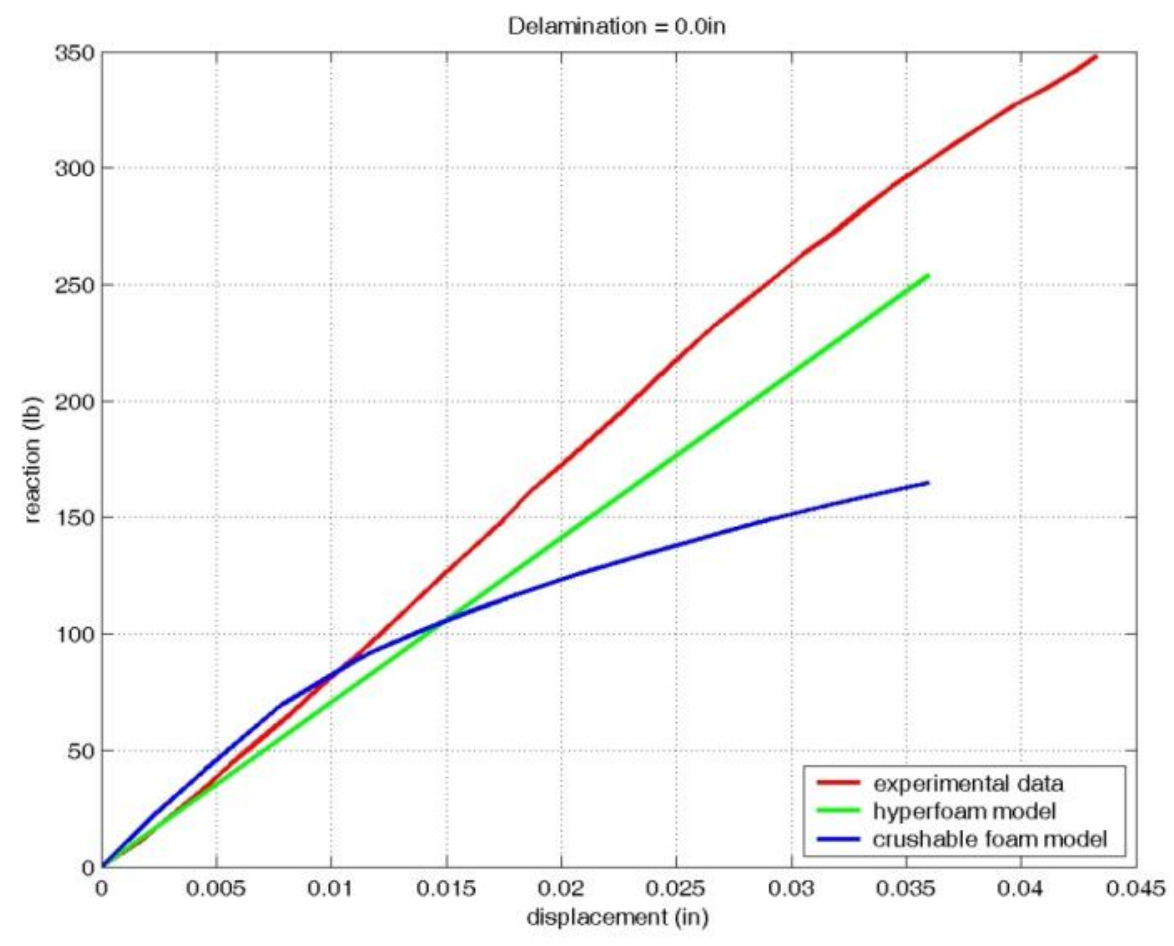

Figure 95 - Experimental/Numerical Analysis comparison (No initial delamination) 
Figure 96 shows the failure stiffness $\left(\frac{l b_{f}}{i n}\right)$ plotted against the vertical displacement for the test specimens with an initial delamination of 0.5 inch. The red curve represent the experimental data and the blue and green curves represent the numerical analysis results. The green curve represents the hyper foam model which is almost a purely elastic curve. The hyper foam model provided good stiffness results for displacement values less than 0.013 inches but afterwards over predicted the stiffness values. The crushable foam model yielded good results all the way up until the experimental results reach fracture. The crushable foam model provided stiffness values within approximately $5 \%$ compared to the experimental results.

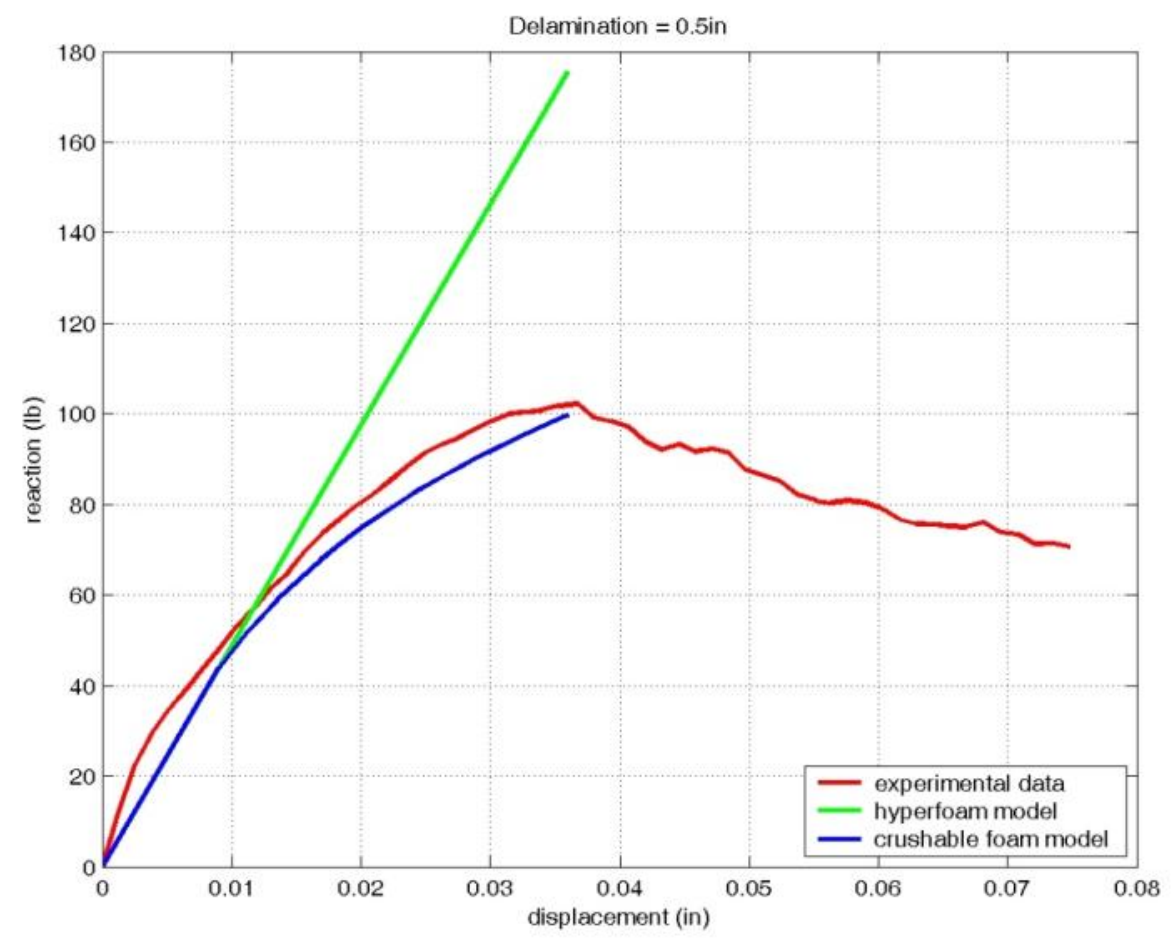

Figure 96 - Experimental/Numerical Analysis Comparison (0.5 inch initial delamination)

\section{Fatigue Results Comparison}

Figure 97 shows the fatigue test results for all three configurations tested. As expected the test specimens without an initial delamination or shear key provided the longest life test specimen. The 
specimens with no initial delamination started to reach its fatigue life limit at a loading rate of approximately $58 \%$ of the ultimate monotonic failure load. Both the test specimens with an initial delamination and an initial delamination with a 0 inch shear key experienced similar fatigue life.

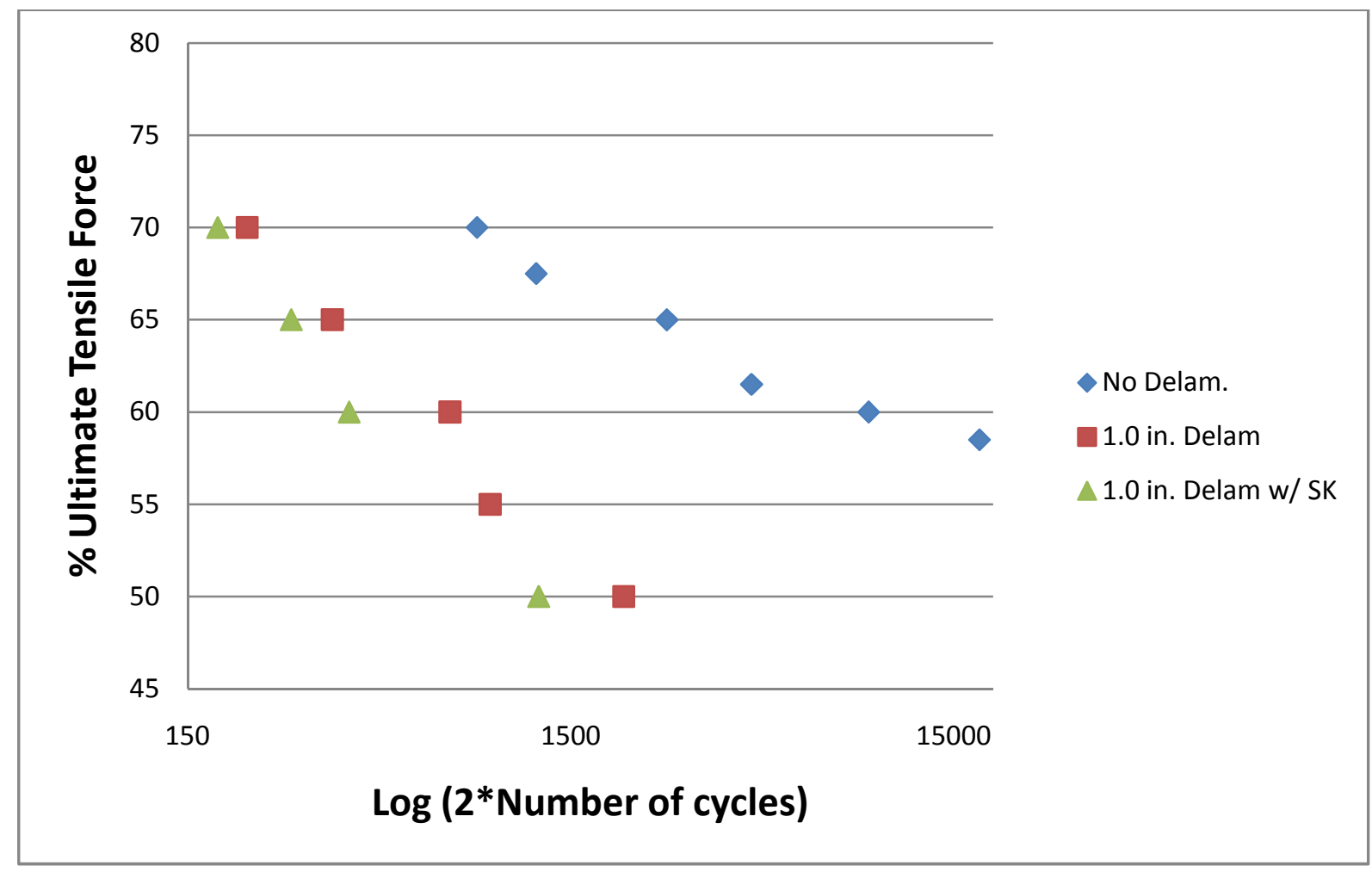

Figure 97 - Fatigue results (all configurations)

Figure 98 shows the fatigue life of only the shear key and initial delamination test specimens. The test specimens with only an initial delamination had a slightly longer fatigue life when compared to the shear key test specimens. At $50 \%$ of the ultimate monotonic failure load the shear key test specimen had a fatigue life of 1238 cycles compared to 2060 cycles for the test specimen with only an initial delamination. This was also expected since the shear key monotonic test specimens were weaker than the test specimens with only an initial delamination. 


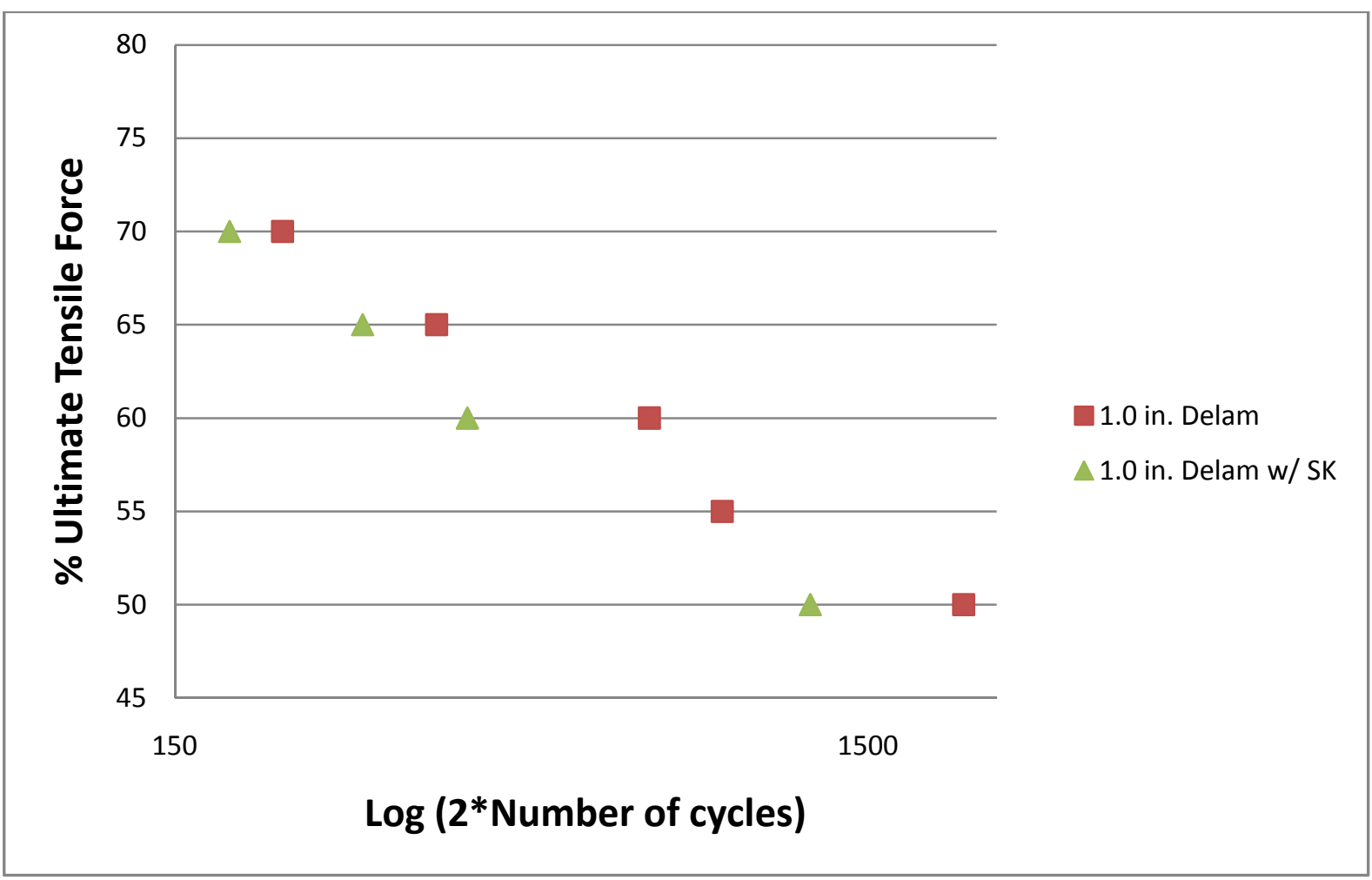

Figure 98 - Fatigue results initial delamination and 0 inch shear key

Table 5 shows a summary of the three different configurations tested under fatigue loading and the corresponding number of cycles to failure depending on the loading rate. Not all loading rates tested are shown in Table 5.

Table 5 - Fatigue failure cycles

\begin{tabular}{|c|c|c|c|c|c|}
\hline & \multicolumn{5}{|l|}{ Fatigue Loading Rate (\% Ultimate Force) } \\
\hline & $\mathbf{7 0}$ & $\mathbf{6 5}$ & $\mathbf{6 0}$ & $\mathbf{5 5}$ & $\mathbf{5 0}$ \\
\hline No Initial Delamination & 854 & 2,672 & 8,991 & N/A & N/A \\
\hline 1.0 in. Initial Delamination & 215 & 358 & 726 & 924 & 2,021 \\
\hline 1.0 in. Initial Delamination w/ 0 in. Shear Key & 180 & 280 & 397 & N/A & 1,239 \\
\hline
\end{tabular}




\section{Future Research Considerations}

Although many specimens were manufactured and tested there were a couple of areas that additional research could be devoted to. Towards the end of the fatigue testing a small sample of test specimens (5) were manufactured with shear keys rotated $90^{\circ}$ from their original orientation (shown in Figure 99). In their original configuration the shear keys appear to provide no noticeable benefit for increasing strength of a composite sandwich structure under a peeling loading. By rotating the shear key $90^{\circ}$ it might have the effect of increasing the stiffness of the fiberglass skin because the shear keys would be acting like a cantilever beam. Preliminary testing showed that the new shear key test specimens had a $30 \%$ increase in the ultimate monotonic failure load. The $30 \%$ increase in the failure load could potentially make the new shear key test specimens stronger that the test pieces with only an initial delamination. The monotonic properties of these newly oriented shear keys could be verified as well as the fatigue behavior of the test specimens. Additionally funding would be necessary to continue the shear key research.

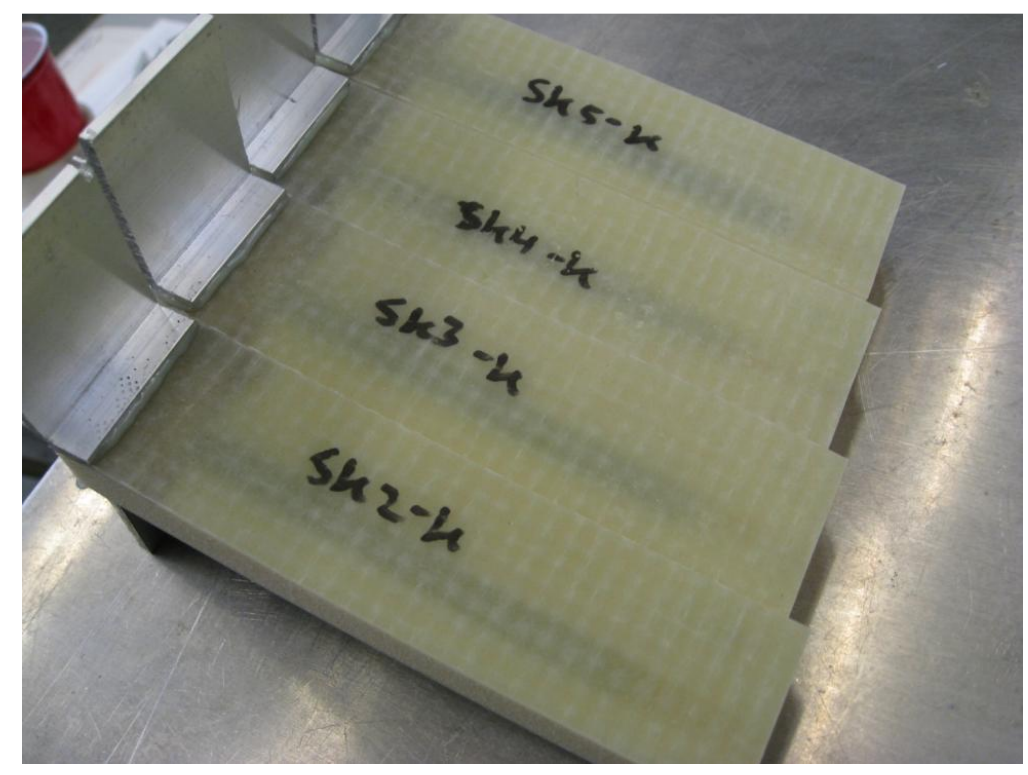

Figure 99 - Test specimens with near shear key orientation 


\section{Conclusion}

This research presents the experimental and numerical results for composite sandwich structures with an initial delamination. The effects of the initial delamination length were varied to see the effect an initial delamination had on decreasing the strength of the composite sandwich structures. Fiberglass rods, called shear keys, were integrated into the initially delaminated sandwich structures with the intent of increasing the ultimate monotonic failure and fatigue life. The location of the shear keys with respect to the back edge of the delamination was varied to see the effect the shear keys had on the strength of the part. The fatigue life and fracture behavior was determined for sandwich structures with no initial delamination, 1 inch initial delamination, and 1 inch initial delamination with a shear key 0 inches from the back edge of the delamination. A numerical analysis was performed using Abaqus/CAE to verify the monotonic loading cases with no initial delamination and an initial delamination of 0.5 inches.

Adding initial delaminations to the sandwich structure reduced the ultimate monotonic failure loads by approximately $70 \%$. Increasing the delamination length had negligible effects on the ultimate monotonic failure load but a larger delamination corresponded to a larger yield force. This was attributed to the additional moment created from the Instron machine to the aluminum tabs. The shear key rods decreased the ultimate failure force of the sandwich structure compared to the test specimens with only an initial delamination. This was likely due to the stress concentration created by the shear key. The location of the shear key had a minimal effect on the overall strength of the composite sandwich structures. Shear keys located further away from the back of the delamination corresponded to a slightly weaker part than one with a shear key at the back edge of the delamination ( 0 inch). Test specimens with initial delaminations had a fatigue life approximately $75 \%$ less than test specimens with no initial delamination. The shear key test specimens had a fatigue life of approximately $80 \%$ less than the test specimens with no initial delamination. The numerical analysis was able to match the monotonic failure

loads for the test specimens with no initial delamination to approximately $15 \%$ using a hyperelastic foam 
model. The numerical analysis was able to match the experimental failure loads for the test specimens with an initial delamination of 0.5 inches to within $5 \%$ using a crushable foam plasticity model. 


\section{Works Cited}

1. "Light Sandwich Constructions." CTiHuati Composites Co., Ltd. 2008.

http://www.ctihuatai.com/Products-sandwichEN.htm

2. Hurwitz, Dr. Frances I., and Sullivan Dr. Roy M."Multifunctional, Foam Core, Ceramic Matrix Composite Integrated Structures Development.” NASA. 14 Dec. 2007. http://www.grc.nasa.gov/WWW/RT/2006/RX/RX11C-hurwitz1.html

3. Bigelow, Chaterine A. "Effects of Fatigue and Environment of Residual Strengths of Centercracked Graphite/Epoxy Buffer Strip Panels.” March 1989.

4. Mitra, Dr. Nilajan and Kasper, Dr. Eric. "A novel technique for preventing delamination of the composite skin from the core: Sandwich panels with shear keys." 2008. pg. 1-15.

5. Mitra, Dr. Nilajan, and Jacobson, Michael. "Sandwich Composite Report." 2008. pg. 1 - 15.

6. Davis, Richard; Engels, Nathanial; Morham, Brett; Ung, Ryan. "Delamination of Fiberglass Sandwich Composites." 8 June 2009.

7. “Composites." NDT Resource Center. 2006. http://www.ndted.org/EducationResources/CommunityCollege/Materials/Graphics/Composites.jpg

8. “Carbon Fiber Panel 12"x12"x0.015"/0.38mm, 2x2 Twill." Carbon \& Fiberglass Sales. 2009. http://carbonsales.com/images/P/\%2361052-50.jpg

9. Plastic World. 2001. http://www.plasticworld.ca/fiberglass.jpg

10. "Subaru Impreza 2.5 rs Kevlar/s-glass skid plate." Bar One Composites. 2008. http://www.baronecomposites.com/images/Kevlar.jpg

11. "Comparison of Theoretical and Experimental Analysis of Unidirectional and Cross-ply Composite Laminate Plates." 2007.

12. “Fibre-reinforced plastic.” Wikipedia. 23 Oct. 2009. http://en.wikipedia.org/wiki/Fibrereinforced_plastic

13. "Composite Material." Wikipedia. 24 Oct. 2009. http://en.wikipedia.org/wiki/Composite_material

14. "Fabrication Methods." Composites World. 8 Jan. 2009. http://www.compositesworld.com/uploadedimages/Publications/CW/Articles/Internal/SB09_com positesthematerials_h.jpg

15. "Vacuum Resin Transfer Molding (VARTM)." Kenway Corporation. 2009. http://www.kenway.com/pictures/vardtr.jpg

16. "Fatigue (material)." Wikipedia. 14 Oct. 2009. http://en.wikipedia.org/wiki/Material_fatigue

17. "Piston fracture." Hirth aircraft engine, diagnosing piston damage to your engine. 2006. http://www.ultralightnews.com/hirth/images/piston7.jpg

18. "Fatigue Testing." Stork Material Technology. 2009. http://www.storksmt.com/images/TechnicalServices/SMT/Failure/FatigueFrac400.gif

19. Pascoe, David. "Parallel Universe - Composite Troubles in Aircraft." Core and Structural Issues. 29 March 2005. http://www.yachtsurvey.com/composite rudder-2.JPG

20. Spiegal, Peter. "F-15 fleet grounded after a jet falls apart." LA Times. 6 Nov. 2007. http://www.latimes.com/news/nationworld/nation/la-na-f156nov06,1,6807945.story

21. Kelly, Shawn. "Fatigue.” Virginia Tech Materials Science Engineering. 4 May 1997. http://www.sv.vt.edu/classes/MSE2094_NoteBook/97ClassProj/anal/kelly/fatigue.html\#tworef 
22. "Vacuum Infusion Guide." Composites World. 2009. http://www.compositesworld.com/uploadedimages/Publications/CW/New_Product_Announceme nts/fibreglast-433.jpg

23. "Vacuum Infusion - The Process of Resin Infusion." Vacuum Infusion Technology. 2008. http://www.bladeoceancraft.com.au/assets/images/autogen/a_infusion-diagramAA.gif

24. "Divinycell H - High Performance Foam." DIAB Products. 2009. http://www.diabgroup.com/americas/u_products/u_divinycell_h.html 